\section{Pacific Northwest}

National Laboratory

Operated by Battelle for the

U.S. Department of Energy

\title{
Engineering Study for Materials Open Test Assembly (MOTA)/Shielded Materials Facility (SMF) South Cell Waste Removal
}

\author{
S.A. Bailey \\ J.M. Alzheimer \\ C.P. Baker \\ M.A. Catalan \\ P.L.J. Valdez
}

December 2002

Prepared for the U.S. Department of Energy under Contract DE-AC06-76RL01830 


\section{DISCLAIMER}

This report was prepared as an account of work sponsored by an agency of the United States Government. Neither the United States Government nor any agency thereof, nor Battelle Memorial Institute, nor any of their employees, makes any warranty, express or implied, or assumes any legal liability or responsibility for the accuracy, completeness, or usefulness of any information, apparatus, product, or process disclosed, or represents that its use would not infringe privately owned rights. Reference herein to any specific commercial product, process, or service by trade name, trademark, manufacturer, or otherwise does not necessarily constitute or imply its endorsement, recommendation, or favoring by the United States Government or any agency thereof, or Battelle Memorial Institute. The views and opinions of authors expressed herein do not necessarily state or reflect those of the United States Government or any agency thereof.

\section{PACIFIC NORTHWEST NATIONAL LABORATORY operated by \\ BATTELLE for the UNITED STATES DEPARTMENT OF ENERGY under Contract DE-AC06-76RL01830}

Printed in the United States of America

Available to DOE and DOE contractors from the Office of Scientific and Technical Information,

P.O. Box 62, Oak Ridge, TN 37831-0062; ph: (865) 576-8401 fax: (865) 576-5728 email: reports@adonis.osti.gov

\footnotetext{
Available to the public from the National Technical Information Service, U.S. Department of Commerce, 5285 Port Royal Rd., Springfield, VA 22161 ph: (800) 553-6847 fax: $(703) 605-6900$ email: orders@ntis.fedworld.gov online ordering: http://www.ntis.gov/ordering.htm
} 


\title{
Engineering Study for Materials Open Test Assembly (MOTA)/Shielded Materials Facility (SMF) South Cell Waste Removal
}

\author{
S.A. Bailey \\ J.M. Alzheimer \\ C.P. Baker \\ M.A. Catalan \\ P.L.J. Valdez
}

D ecember 2002

Prepared for

Fluor Hanford 


\section{Summary}

This engineering study provides a path forward for the disposal of SMF south cell wastes, including the items in the long-term storage cabinets (i.e., MOTA specimens). In developing this path forward, waste inventories with preliminary characterization data have been developed, and packaging and transport options evaluated. Significant effort was expended to recover data related to the MOTA specimens, and to develop a realistic inventory of the remaining waste in south cell. While there is missing data related to the waste in the cell, there is enough to information to assess options and develop a path forward.

The total estimated volume of waste in the SMF is approximately $9-\mathrm{m}^{3}\left(320-\mathrm{ft}^{3}\right)$, weighing approximately 5000-kg (11,000-lb).

The recommended approach for removal of the waste from the south cell is to remove all the high source items (with the exception of the MOTA samples) first, then continue removing items until the radiation levels are low enough to permit manned entry to replace the crane. This approach will require use of the MSMs, and a powered drum/container pallet.

Once manned entry is achieved, a complete replacement of the south cell crane is recommended. A fully functional crane will assist greatly in the completion of the cell cleanout. If manned entry into the south cell does not become possible, the alternative is to design a special piece of equipment that can be used to raise the lids off the longterm storage (MOTA) cabinets and remove other large debris from the south cell.

The primary approach for removal of the waste is intended to use the SERF cask to package the higher activity wastes in the REC airlock, and type-A containers for the balance of the wastes. The alternate approach assumes that the SERF cask and/or the REC airlock are not available, and uses a custom type-A container with internal subcontainers as a single integrated system.

Previous operations that required the opening of the south cell door have resulted in contamination of the air lock itself. The air lock had to then be decontaminated. While it is highly desirable to perform as much of the south cell cleanout without opening the south cell door, it is unrealistic to assume that the entire south cell cleanout can be performed without opening the south cell door. 


\section{Contents}

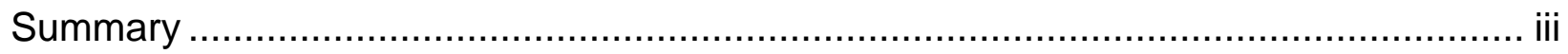

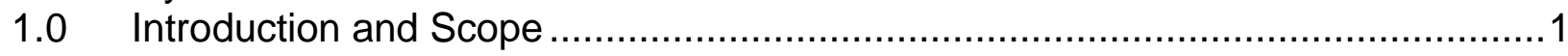

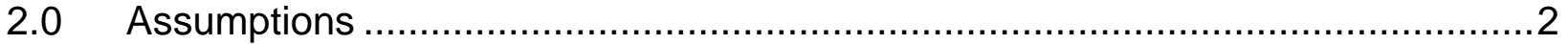

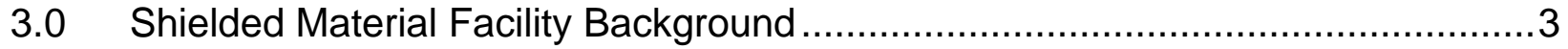

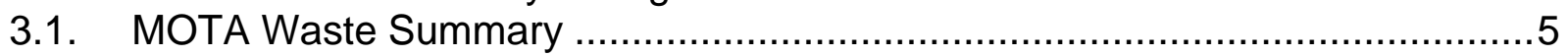

3.2. SMF South Cell Waste Summary ......................................................... 7

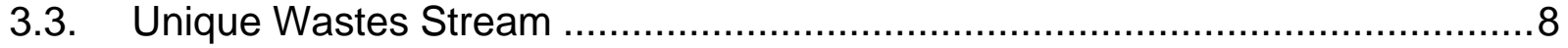

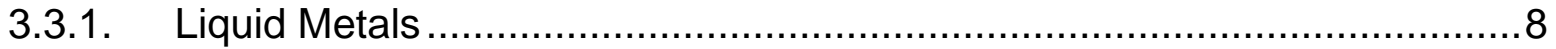

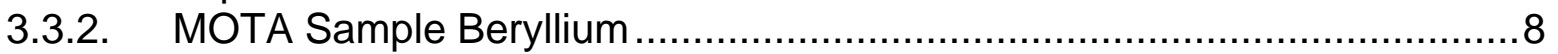

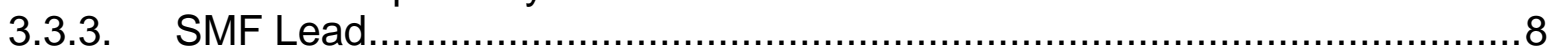

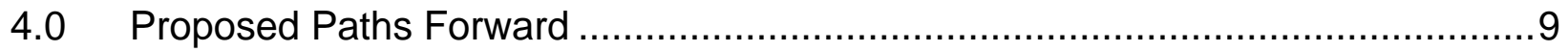

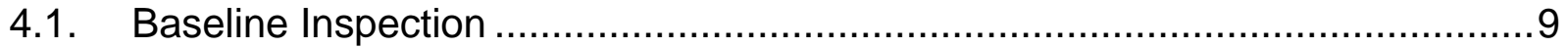

4.2. South Cell Waste Removal .............................................................. 10

4.2.1. Primary Approach ..................................................................... 11

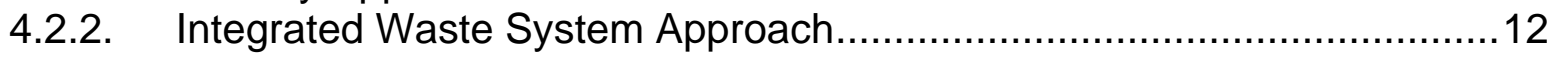

4.3. Individually Addressed SMF Wastes ....................................................13

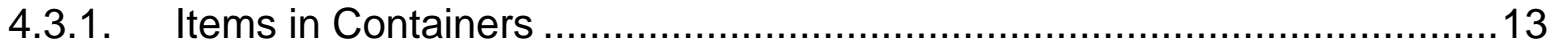

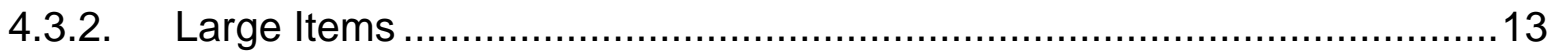

4.3.3. Compartment 1 Waste Handling ..................................................... 14

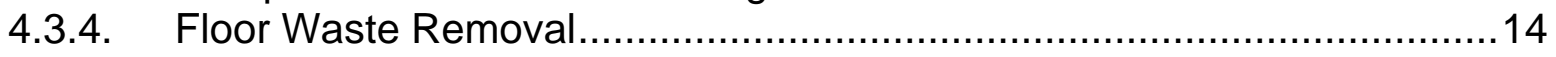

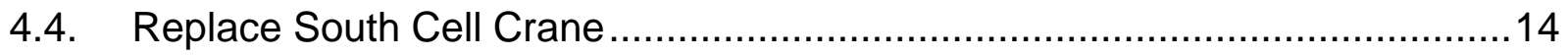

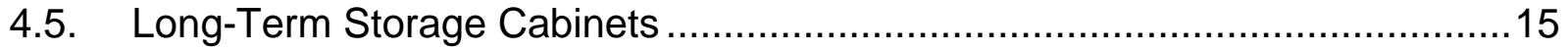

4.5.1. Stuck Drawer Recovery Plan ..........................................................16

4.5.2. Unique Samples ......................................................................... 16

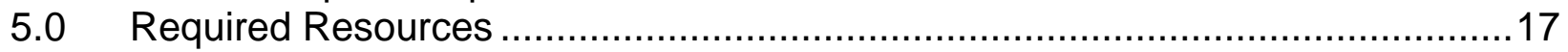

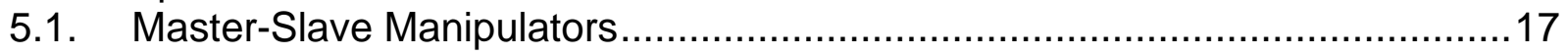

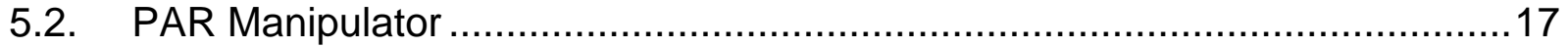

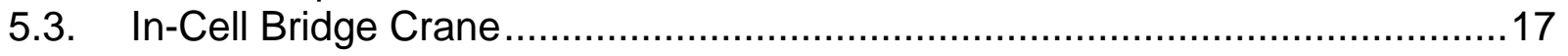

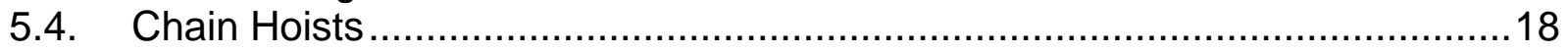

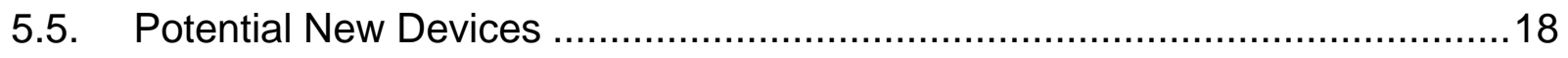

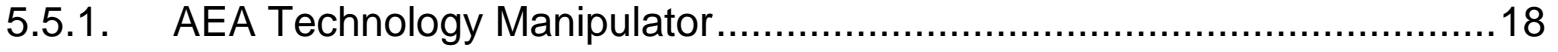

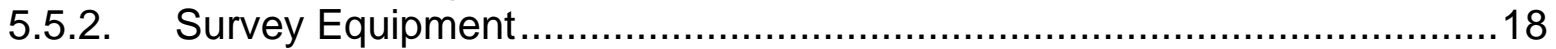

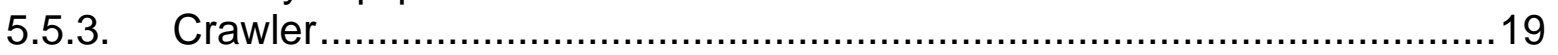

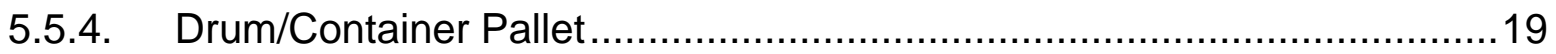

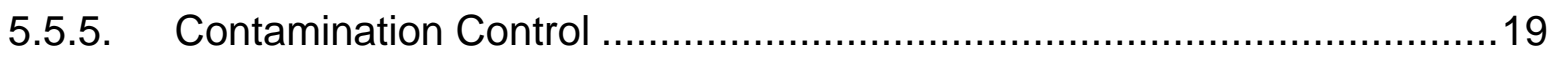

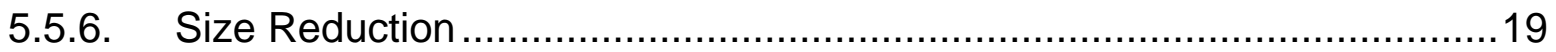

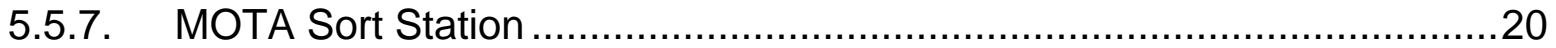

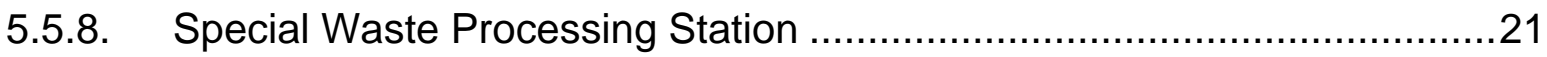

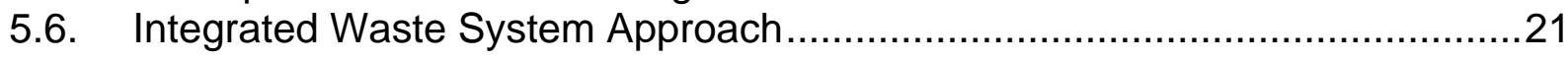

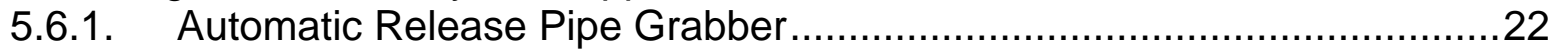

5.6.2. Airlock Sub-container Positioning System ............................................22

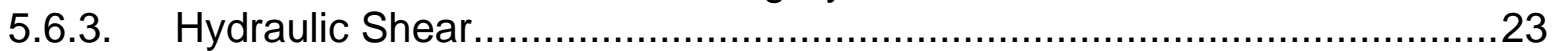

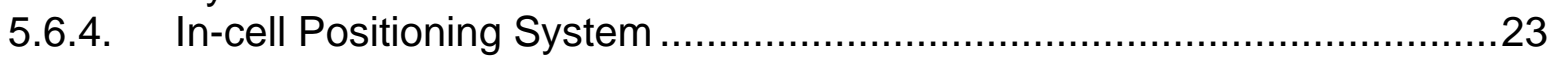

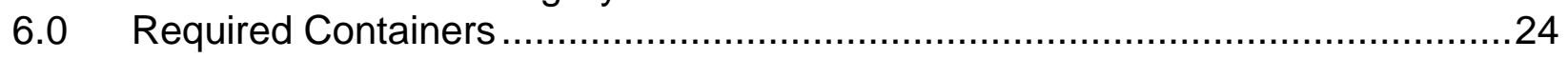


6.1. Containers for Low-Level Radioactive Wastes ..........................................24

6.2. Containers for Remote-handled Wastes ..................................................24

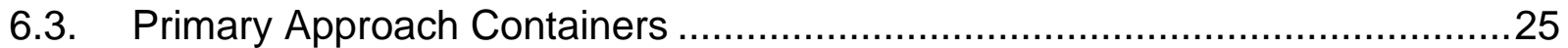

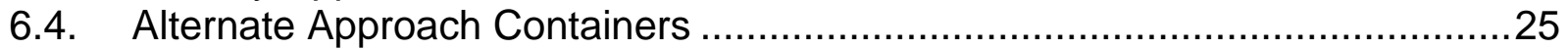

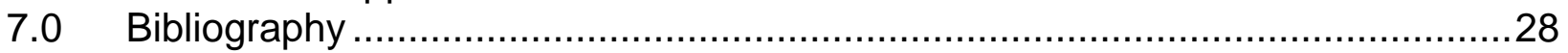

Appendix A. Shielded Material Facility Description ........................................ A-1

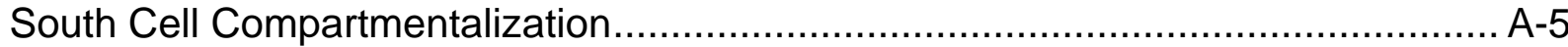

Appendix B. Personnel Interviews and Data Source Reviews ........................... B-1

Appendix C. MOTA Waste Forms, Characterization, and Inventories...................... C-1

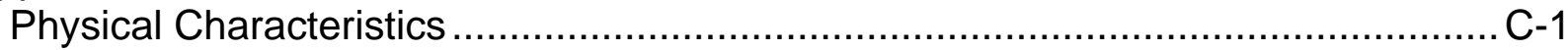

Simplified Activity Calculation .........................................................................

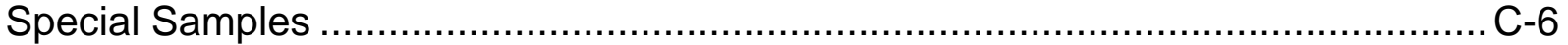

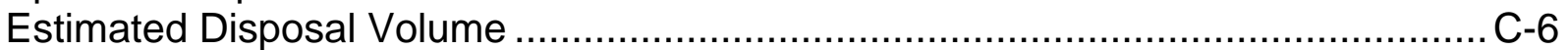

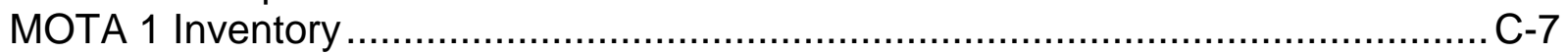

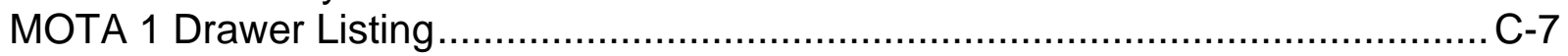

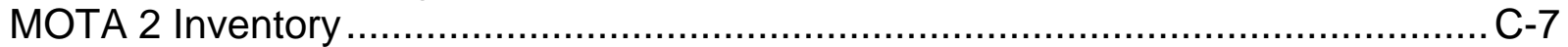

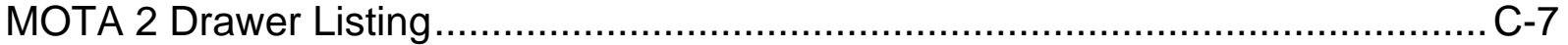

Appendix D. SMF South Cell Waste Forms, Characterization and Inventory.......... D-1

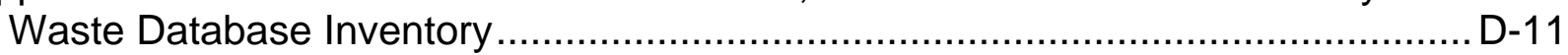

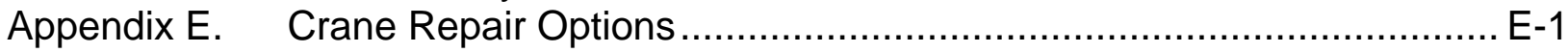

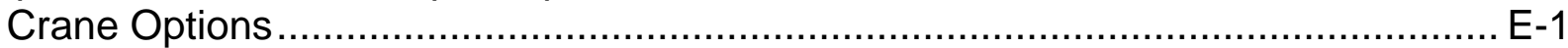

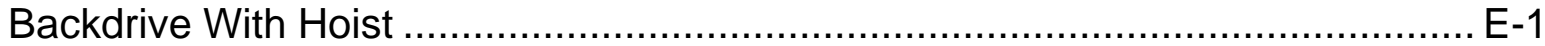

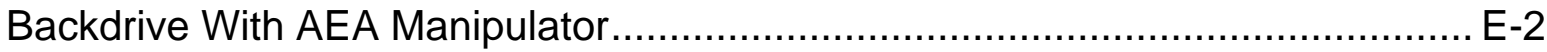

Backdrive with Engineered Device ............................................................ E-2

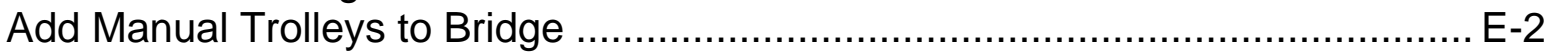

Lift Cabinet Lids With Engineered Device .................................................. E-2

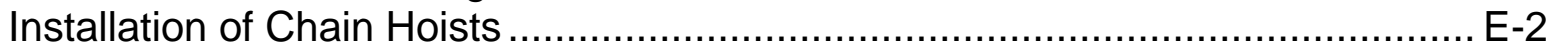

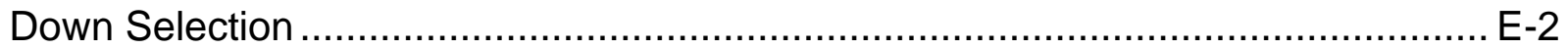

Recommended South Cell Crane Option ........................................................... E-3

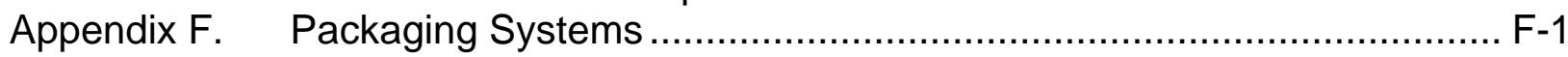

Packaging Within the South Cell......................................................................... F-1

Packaging Outside of South Cell ......................................................................... F-1

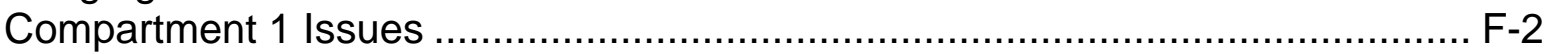

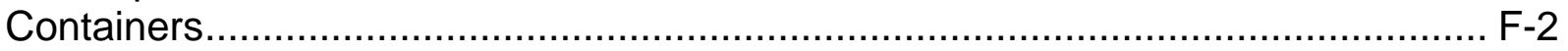

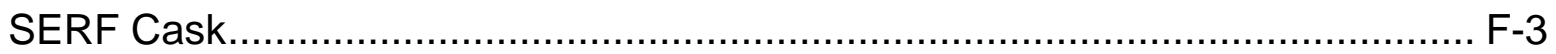

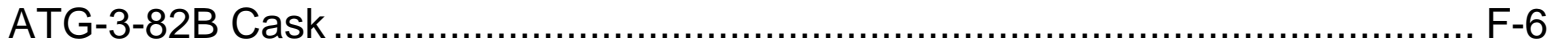

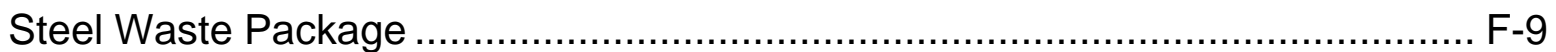

Lead-lined Drum ................................................................................. F-11

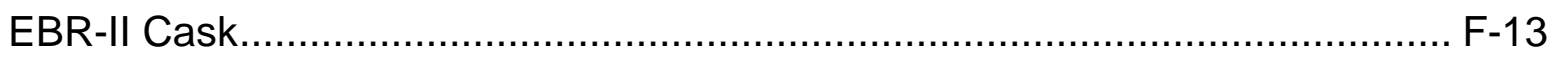

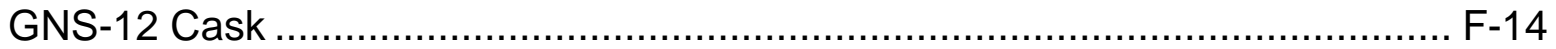

Available Type-A Containers for SMF Wastes …....................................... F-14 


\section{Figures}

Figure 3-1 Cutaway of SMF Before Compartments Were Constructed ..........................

Figure 3-2 Shielded Materials Facility (SMF) ................................................... 4

Figure 3-3 Close-Up of South Cell Proper ................................................................. 4

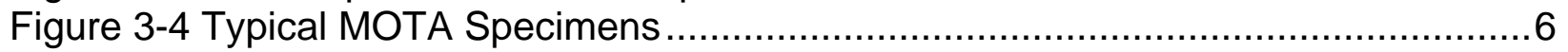

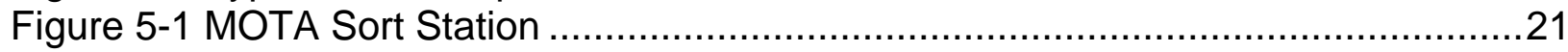

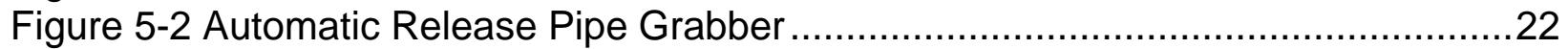

Figure 5-3 Airlock Sub-container Positioning System .............................................22

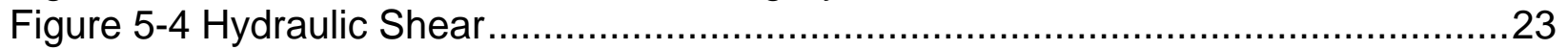

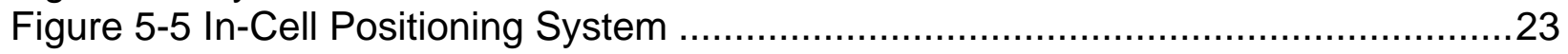

Figure 6-1 Section View of Type-A Container with Sub-containers .............................26

Figure A-1 Cutaway of SMF Before Compartments Were Constructed..................... A-1

Figure A-2 Compartment 2 Exterior Pass-Through ............................................. A-2

Figure A-3 SMF Exterior View Manipulators ..................................................... A-2

Figure A-4 South Cell East Wall (Exterior) ....................................................... A-3

Figure A-5 South Cell with Long-Term Storage Cabinets Indicated ....................... A-4

Figure A-6 Long-Term Storage Cabinet Lid ...................................................... A-4

Figure A-7 Long-Term Storage Cabinet Dividers................................................. A-5

Figure A-8 Compartment 2 Under Construction (Interior) ..................................... A-6

Figure A-9 South Cell View (Interior) ................................................................ A-

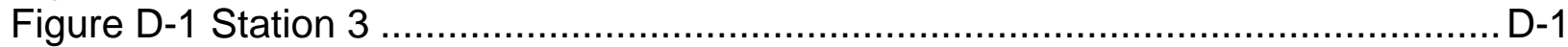

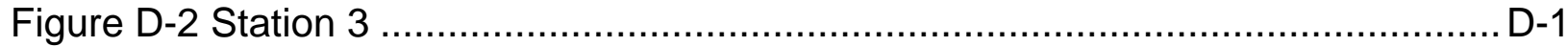

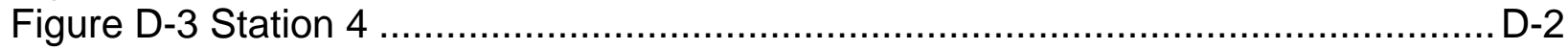

Figure D-4 Station 6 (Compartment 3) ............................................................... D

Figure D-5 Station 7 (Compartment 2) ……..................................................... D-3

Figure D-6 Station 7 (Compartment 2) ……......................................................

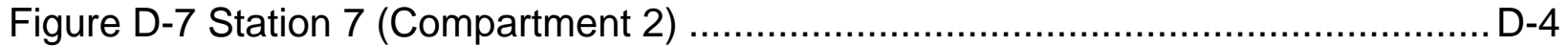

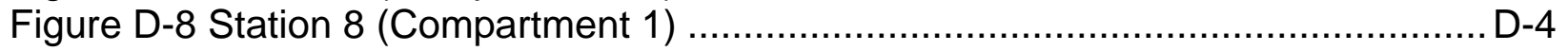

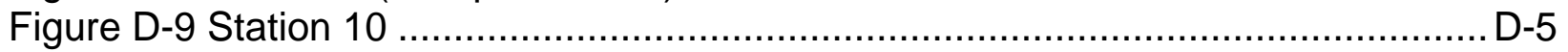

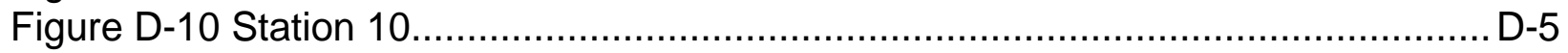

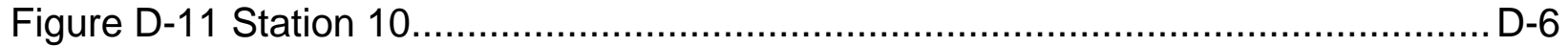

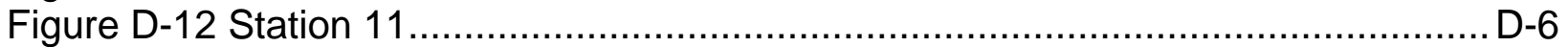

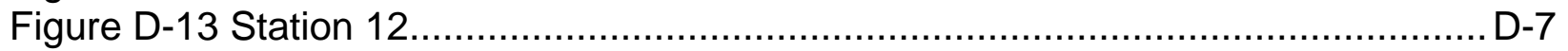

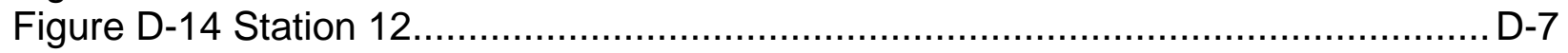

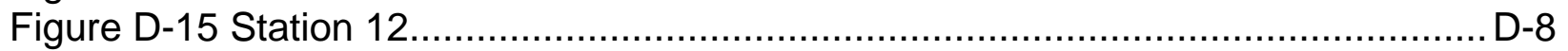

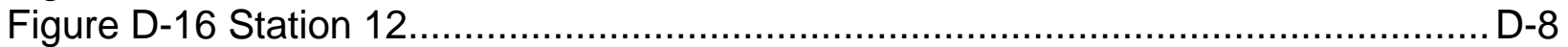

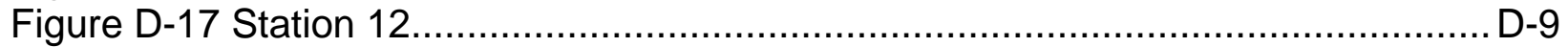

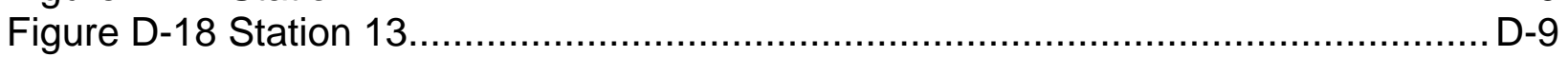

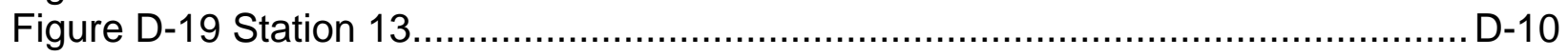

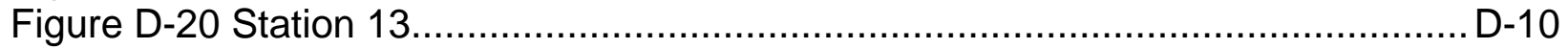

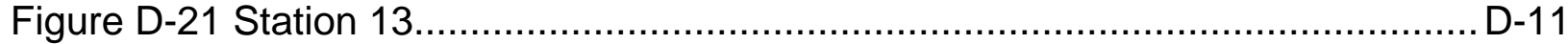

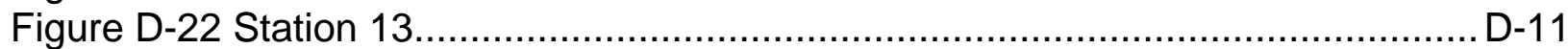

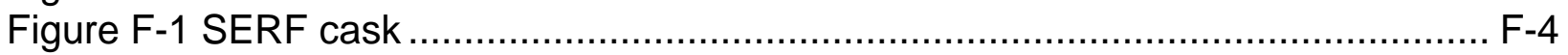

Figure F-2 SERF Cask Cart........................................................................ F-5

Figure F-3 ATG-3-82B Cask ...................................................................... F-6 


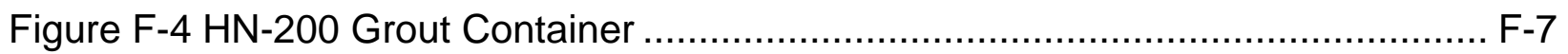

Figure F-5 HN-200/3-82B Liner ...................................................................

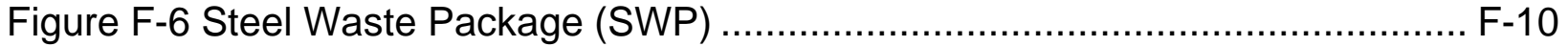

Figure F-7 Lead-Lined Drum ..................................................................... F-12

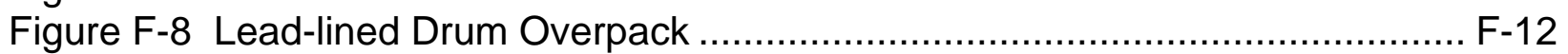

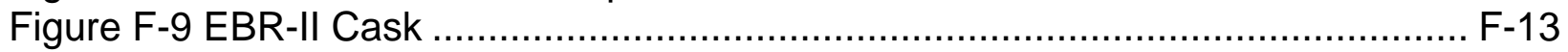

Figure F-10 GNS-12 Cask ...................................................................... F-14 


\section{Tables}

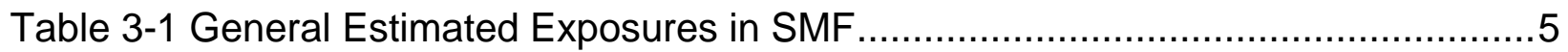

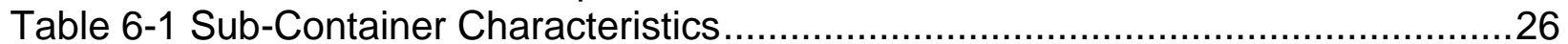

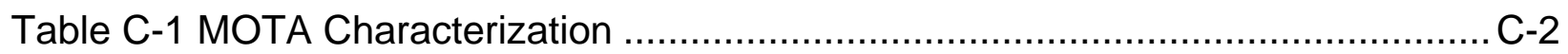

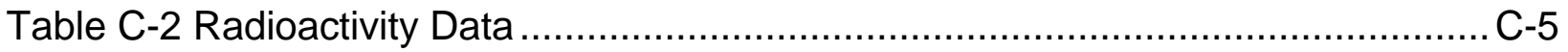

Table C-3 Expected Exposure Rates at 100-cm ............................................... 


\subsection{Introduction and Scope}

This engineering study identifies the options for removal of radioactive waste from the south cell of the Shielded Materials Facility (SMF) located within the 324 Building, 300 Area, Hanford Site. The recommendations and conclusions were developed after a significant effort was expended to collect data, create inventory databases, and determine the problem boundaries. The wastes considered are items within the south cell excluding the infrastructure (i.e., manipulators, crane, worktables, and compartment walls).

This report documents the engineering studies concerning various test specimens including Materials Open Test Assembly (MOTA) specimens located in two cabinets within the south cell, as well as the other radioactive wastes located within the south cell. Decontamination is considered only as required to permit the removal of waste items.

The overall remediation plans, provided later in this document, operate on the assumption that there are no differences between the MOTA and SMF wastes (i.e., similar waste forms and disposal options).

This report provides a description of the SMF, MOTA samples, and other waste items. Primary and alternate paths forward for the removal of waste are described, along with a listing of the existing equipment, new equipment, and packaging options required to achieve them. 


\subsection{Assumptions}

Complete characterization information of the waste materials was not available. However, it was possible to complete the intent of this engineering study without this information by making several assumptions. The following list details the assumptions.

1. All facility-specific equipment [e.g., overhead cranes, programmable and remote (PAR) manipulator, mechanical master slave manipulators (MSMs), empty longterm storage cabinets, lead bricks associated with the compartment and/or cell structure, and compartment walls] are not considered waste for this study and are assumed to be left in the south cell upon completion of the cleanup activities.

2. The south cell will have a full set of working MSMs in at least two stations. The sets can be a combination of model E\&F variants.

3. The plan proposed by this study does not include decontamination efforts, except for those that assist waste packaging, contamination control, and waste removal.

4. Manned entry will not be possible until after removing some of the waste from the south cell. General radiation field information precluding manned entry was based on interviews with personnel familiar with the SMF.

5. The lack of detailed information, on the MOTA samples in long-term storage cabinet 1 , required basic assumptions concerning their characteristics (i.e., activity and volume) to provide upper bounds and a worst-case scenario.

6. Samples within long-term storage cabinet 2 are similar (i.e., physical and radiological characteristics) to the MOTA samples (long-term storage cabinet 1) for initial planning purposes. However, cabinet 2 must be opened and explored to confirm this.

7. The information on the long-term storage sample cards is accurate in terms of the quantity of cells that are filled.

8. The use of grout containers assumes that the Radiochemical Engineering Cell (REC) airlock, or an alternate suitable location, is available.

9. Existing lead bricks (with the exception of those associated with the compartment and/or cell structure) will be recycled or removed as waste.

10. There is no transuranic waste present. 


\subsection{Shielded Material Facility Background}

The 324 Building SMF, shown in Figure 3-1, was developed to provide containment for research and fabrication development studies on highly radioactive metallic and ceramic fuel materials. The early radiometallurgical missions (non-destructive examination of long fuel pins) and reconstructive testing (reassembly of fuel pins for reinsertion into a reactor) for SMF took place between 1970 and 1980. Between 1983 and 1992, the SMF was used to process MOTA specimens for the Fast Flux Test Facility (FFTF) MOTA campaigns. MOTA processing included measurement of specimens, reassembly for replacement in the FFTF, and long-term storage. Later, between 1991 and 1992, the SMF was used to process and encapsulate cesium chloride $(\mathrm{CsCl})$ for Nordion Corporation of Canada. This process, according the personnel interviews, contaminated the south cell and the compartments.

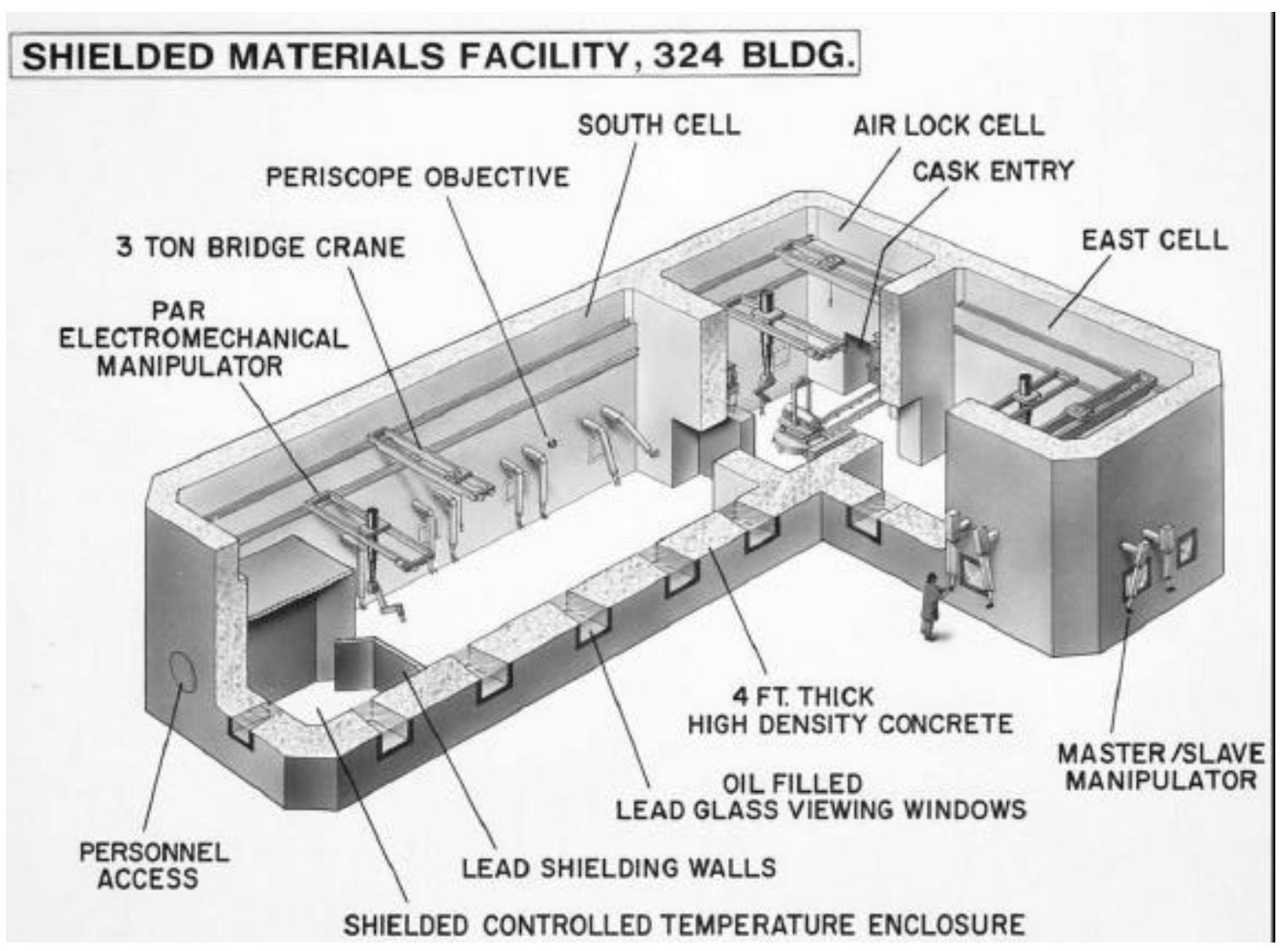

Figure 3-1 Cutaway of SMF Before Compartments Were Constructed

The SMF consists of three cells, arranged in the shape of an "L", surrounded by an operating gallery. The cells include the air lock, the preparation or east cell, and the fabrication or south cell (see Figure 3-1). The air lock, located at the knee of the Lshaped arrangement, functions primarily as a transition and ventilation barrier for shielded material movement between the radioactivity-free areas and the two operating cells. SMF operations are conducted with 36 remotely operated MSMs located at or near 22 lead glass, oil-filled windows. A remotely operated overhead crane and a PAR 
manipulator serviced each cell. However, both the south cell crane and PAR are currently inoperable and inaccessible for hands on repair because of the elevated dose rates. The south cell has been subdivided into smaller work areas (Figures 3-2 and 33 ). The work areas include south cell proper and four isolated compartments.

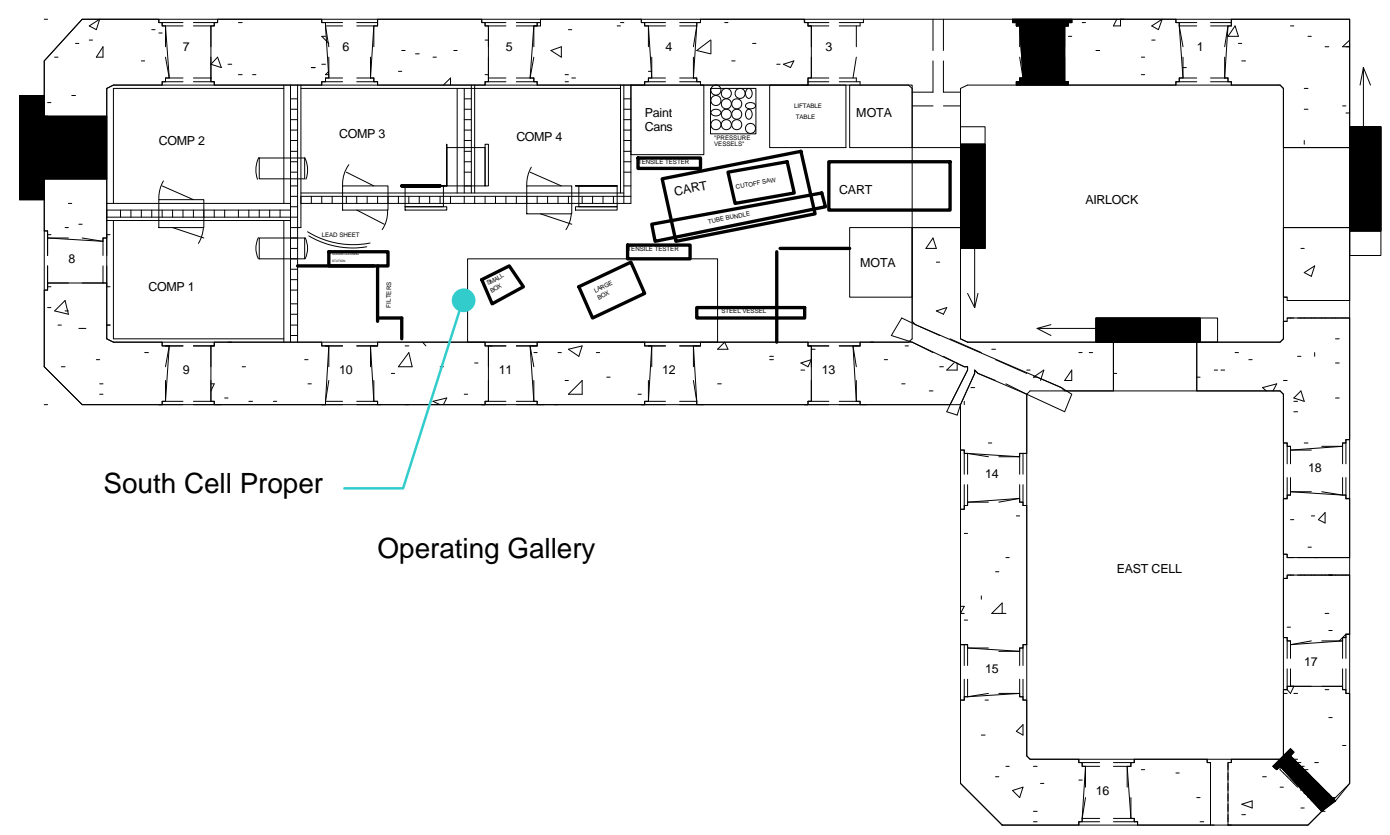

Figure 3-2 Shielded Materials Facility (SMF)

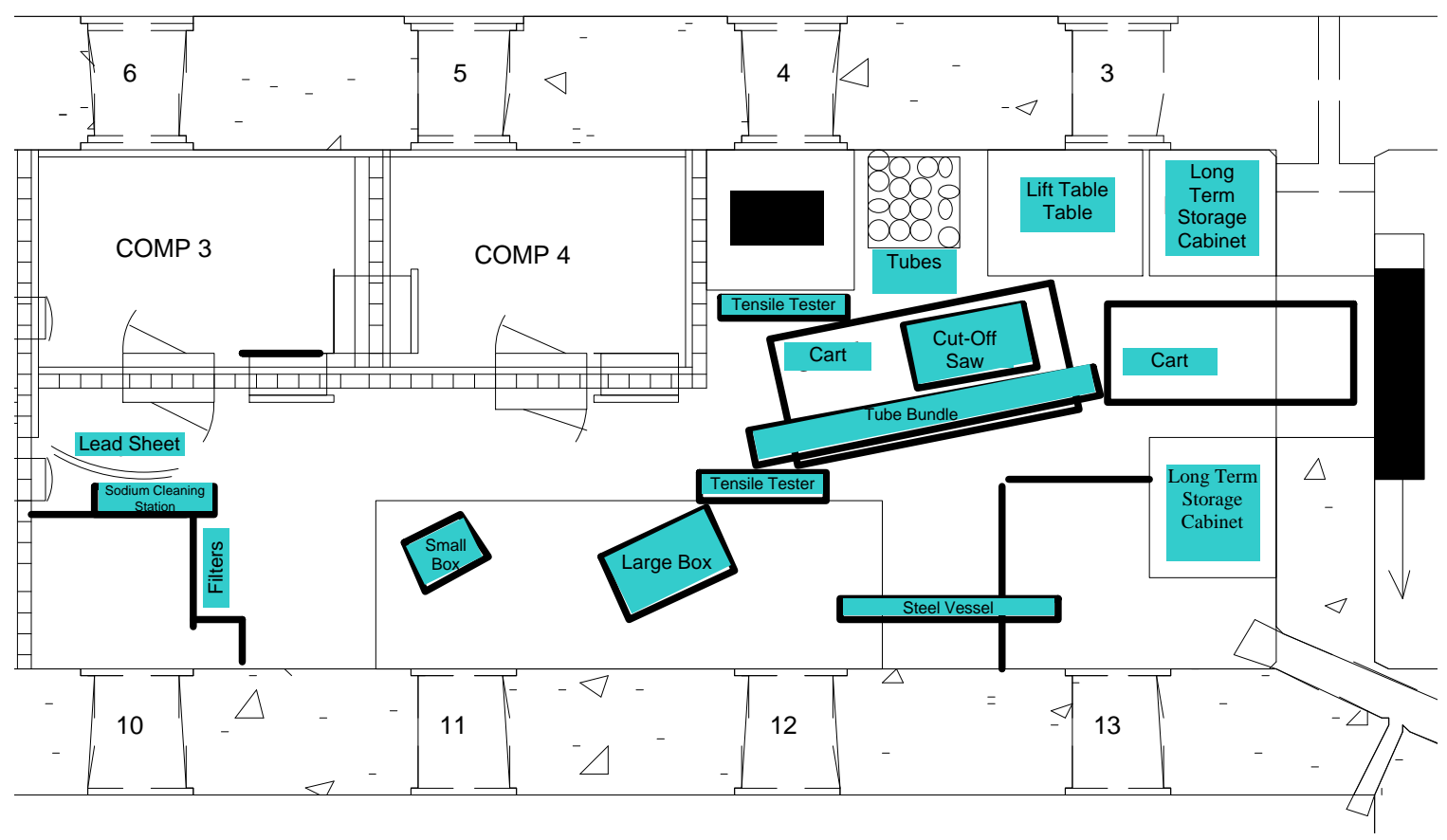

Figure 3-3 Close-Up of South Cell Proper 
In the mid-1970s, two shielded long-term storage cabinets were installed at the north end of south cell near Stations \#3 and \#13. Each cabinet contains 2435 storage cubicles. Lifting a $2268-\mathrm{kg}(5000-\mathrm{lb})$ lead-filled lid provides access to the cabinets, suspended below the lid.

Historical radiological survey data was not available to accurately determine the conditions within the SMF and the long-term storage cabinets. A report (Bitten 1998) was located detailing alpha contamination that included beta/gamma contamination levels; however, the general field information was not provided. This report, in addition to some process knowledge information, indicates the presence of $\mathrm{CsCl}$ contamination. These estimates range from low to extremely high contamination levels. Exposures at a few locations have been estimated (from the values in the report (Bitten 1998) and assuming that the beta-gamma contamination is Cs-137) and are provided in Table 3-1. A complete description of the SMF is included in Appendix A.

Table 3-1 General Estimated Exposures in SMF

\begin{tabular}{|l|c|c|c|}
\hline Location & $\begin{array}{c}\text { Contamination } \\
(\mathbf{m C i})\end{array}$ & $\begin{array}{c}\mathbf{X} \text { (mR/hr) } \\
\text { at 100-cm }\end{array}$ & $\begin{array}{c}\mathbf{X}(\mathbf{m R} / \mathbf{h r}) \\
\text { at 30-cm }\end{array}$ \\
\hline Station 3 (south cell) & 222 & 71 & 788 \\
\hline Station 3 (south cell) & 288 & 92 & 1,023 \\
\hline Floor (east cell) & 0.0472 & $\sim 0$ & 0.168 \\
\hline Station 13 (south cell) & 171 & 55 & 607 \\
\hline Compartment 1 (station 9) & 778 & 248 & 2,763 \\
\hline Compartment 1 (station 8) & 1040 & 331 & 3,694 \\
\hline Compartment 4 (floor) & 0.20 & $\sim 0$ & 0.710 \\
\hline
\end{tabular}

\subsection{MOTA Waste Summary}

During the period from 1983 to 1992, nine MOTA irradiation campaigns were conducted at the FFTF in support of the Alloy Development For Irradiation Performance (ADIP) and Damage Analysis and Fundamental Studies (DAFS) Programs. Each campaign, designated as MOTAs $1 \mathrm{~A}$ through $1 \mathrm{G}$ and MOTAs $2 \mathrm{~A}$ and $2 \mathrm{~B}$, produced thousands of MOTA specimens. The specimens (see Figure 3-4) were prepared in various alloy and shape configurations. The test program objective was to characterize the mechanical properties and damage parameters caused by exposure to the reactor environment. It is known that MOTA specimens from campaigns $1 \mathrm{~A}$ through $1 \mathrm{G}$ are currently stored in one of the two shielded long-term storage cabinets in SMF south cell proper, near the south cell door.

Lack of available alloy information, especially the low percentage components of each alloy, makes it impossible to accurately determine the activity (and thus the radiation levels) of a particular MOTA sample. In lieu of this data, an exhaustive literature search (Hanford's Record Management Information System (RMIS), Google, and DOE's Information Bridge) was performed to supplement the customer-provided information. Laboratory notebooks, from the MOTA and related experiments, located in 
the basement of 326 Building, were also examined in an attempt to obtain the required characterization data. Finally, interviews (summarized in Appendix B) were conducted with personnel who worked on the MOTA project. None of these efforts provided a complete set of information.

However, a generalized volume and radiological characterization has been estimated. Appendix C contains the analysis as well as the MOTA inventories (Catalan 2002). It was assumed that 1500 cells in the cabinets are filled with 13 Fermi samples, providing an upper bound for material. This results in $108 \mathrm{~kg}(238 \mathrm{lb})$ of material with a $100 \%$ packed volume of $0.031 \mathrm{~m}^{3}\left(1892 \mathrm{in}^{3}\right)$. The corresponding activity was based on the total of $18.4 \mathrm{~kg}(40.5 \mathrm{lb})$ of material possible from the MOTA runs. The resulting activity levels would require about $14-\mathrm{cm}$ (5.5 in) of lead shielding reduce the exposure rate to < $200 \mathrm{mR} / \mathrm{hr}$, the limiting value of a type-A container.

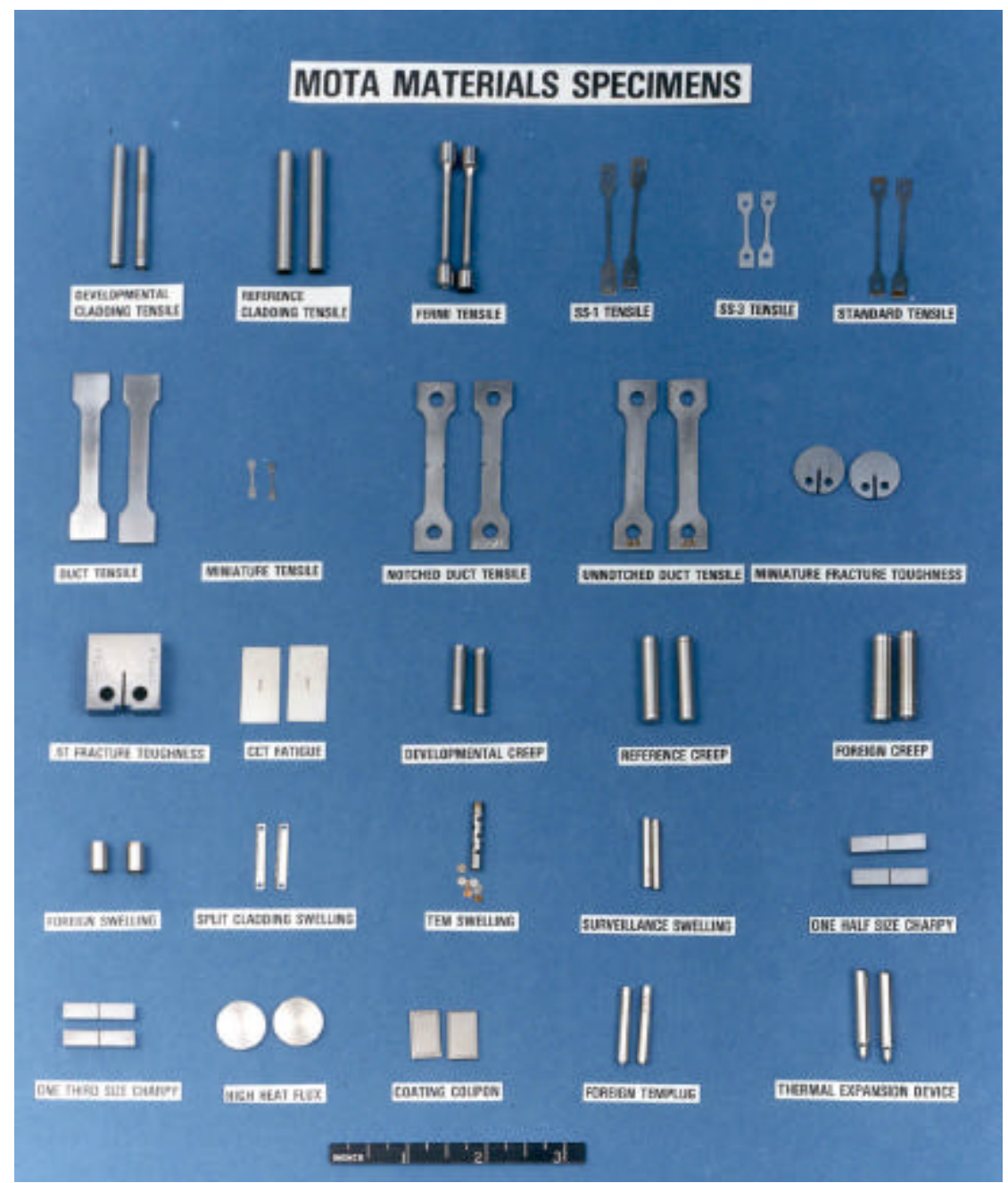

Figure 3-4 Typical MOTA Specimens 
There are 419 'special' samples containing unusual materials (beryllium, vanadium, or metals like Ni-59 or Co-59), which are expected to have higher activation than the bulk of the samples. Research efforts concentrated on these special samples, attempting to locate them on the storage cabinet cards. The research was only able to identify some of these sample locations. The actual quantity of these materials cannot be confirmed for the majority of the samples.

In addition to the MOTA specimens with unique materials, there are pressurized tubes. According to the MOTA documentation, there are less than 2500 pressurized tubes. Presence of these tubes can be confirmed from the cabinet information, however their exact quantity cannot be confirmed. Special steps for handling these tubes are provided in the Proposed Path Forward Section (4.0).

\section{2. $\quad$ SMF South Cell Waste Summary}

The south cell was visually surveyed to estimate the nature and extent of the waste (cell entry was not permitted). Digital photographs were taken through the facility windows and a preliminary database of all visible items was developed. This database was subsequently revised and expanded by direct observation of the materials in the cell. Because the data was developed by visual observation only, the weight, materials, characteristics, and dimensional information is estimated. See Appendix D for a full description of the south cell waste forms, characterization, and full inventory (Baker 2002).

No process or facility information indicating what is in the south cell was available other than the established information that the cell (especially the compartments) was used to process $\mathrm{CsCl}$ salt. A verbal report indicated that the remains of an old canister vacuum cleaner are stored under one of the tables, however the precise location was not known. This vacuum cleaner had been used to clean up $\mathrm{CsCl}$ and can be expected to be quite radioactive. Also, it has been reported that some of the MOTA specimens have been dropped in the south cell proper. The waste in compartment 1 is expected to have higher levels of contamination than the other south cell wastes because of the historical activities (initial processing of $\mathrm{CsCl}$ ) that took place there.

The estimated weight of waste recorded in the database is approximately $4990-\mathrm{kg}$ $(11,000-\mathrm{lb})$ and estimated volume is approximately $9.17-\mathrm{m}^{3}\left(324-\mathrm{ft}^{3}\right)$. The vast majority consists of hand tools, materials, lifting fixtures, polyvinyl chloride (PVC) pipe, steel pipe, tubing, process waste, and other items that may be contaminated, but can almost certainly be disposed of as low-level waste in type-A containers.

Other waste items include anything designated in the database as a container - the paint cans, the sheet metal boxes, and the pressure vessels. These may contain high source-term wastes. Also, the sodium cleaning station (SCS) (inventory database item $47)$ is reported to have a high level (10 R/hr) hot spot on it. The vacuum cleaner motor could also constitute a high dose source. 


\subsection{Unique Wastes Stream}

Within the south cell, and the MOTA samples, the possibility exists that there are items that may not be classified as low-level radioactive waste. Therefore, during the cleanup operations in the SMF, it will be necessary to identify these items and assign them to the appropriate waste stream.

\subsubsection{Liquid Metals}

Among the MOTA samples, there is a definite (but unquantifiable) possibility for the presence of hazardous materials. The transmission electron microscope (TEM) disks could also contain hazardous materials. Because of the large numbers of TEM disks, their materials and locations were neither documented nor recorded. The TEM disk packets and thermal expansion devices (TEDs) both contained liquid metals (sodium and lithium). The TEM disks were cleaned for experimentation, however, it is possible that the packet containers were not as fully cleaned.

In addition to the MOTA samples, items such as the SCS likely contain some sodium and radioactive contamination. The determination of proper requirements will need to be made at the time of disposal. It will be necessary to process waste items that contain liquid metals prior to disposal.

\subsubsection{MOTA Sample Beryllium}

Based on an examination of the MOTA documentation, there appears to be beryllium metal samples present. Actual cell locations within the storage cabinets could not be found, however their presence cannot rule out. It is unlikely that there are airborne beryllium concerns. This corresponds to the Hanford Beryllium Fact Sheet (http://www.hanford.gov/safety/beryllium/fctsheet/324.htm), which states that there has been no past exposure to beryllium and there is not expected to be any future exposure in the 324 Building.

\subsubsection{SMF Lead}

Within the south cell, there is a lead sheet and many lead bricks that were used for shielding. It is likely that these bricks were contaminated during SMF operations (especially the cesium processing). Depending on the disposal requirements of the high activity items, it may be possible to recycle these bricks into shielding for some of the disposal containers. If recycling of these bricks into shielding for the waste containers is precluded, it may be possible to process the lead to minimize the actual contaminated lead waste stream. The lead likely only has surface contamination; therefore, it should be possible to remove the contamination by either wiping the lead, or shaving off a thin layer. Final disposition of the lead within the SMF needs to be determined in the initial planning stages of the cleanout. However, it is believed that the lead would be most beneficial if recycled into shielding for the disposal containers. 


\subsection{Proposed Paths Forward}

The proposed paths forward for cleanup of MOTA and other wastes from the SMF are based on the current understanding of the conditions inside the long-term storage cabinets, south cell proper, the four compartments, and a somewhat incomplete inventory of waste items. The inventory of waste items is incomplete because of missing records for the long-term storage cabinets and lack of visual access to anything in the cell below tabletop level. No recent radiological survey information is available on any of the contents of the south cell. However, the incompleteness of the information does not prevent the development of a reasonable path forward. While some of the details may need to be changed to accommodate unexpected situations, the proposed paths forward permit the handling of all anticipated waste types and the range of possible radiological conditions.

Previous operations that required the opening of the south cell door have resulted in contamination of the air lock. The air lock had to then be decontaminated. While it is highly desirable to perform as much of the south cell cleanout without opening the south cell door, it is unrealistic to assume that the entire south cell cleanout can be performed without opening the south cell door.

Three categories of waste items are expected to be present in SMF. It is believed that the majority of the waste can be disposed of as contact-handled wastes. This means that, when placed in appropriate type-A containers, the surface dose level is below 200 $\mathrm{mR} /$ hour contact and $100 \mathrm{mR} /$ hour at $30.5-\mathrm{cm}(12 \mathrm{in}$.). Some of the wastes are radioactive enough that they will have to be treated as remote-handled wastes, requiring shielding or special handling. Some of the waste items may contain hazardous materials. A determination of the appropriate waste stream will need to be made during the cleanup operation.

\subsection{Baseline Inspection}

A more complete baseline inspection of the contents of the south cell will be required as one of the first steps in implementing a cleanup activity. What has been done to date in planning the SMF/MOTA cleanup is analogous to the preliminary, off-site activities that take place during the initial stages of cleaning up a hazardous waste site. As much information is accumulated as possible without actually setting foot on the site. This permits a reasonable plan to be developed, but the plan is flushed out as more on-site information is collected. For SMF cleanout, the type of information that is most needed to progress to the next stage of planning is the radiological conditions inside the cell. Based on the visual characterization activities, review of available documents, and discussions with staff, it is believed that the types and approximate number of waste items are known (i.e., the problem is bounded). The general radiation levels inside the cell and the source term presented by the majority of the individual items is not available. A visual inspection of the area below tabletop level has been impossible. It is suspected that there are waste items on the floor that were not in the view of the windows. 
A baseline radiological survey of the cell is required for two reasons. First, the level of the background radiation will determine how difficult it may be to reduce the dose rate to allow manned entry (i.e., to replace the crane or perform other hands-on activities). Second, it is important to determine as accurately as possible the source term for individual waste items so that proper packaging decisions can be made. As much as possible, the waste should be packaging as contact-handled to minimize the handling difficulties and disposal costs. It is believed that the existing RO7 probe (likely with collimation) and other available survey equipment are adequate for performing this survey.

It is also important early on to collect smear samples from within the cell. This also has two purposes. First, there are specific requirements on smearable contamination associated with use of the Special Environmental Radiometallurgy Facility (SERF) cask. Use of the SERF cask is proposed as the primary means to move high activity wastes to the REC air lock for placement in the grout container. This can only be done if smearable contamination levels are known. If the smearable contamination levels are too high for use of the SERF cask, other options exist but will require more effort to implement. The second purpose for the smears is to determine if general surface contamination will be a significant factor in determining the general dose rate. It is currently assumed that the general contamination is not high enough to prevent a manned entry if the individual, high source waste items are removed. If this is not the case, alternative crane repair/replacement or long-term storage cabinet opening methods will be required.

Though not as critical as radiological information, it would be beneficial for planning purposes if some type of visual inspection of the area below tabletop level could be performed. Two options that have been considered are a remote vehicle with video camera that enters the south cell door and a remote video camera held using either the MSMs or the AEA manipulator. The deployment system for the remote vehicle would need to ensure that contamination does not spread into the air lock.

Both the baseline radiological characterization and the initial, in-cell video inspection are only the first step in an ongoing characterization activity. As conditions change within the south cell (i.e., waste removed), there needs to be a continual updating of the radiological situation so that progress can be tracked and to assist in the ongoing planning process.

\subsection{South Cell Waste Removal}

A primary approach and alternate approach were identified for the removal of waste from the south cell, including the long-term storage cabinets. These approaches are generally very similar, with the primary differences generated by the waste container used. The primary approach is intended to use the SERF cask (to grout container to disposal) to package the higher activity wastes, and type-A containers for the balance of the wastes. The alternate approach assumes that the SERF cask or the REC airlock are not available. This approach then uses a custom engineered system. 
The SMF cleanout, regardless of approach, can use compartments 3 and 4 for staging or as a buffer area for waste. There are several reasons to use the buffer/staging area approach:

- Cell background radiation level is too high to obtain survey data for waste characterization.

- Cell background must be lowered for a manned entry and waste cannot be removed.

- If other facility requirements demand it. For example, if a grout container is currently not available or the REC air lock is tied up.

- To provide flexibility in waste container loading (i.e., scheduling) and contamination control.

\subsubsection{Primary Approach}

The general scheme for removal of the waste from the south cell (including compartments 2-4) is to remove all the most radioactive items (with the exception of the MOTA samples) first, then to continue removing items until the radiation levels are low enough to permit manned entry to replace the crane and until there is enough physical room for the work. The expected high contamination levels in compartment 1 require special consideration and will be discussed separately. It is anticipated that the high activity items (excluding the MOTA samples) are the paint cans. However, it is also possible that the boxes (Inventory Items 211 and 192), tube bundle (Inventory Item 74), and pressure vessels (Inventory Items 75 and 155) may be high activity items. The SCS (Inventory Item 47) is reported to have a $10 \mathrm{R} /$ hour hot spot, and there is a vacuum cleaner motor on the floor of the south cell proper that process knowledge evidence suggests is also a high source term. The MSMs, AEA manipulator, or crawler could place lead shielding over high source terms that cannot be immediately removed.

Removal of the paint cans, most of which are located near window 4, will be one of the first activities. These can be moved to near the south cell door, bagged, and loaded into the SERF cask using the "boat" inserted through the south cell door. Some minor house keeping activities will be required on the counter tops near window 3 to provide room for efficient manipulation of the cans and the plastic bags. The MSMs, once repaired, are adequate for this activity. It will likely be necessary to open the cans and repackage them with the MSMs.

While it is the intent to remove the high radioactive items from the south cell as quickly as possible, some low/non-source items may need to be removed to make room within the cell for other activities. A cart currently occupies the area just inside the south cell, near the door. This cart was used to transfer equipment in and about south cell proper. It is assumed that this cart does not present a high source term and could be removed from the south cell. Depending on the survey results from this cart, it might be removed from the south cell and disposed of, or stored in the east cell. If it is determined that this cart cannot be removed from the south cell in its present condition, or moved away from the air lock door, an alternate plan will have to be developed. 
Once space is available inside the south cell between the two long-term storage cabinets, a 55-gallon drum could be staged into the south cell when the SERF cask is being moved to the REC air lock. In the past, a manned entry was used to move waste containers as large as a 55-gallon drum into the cell. Until the background radiation can be lowered, a different method will be required. It is proposed that a powered cart or drum-carrying platform be procured to permit the insertion and removal of a drum and/or other container between the air lock and the south cell. While initially to be used for 55gallon drums, this device might also be required for moving lead-lined drums or other heavier containers later in the cleanup process. Air pallets have been used in the past for moving items into and out of the south cell so there should not be any concerns about the smoothness of the floor between the air lock and the south cell. However, because of loose contamination issues, an air pallet might be undesirable and another type of pallet would be used. There is adequate clearance under the pass-through hole in the door to accommodate a 55-gallon drum on a reasonable height platform.

The intent of the initial cleanup activities should be to reduce the dose levels to those permitting manned entry as soon as possible. This will not only permit replacement of the crane as soon as possible, it will also permit other activities to be performed directly instead of remotely. The feasibility of this can only be determined as the cleanup progresses.

Cleanout activities of compartments 2-4 can proceed in parallel to cleanout of south cell proper. Waste from the compartments should be bagged in an assembly line fashion passing from compartment 2 to 3 to 4 before being passed into south cell proper to minimize contamination. The waste from compartments 2-4 would then be characterized in south cell proper, the same as any other in-cell waste. Wastes from the compartments would be packaged either in 55-gallon drums inside the south cell or transported in the SERF cask to the REC air lock for disposal in the grout container. The path will depend on the characterization of each waste item.

\subsubsection{Integrated Waste System Approach}

An alternative to using the SERF cask and REC airlock to package the waste into grout containers is to package the majority of the waste directly in the SMF airlock. This may be necessary if the SERF casks are not available or if the REC airlock is not available.

The alternate clean out approach uses a custom type-A container with internal subcontainers as a single integrated system. The basic type-A container is a $1.2 \times 1.2 \times$ 2.4-m ( 4 × 4 × 8-ft) box with 25 -mm (1-inch) walls fabricated from steel or stainless steel. In order to minimize the potential for contamination spread from the south cell to the airlock, the pass through in the door will be used. Specially designed containers and container handling equipment would be fabricated so that the containers can interface with the hole in the door. Details on the conceptual design of the type-A container may be found in Section 5. The sub-containers would be 8-inch pipe (the existing SERF cask uses 8-inch schedule 80 pipe as an inner liner). The pipe material and schedule could be varied depending on shielding, structural and packaging requirements. 
One end of these pipes would be sealed closed and the other left open. The open end would be inserted through the pass through in the door between the airlock and south cell. The pipes would be filled from the south cell side. Once filled, the pipes would be capped and withdrawn back into the airlock and placed into the type-A steel box. The box could hold up to 25 such sub-containers. This approach would reduce the potential for contamination of the airlock while significantly reducing the number of containers needed for removal of the wastes from south cell.

To pass objects from inside the cell to the outside will require a tray mounted inside the cell; this would be used to feed waste items through the pass-through and into the container. The waste containers would be placed in the airlock at the same time as the waste box. The airlock crane would be used to open the box, acquire each waste container in turn, and position it in alignment with the pass-through. Once the container was filled, the crane would be used to place the container in the box. A method for capping the waste containers once filled will be required, as will a method for sealing them to the pass-through opening.

Some type of cart (possibly powered) would be required to place the empty containers in the airlock and remove the full ones. Once the containers are out of the airlock, they can be moved using the facility overhead crane. This approach will require more tooling to be engineered and fabricated, but it reduces the number of waste packages required, eliminates the reliance on other facility resources, and minimizes handling of the waste.

\subsection{Individually Addressed SMF Wastes}

Several waste items have been identified that require special consideration during planning. These waste items include: items in containers, items too large to fit though the pass-through, compartment 1 wastes, and floor wastes. The wastes in the longterm storage cabinets are addressed separately.

\subsubsection{Items in Containers}

Several waste items are already located in containers, i.e. paint cans or boxes. It is assumed that all the items already located within a container would be opened, examined, recorded, and repackaged. While it is likely that it would be possible to obtain records of what was supposedly placed into these containers, the records may not have the required pedigree or information to allow the containers to be disposed of as is.

\subsubsection{Large Items}

The large items that will not fit through the pass-through will include the testing machines (Inventory Item 78 and item 58), the large sheet metal box (Inventory Item 211 , which is believed to contain contaminated air filter), the pressure vessel stand (Inventory Item 236), the bench top hydraulic press (Inventory Item 166), the abrasive cutoff saw (Inventory Item 23), electric tool fixtures (Inventory Items 143 and 172), the three-jaw chuck fixtures (Inventory Items 27 and 28), the filter bank (Inventory Item 181), specimen stands (Inventory Items 232 and 214), the smaller sheet metal box 
(Inventory Item 192), the capsule processing (welding) machine (Inventory Items 136 and 113). Also, many of the worktables and carts will not be easy to size reduce so they will fit through the pass-through. It may be practical to cut up many of these items using a reciprocating saw or a hydraulic shear. However, it seems likely that any attempt to size-reduce the contaminated filter would result in further contamination of the cell. For these items, it will be necessary to open the south cell door, insert an empty disposal box, and put the waste in the box. It may be possible (and necessary) to seal the box while it is still in the cell; appropriate contamination reduction measures will be required to minimize the spread of contamination from inside the cell to the outside of the container and the airlock.

\subsubsection{Compartment 1 Waste Handling}

The waste in compartment 1 is expected to be similar in physical characteristics to that in the south cell proper and compartments 2-4. However, because of the $\mathrm{CsCl}$ processing that took place in compartment 1 , it is believed that the waste will be significantly more contaminated (likely resulting in high source terms).

After cleanout of compartments 2-4, a survey station for waste characterization should be set up in compartment 2 for waste coming from compartment 1 . Waste can then be sorted prior to entry into south cell proper. Except for some equipment items, the compartment 1 wastes will be packaged in paint cans prior to entering compartment 2. This will aid in manipulation of the wastes, as well as assist in contamination control. Once in compartment 2, the wastes from compartment 1 can be treated the same as those from compartments $2-4$.

\subsubsection{Floor Waste Removal}

A remotely deployed crawler may be necessary for removal of debris from the floor. It is believed that some high dose waste items are on the floor of the south cell. In addition to the contaminated vacuum cleaner motor, it is suspected that some activated MOTA specimens were dropped, likely on the floor. Neither the MSMs nor the AEA manipulator can reach the floor, and it is unlikely that either could use a tool to remove waste items from the floor (i.e., vacuum). These manipulators could be used to hold a remote camera and radiation probe to help locate and characterize such items. A crawler can also be used to vacuum up any loose contamination that may prevent manned entry to repair the crane. This crawler would need the ability to perform visual and radiological surveys, deploy a vacuum tool, and manipulate debris.

\subsection{Replace South Cell Crane}

The complete replacement of the south cell crane trolley is recommended. This replacement would be performed via a manned entry; after all high source term wastes have been removed (and enough other waste has been removed to allow room to work). It is believed that with the removal of the majority of the highly active items and possibly some preliminary decontamination, manned entry would be possible.

All the high activity/high source term waste that can be removed with the MSMs and AEA manipulators should be removed prior to attempting manned entry. However, 
there are two possibilities (high contamination levels or unreachable highly radioactive debris) that may keep the radiation levels too high to permit manned entry. In either case, the crawler described previously can be used to clean out the cell. If this fails to permit manned entry, it will be necessary to stop, regroup, and engineer a different approach to handle the heavy items in the cell and lift the long-term storage cabinet lids.

\subsection{Long-Term Storage Cabinets}

The drawers of the long-term storage cabinets contain both the MOTA specimens and other samples that have been assumed to be similar in physical characteristics as the MOTA specimens. These drawers are mounted to the lids to the cabinets. Once the lids have been lifted (either through the replaced crane or an engineered device), it will be possible to open the drawers with the manipulators and remove the samples from the cubicles. It is believed that the samples are located within sample holders (small pieces of tube with stoppers and/or end-caps). Therefore, the MSMs would be used to remove these sample holders from the drawers. There are concerns that the stoppers used with the holders may have degraded, thus care must be taken when removing the sample holders from the drawers to ensure that the samples are not spilled.

Once removed from the drawers, the contents of the sample holders would be emptied onto a sorting station. The sorting station would allow operators to use MSMs to separate the specimens into the appropriate waste stream, without the need to pick up and attempt to identify individual samples. The flat samples would be placed in a paint can for disposal. The Fermi samples, while cylindrical, are distinctly different in appearance (the ends are larger in diameter than the body) to the unique samples and would be easy to separate for inclusion to the same waste stream as the flat samples. It is important to note that the samples that are disks (i.e. the diameter is larger than the length) are not considered to be cylinders. The disks are expected to be limited to the compact tension, high heat flux, and TEM samples.

The TEM disks themselves are best described as foil disks about the diameter of a pen. No detailed records were available on the materials of these disks (and they were not individually marked). However, their total volume (or mass) when compared to the remainder of the MOTA samples is negligible. Therefore, special treatment is not recommended since extensive material testing would be required to determine their construction and the majority were various types of steels.

The samples that require special handling, namely non-Fermi cylinders, would be separated for closer examination. The cylindrical samples would then be placed into the appropriate waste stream for disposal or treatment. The open tube samples, numbering in the hundreds, would require individual examination to separate them from the sealed or pressurized tubes. Therefore, it is recommended that the all tubes, except for the Fermi samples be treated identically.

The sample identification (ID) numbers, and physical descriptions of the MOTA samples are included in Appendix C (Catalan 2002). 


\subsubsection{Stuck Drawer Recovery Plan}

If the long-term storage cabinet drawers are jammed (and there is process knowledge evidence that suggests this), attempts will be made to force the drawers open with the MSMs and AEA manipulator. If these manipulators cannot open certain drawers, the MOTA specimens will be removed from those drawers that can be opened. It will then be necessary to place the drawers back into the shielded cabinets and engineer a method to force the jammed drawers open.

\subsubsection{Unique Samples}

While it has not been possible to confirm the location(s) of any MOTA samples with liquid metals (lithium, sodium) or dangerous materials (beryllium), some were irradiated in the MOTA experiments. The liquid metals in the TEMs were used as a thermal conductive fluid and were supposed to be cleaned off the samples prior to testing them. As a result of the small size of the MOTA samples and the possibility for corrosion, it may not be possible to determine the presence of residual liquid metals. The TEDs also contained liquid metals and it is likely that liquid metal remains within the TEDs. There are also a large number of tubes, some of which are pressurized. The pressurized samples need to be depressurized prior to disposal. Each type of unusual sample class (TEDs, TEM packets, or pressurized tubes) consists of thousands of pieces. Combined with the open tubes, which would be difficult to separate from the pressurized tubes without a magnifying glass or microscope, the total number of these unique samples exceeds several thousand.

These unique samples require treatment and processing prior to disposal. The recommended approach is to have a single treatment stream to process all the samples together. The disadvantage to this is that the open tubes and pressurized tubes would be reacted as if they contained liquid metal. However, all the unique samples require some form of shredding (to either remove the potential pressurized gas or to open them up to allow the reactive agent (i.e. water) to reach any liquid metal present. Also, this approach removes the need to individually examine the thousands of unique samples under a microscope to place them in a more individualized treatment path. Also, the risk of dropping the samples is greatly reduced since they would not be individually picked up. 


\subsection{Required Resources}

The SMF facility has several in-cell resources for handling material in the south cell. These include the MSMs, the programmable and Remote (PAR) manipulator, and the south cell in-cell bridge crane. Additional new support equipment required for the proposed cleanout approach(s) is also described.

\subsection{Master-Slave Manipulators}

The MSMs are Central Research Laboratories Model E or F with two different boot systems. They are quite old and were designed into the facility when it was constructed in the mid-1960s. However, they are kept in reasonably good repair and can be removed and reinstalled for repair or replacement as required. The primary limitations of these devices are reach (i.e., cannot reach the floor) and payload [9.1-kg (20-lb)]. The MSMs operate via direct mechanical connection (steel tape tendons) and the operator bears the weight of any object picked up in the gripper jaws. This is fatiguing when routinely handling heavy objects. The MSMs cannot reach throughout the cell. They are primarily intended to work near the windows and the worktables. However, they will be very necessary for the cell cleanout.

Currently, the MSMs must be repaired in room 147, unless the SMF MSM repair shop is reestablished. Depending on the requirements for the SMF cleanout, it may be desirable to reestablish the repair shop to ensure the MSMs are available for operations. Furthermore, it is expected that nearly a full set of MSMs, in a combination of light duty $(E)$ and heavy duty $(F)$ variants, will be required to complete the SMF cleanout. Sufficient numbers of repaired MSMs and associated boots are required.

\subsection{PAR Manipulator}

The PAR manipulator has expanded reach (and payload) over the MSMs because it is mounted on a traveling bridge in the cell. However, the PAR in the south cell is broken. An unidentified piece was ejected from the PAR and was subsequently lost in the cell. A functional test has not been completed. The PAR manipulator is not believed to offer any substantial additional workspace or payload capability that cannot be accomplished with the existing MSMs, south cell crane, or AEA manipulator. Because of this, it is not recommend that a functional test and subsequent repair be pursued.

\subsection{In-Cell Bridge Crane}

The south cell in-cell bridge crane is rated to lift $2772-\mathrm{kg}$ ( 3 tons). It is operated remotely by connecting a control pendant to any of a number of connectors located near the cell windows on the gallery side. This allows the operator to move to a vantage point where the crane operation can be most easily seen. A functional test was completed that diagnosed that the bridge and hoist work, but the trolley does not. The problem is currently diagnosed as a failed trolley motor. Vendor cost estimates range from $\$ 10,000$ to replace the motor to $\$ 38,000$ to replace the trolley. These price estimates reflect the unburdened hardware costs. The preferred approach is to replace the entire crane, which the vendor has preliminarily estimated at $\$ 50,000$ (unburdened 
hardware costs only). The primary driver for having an operable crane is the removal of the long-term storage cabinet lids and several other heavy items. The MOTA samples cannot be accessed without removing the cabinet lids.

Details on the bridge crane analysis and alternatives may be found in Appendix E. A full crane replacement is recommended because the old crane has not had its preventive maintenance, and of particular concern is the possibility that the high radiation levels during operations may have destroyed the insulation of the electrical cables. The preliminary diagnostics test has indicated a failed trolley, but it is suspected that there will be additional components that will fail once the trolley has been replaced.

\subsection{Chain Hoists}

Compartments 1, 2 and 3 are fitted with $91-\mathrm{kg}(200 \mathrm{lb})$ capacity chain hoists. These hoists are mounted on the ceiling near the pass-throughs between the compartments. They were apparently used to facilitate handling heavier items and particularly to aid in passing them from on compartment to another. While they have not been used in quite some time, they require little maintenance and have been stored in a controlled environment. Therefore, it is believed that they should be completely serviceable. However, they are unlikely to be of general utility. They provide a relatively short chain travel and a small payload and it is not clear that it is possible to remove them from the compartments and reinstall them in another location.

\subsection{Potential New Devices}

The following potentially useful devices have been identified.

\subsubsection{AEA Technology Manipulator}

The AEA Technology manipulator was recently delivered to the 324 Facility. The AEA Technology manipulator is a six degree-of-freedom hydraulically powered tele-operated manipulator. The manipulator has been designed to be installed in a standard $25.4-\mathrm{cm}$ (10-in.) MSM port in place of a standard mechanical MSM. Preliminary data implies that the manipulator has a $91-\mathrm{kg}(200-\mathrm{lb})$ payload. Preliminary information also shows a $3.35-\mathrm{m}(11-\mathrm{ft})$ reach (from the wall penetration to the gripper). No other data, such as work envelope, is currently available. It is expected that this manipulator will be helpful to the cell cleanout.

\subsubsection{Survey Equipment}

Video and gamma survey devices should be used to survey the south cell. These devices should be crane and/or manipulator deployable. They will be used to identify the hot spots as well as look for debris (such as MOTA samples on the floor). It is expected that the gamma survey device will require collimation to determine the dose of individual pieces and also to reduce background readings. It may be desirable to integrate a video system into the crane. This would expand the existing capabilities within the south cell for future activities.

Because of the size of the south cell, and the likelihood of multiple simultaneous operations, it may be desirable to have multiple video camera units. There are many 
locations within the SMF where the current windows do not provide adequate viewing. Because of the unknown radiological conditions within the south cell, those cameras should be radiation hardened.

\subsubsection{Crawler}

Debris is expected to be on the floor that the manipulators cannot reach. A remote crawler may be necessary for retrieval of that debris and to vacuum up any loose contamination. In the event that a manned entry is unachievable, a remote crawler may be required to aid in cleanup and inspection of items beneath tabletop level in the south cell. This crawler would ideally be equipped with a video camera, gamma detector, manipulator, and/or vacuum mechanism. The manipulator and/or vacuum would allow removal of potential high source items (such as MOTA specimens) into waste containers to lower the general area dose for future manned entries. The deployment system for the crawler needs to ensure that any contamination within the south cell proper does not spread into the air lock.

\subsubsection{Drum/Container Pallet}

A powered pallet will be required for transferring waste containers into and out of south cell proper. While the SERF cask has its own cart, the other waste containers will need some type of platform. This most likely would be a commercially available platform that could be operated from outside the air lock.

\subsubsection{Contamination Control}

Previous operations that required the opening of the south cell door have resulted in contamination of the air lock. The air lock had to then be decontaminated. While it is highly desirable to perform as much of the south cell cleanout without opening the south cell door, it is unrealistic to assume that the entire south cell cleanout can be performed without opening the south cell door. The primary cleanout plan proposes to use containers placed within the south cell proper for some waste handling and the replacement of the bridge crane. Both these activities will require the south cell door to be opened. Therefore, it is envisioned that a multi-layered contamination control approach would be used to minimize and/or prevent the contamination of the air lock.

- Minimize required south cell door openings

- Spray removable coating on all south cell door surfaces

- Add greenhouse structure around the south cell door

- Increase the localized air flow around the south cell door

\subsubsection{Size Reduction}

Within the south cell, there are waste items that are too large for the pass through in the cell door. Opening of the south cell door is considered undesirable (due to the likely spread of contamination). Therefore, it will be necessary to size reduce these items prior to placing into a waste disposal container. Most items can be disassembled to fit though the pass through and others will require mechanical segmentation. Mechanical segmentation is limited to tooling that does not generate heat (i.e. no plasma torches, lasers, or cut-off saws). Additional permitting issues reduce the attractiveness of 
abrasive water jet technology. However, the following tooling has been identified to perform the size reduction activities.

- Tool Kit. While it is likely that the necessary tools (i.e. wrenches) are located within the south cell proper for disassembly of the large items, it is also possible that the tools were moved or disposed of previously. Therefore, it is recommended that a tool kit be purchased.

- Shear. There are currently several commercially available hydraulic shears that can be used to size reduce objects up to 152-mm (6-in.) in diameter. It is unlikely that the existing MSMs would be able to handle the reaction forces from such a tool. It would need to be mounted on a portable stand or deployed with the AEA manipulator.

- Saw. Various types of saws might be desirable. Band saws are currently used in machine shops to cut through solid steel bars greater than 304-mm (12-in) in diameter. The feed mechanisms for these saws are well known. Reciprocating saws are popular hand tools for cutting materials, however they require frequent blade changes when cutting though stainless steel. Additionally, with saws, the resulting chips from the cutting process must be recovered.

\subsubsection{MOTA Sort Station}

Since the MOTA samples must be sorted, it is recommended that a simple sort station be designed and fabricated. This sort station would have a flat work area where the samples can be placed and those samples representing cylinders would be more closely examined. The MOTA samples (and the samples from long-term storage cabinet 2) that are not cylindrical could then be 'swept' into a paint can for disposal. This would reduce the need to attempt to pick up all the individual samples. The cylinders could also be 'swept' into a different container for processing. Figure 5-1 provides a conceptual design for the sorting station. This design has physical barriers (lips) to prevent the samples from falling off the station or being accidentally placed in the wrong container. Different sized containers are used to further differentiate between sample types. The small container would be used for the cylindrical samples while the large one would be used for the non-cylindrical samples (since it would be directly sent for packaging once full) and Fermi samples. A simple wiper (not shown) would be used to sweep the samples to the appropriate paint can. The process would be similar to that used by pharmacists when filling out prescriptions. 


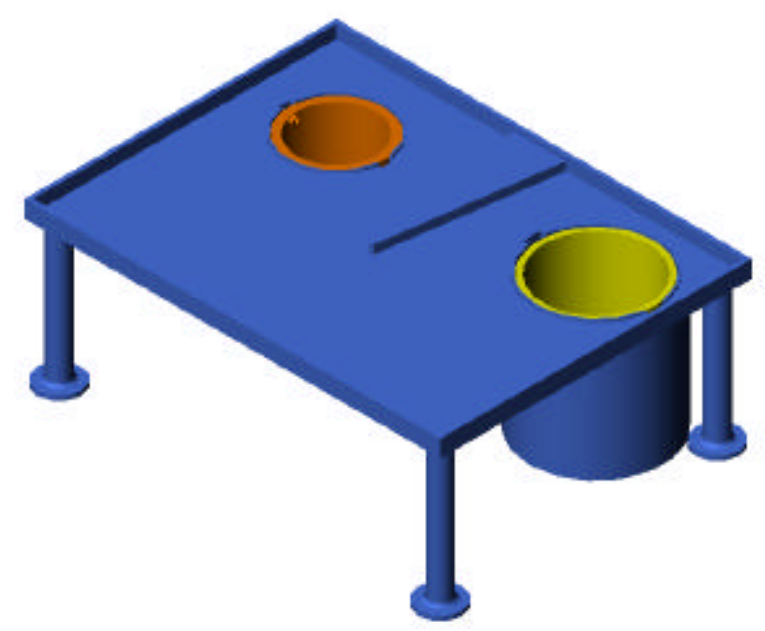

Figure 5-1 MOTA Sort Station

\subsubsection{Special Waste Processing Station}

There are two known types of MOTA samples that require treatment prior to final disposal. Additionally, there are the lead bricks, lead sheets, and SCS that may require some additional treatment prior to final disposal. Of particular concern are liquid metals. These metals are not acceptable for disposal and if necessary must be reacted. The other type of MOTA sample that requires treatment are pressurized tubes. These tubes must be crushed or shredded prior to disposal to ensure that they are not pressurized when disposed of. The MOTA samples will be sorted and the cylindrical ones (pressurized tubes and those potentially containing liquid metals) will be segregated for this processing. The processing may or may not be performed within the south cell, however, contamination issues may be less if it occurs in the south cell.

The simplest approach for the processing of the MOTA samples is to use a custom engineered device that will shred the cylinders, then react them (i.e. in a water bath), and finally compact them. The combination of these processes should ensure that all the MOTA specimens are adequately treated to meet disposal requirements. Treatment of the SCS and the various lead forms should be performed during actual retrieval operations. It is possible that they may be simply wiped down to remove the undesirable contamination. Furthermore, it has been recommended that the lead be recycled into shielding.

\subsection{Integrated Waste System Approach}

The alternate approach for removal of waste from the south cell requires some additional equipment. This equipment is intended to reduce the contamination control issues, SERF cask availability, and waste packaging concerns possible with the primary plan. The custom engineered equipment required for this approach is simple in nature and would ensure that a) the potential for spreading contamination is minimized, b) equipment such has the SERF cask is not necessary, and c) waste is packed to minimize container requirements. 


\subsubsection{Automatic Release Pipe Grabber}

The first piece of additional equipment is an automatic release pipe grabber (Figure 52). This would be used to pick up the 8-inch pipes used for initial waste packaging. The pipe grabber would allow the operators to pick up, handle, and place the 8-inch pipes remotely using the existing overhead crane.

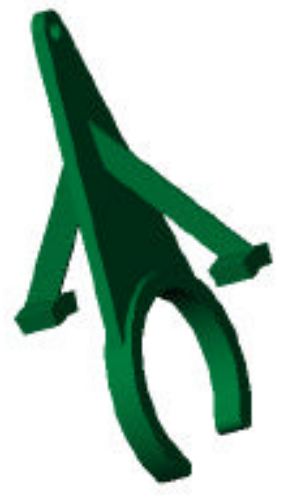

Figure 5-2 Automatic Release Pipe Grabber

\subsubsection{Airlock Sub-container Positioning System}

The largest piece of custom equipment is the positioning system (Figure 5-3) installed within the air lock. This will interface with the port in the south cell door and support the sub-containers during filling operations. The positioning system consists of the frame, the positioning cylinder, Ultra-High Molecular Weight (UHMW) guide supports, and the inflatable seal. The frame is simple welded steel construction. The positioning cylinder is a large bore hydraulic cylinder designed to both push the waste sub-container through the airlock pass-though and to react any forces generated by the waste filling process (to prevent the sub-container from moving). The final component is an inflatable seal. This seal provides a positive seal between the south cell door and the sub-container. The intention of this seal is to prevent the migration of contamination into the air lock.

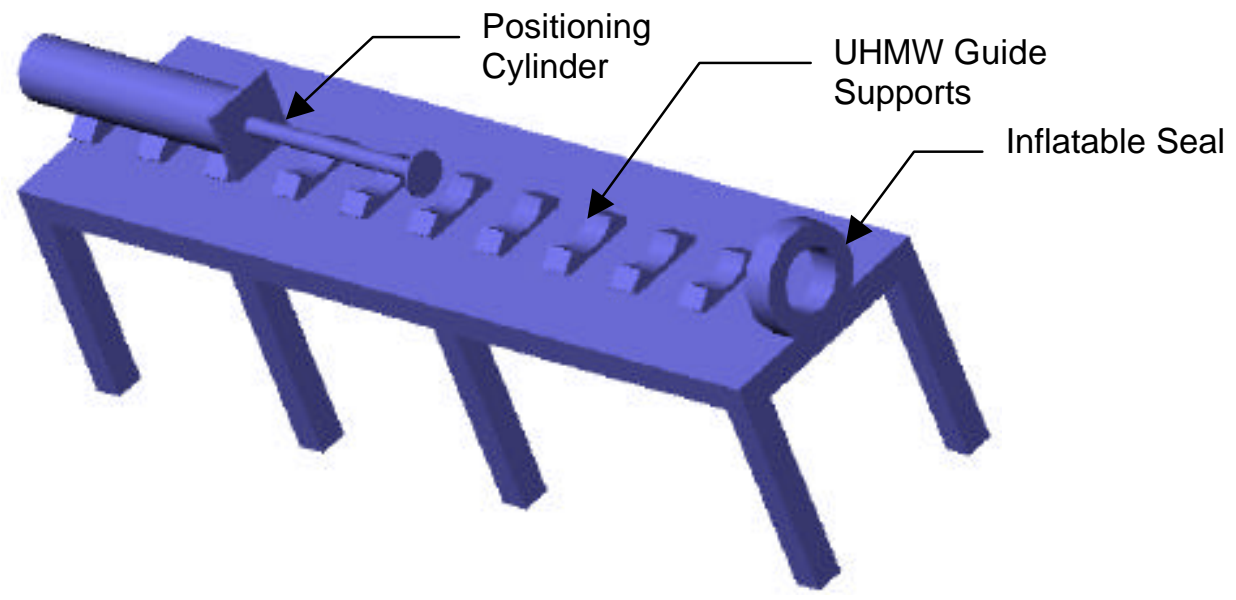

Figure 5-3 Airlock Sub-container Positioning System 


\subsubsection{Hydraulic Shear}

There are multiple items within the south cell proper, which require size reduction. Since the alternate approach uses an in-cell positioning system, it is desirable to design a shear mechanism (Figure 5-4) that can be installed within the in-cell positioning system to cut items up.

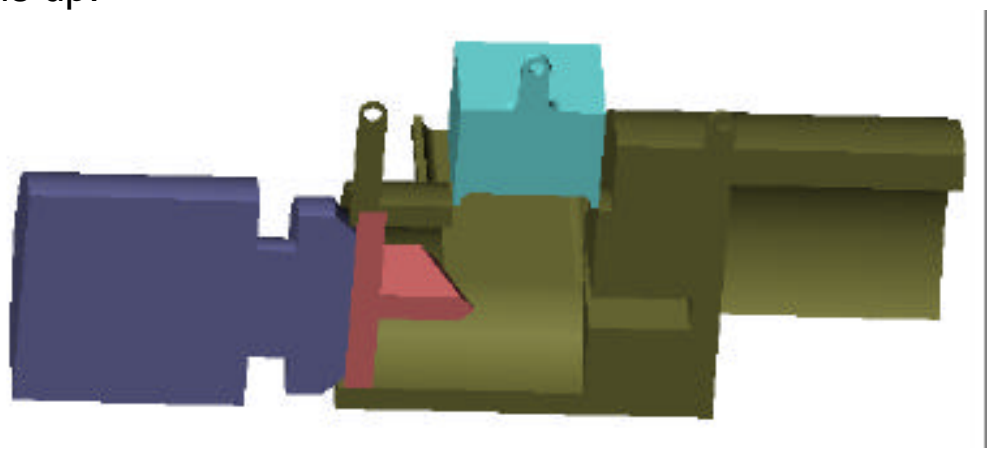

Figure 5-4 Hydraulic Shear

\subsubsection{In-cell Positioning System}

Actively loading the waste into the sub-container requires the use of some type of ram (Figure 5-5) to 'push' the waste into the container, ensuring that the container becomes packed. It would be desirable that this device would also center the sub-container to simplify the loading process, react any necessary forces from the size reduction tooling, and provide additional sealing around the south cell pass-though.

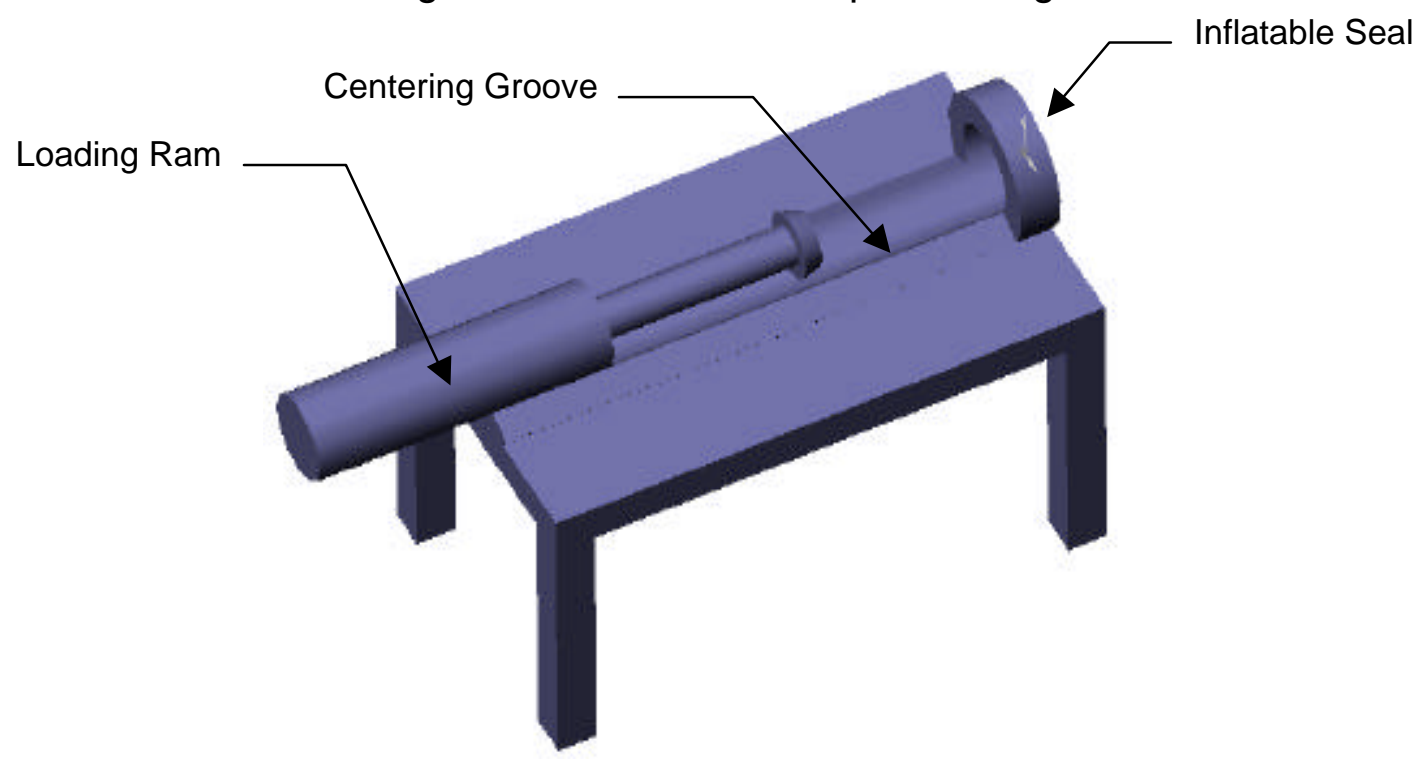

Figure 5-5 In-Cell Positioning System

The in-cell positioning system requires at least a single entry into the south cell proper and removal of the cart and other items from around the south cell door. However, it is possible that the in-cell positioning system could be mobile (i.e. drive itself into the south cell proper), contain any necessary engineered device to lift the lids of the long-term storage containers, and provide the deployment platform for the in-cell crawler. 


\subsection{Required Containers}

More than one packaging system will be used for disposal of wastes from the SMF. The primary component of each waste packaging system is the actual container in which the waste will be disposed of in the Central Waste Complex (CWC). For most wastes disposed of in unlined type-A containers, no other packaging system components are needed. The containers most appropriate for transporting remotehandled wastes to the CWC cannot be moved into the south cell and cannot be reasonably filled and packaged in the SMF air lock. Therefore, a shielded package is needed to move wastes from SMF to the REC air lock. For these wastes, the SERF cask is the best choice because it interfaces well with the SMF and is of appropriate size for the majority of the waste items. For remote-handled wastes too large (and not size reduced) or otherwise not appropriate for the SERF cask, an alternative container would have to be used. One option would be a type-A container (steel box), with added internal shielding.

\subsection{Containers for Low-Level Radioactive Wastes}

Many waste items will be loaded directly into type-A containers in south cell proper. It is recommended that standard 55-gallon drums be the primary type-A container for such wastes. For some specific items, it may be more appropriate to use a box because of the size or shape of the waste item. The large box (SMF Inventory Item 211) in the south cell may require a larger container. A type-A box could be used. Details of these containers may be found in Appendix F. The containers would be inserted into the south cell proper with the powered pallet.

\subsection{Containers for Remote-handled Wastes}

For remote-handled wastes, a cask or other shielded container will be required to hold the primary container for its transport to the CWC. The optimum approach for packaging remote-handled wastes is to use the REC air lock as a package filling location. Therefore, the SERF cask or other shielded container will be required to move wastes to the REC air lock from SMF. It is also possible, depending on the amount of radioactive materials present in certain items and the size of these items, that some remote-handled wastes will have to be loaded into shielded containers either in the south cell proper or perhaps in the SMF air lock. Packages exist that would be appropriate for such activities, however, moving such a heavy package into the south cell proper has not been done previously except with a manned entry. In the event that the dose rate in the south cell proper cannot be lowered enough for manned entry, a new method or equipment for moving a heavy container in and out of the south cell will have to be developed. Most of the remote-handled wastes, such as the majority of the paint cans, will be moved from the SMF to the REC air lock in the SERF cask, for packing in either a HN-200 grout container or a rectangular grout container. These grout containers will be shipped to the CWC in the ATG-3-82B cask and/or the steel waste package, respectively. Details of all these container systems maybe found in Appendix F. 


\subsection{Primary Approach Containers}

The south cell waste will be packaged into several containers depending on the waste characteristics.

- Remote-handled low-level radioactive waste will be packaged into HN-200 grout containers and shipped in ATG-3-82B casks. The non-contact-handled, nonhazardous waste is expected to consist mostly of the paint cans, vacuum cleaner motor, and the two sheet metal boxes. The estimated number and cost of the packages are:

○ Two HN-200 grout containers at $\$ 4500$ (unburdened for two).

- Two liners at $\$ 5554$ (unburdened for two)

- Two ATG-3-82B casks at $\$ 274,540$ (unburdened for two casks and a 6 month lease).

- The MOTA samples will be treated as mixed low-level radioactive waste and will be packaged in lead-lined drums (so that they do not require remote handling). The estimated number and cost of the packages are:

- Two lead-lined drums at $\$ 41,000$ (unburdened for two).

- A larger lead-lined (so it does not require remote handling) type-A container, such as a steel box, is also required for the SCS (SMF Inventory Item 47), also considered mixed low-level radioactive waste. The tensile test machines (SMF Inventory Items 78 and 58), tube bundle (SMF Inventory Item 74), and steel vessel (SMF Inventory Items 210) are expected to be low-level radioactive waste and disposed of in fabricated type-A box(s). The estimated number and cost of the packages are:

- Six fabricated type-A boxes (some with shielding, price to be determined based on actual requirements).

- The remaining waste is expected to be low-level radioactive waste and to be packaged in standard 55-gallon drums. Assuming a 50\% packing factor, the estimated number and cost is:

○ 40 drums at $\$ 1280$ (unburdened cost for 40 ).

- Paint cans will be used for sub-packaging.

- Estimate a minimum of 61 and maximum of 100 paint cans required.

\subsection{Alternate Approach Containers}

The alternate clean out approach uses a custom type-A container with internal subcontainers as a single integrated system. The basic type-A container is a $1.2 \times 1.2 \mathrm{x}$ 2.4-m (4 x $4 \times 8$-ft) box with $25-\mathrm{mm}$ (1-inch) walls fabricated from steel or stainless steel, weighing around $3180-\mathrm{kg}(7000-\mathrm{lb})$. This box is similar to current steel boxes already in use; the current box has a mass of $680-\mathrm{kg}(1500-\mathrm{lb})$ and a gross weight limit of $3175-\mathrm{kg}(7000-\mathrm{lb})$. The type-A container with 1 inch walls has a mass nearly that of the gross weight limit of the current box. Therefore, it may be desirable to reduce the wall thickness to reduce the gross weight of the box and simplify handling. Based on 
the gross weight/box weight relationship of the current box, the proposed box would have a gross weight limit of 14,150-kg (31,200-lb). A full load of empty sub-containers would weigh $6,500-\mathrm{kg}(13,750-\mathrm{lb})$. The waste generated from the south cell cleanout is estimated to be $5000-\mathrm{kg}(11,000-\mathrm{lb})$. Therefore, the estimated $3-5$ boxes would be more than sufficient to handle the complete mass of waste items.

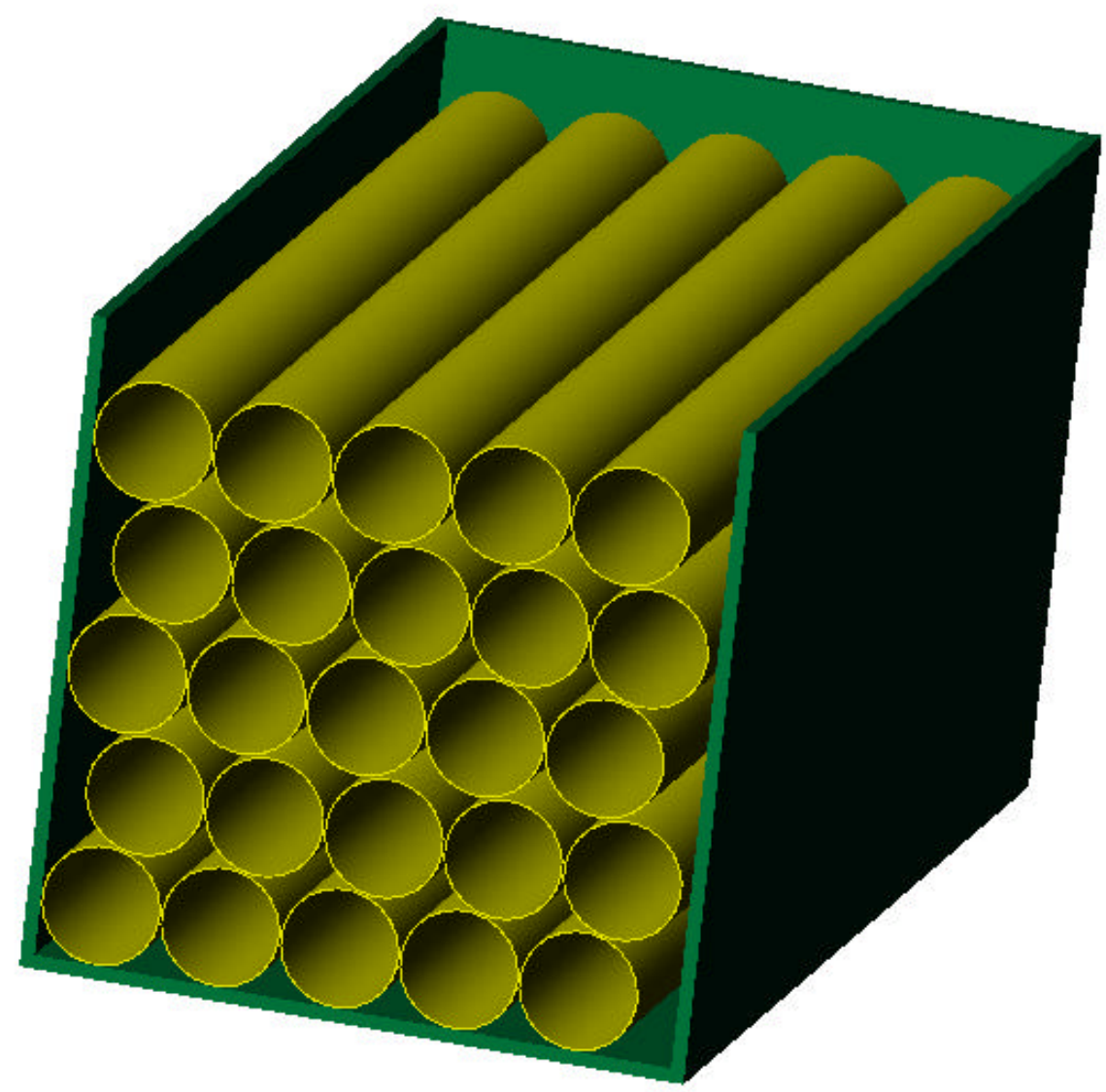

Figure 6-1 Section View of Type-A Container with Sub-containers

The sub-containers would be formed from pieces of 8-inch pipe 2.34-m (92-in.) long. The wall thickness of the pipe would change depending on the type of waste being loaded. As shown in Table 5-1, the wall and material thickness can vary greatly, while still using standard pipe sizes and materials. The waste handling pipes would be sealed within the south cell, minimizing the potential to spread contamination.

Table 6-1 Sub-Container Characteristics

\begin{tabular}{|c|c|c|c|c|}
\hline Schedule & Wall Thickness & $\begin{array}{c}\text { Waste } \\
\text { Volume }\end{array}$ & $\begin{array}{c}\text { Empty } \\
\text { Weight } \\
(\text { Steel) } \\
\mathrm{kg}(\mathrm{lb})\end{array}$ & $\begin{array}{c}\text { Empty } \\
\text { Weight } \\
(\mathrm{Al}) \\
\mathrm{kg}(\mathrm{lb})\end{array}$ \\
\hline 10 & $3.8(0.148)$ & $0.082(4966)$ & $46(103)$ & $16(34)$ \\
\hline 40 & $8.2(0.322)$ & $0.075(4588)$ & $99(219)$ & $33(73)$ \\
\hline 80 & $12.7(0.500)$ & $0.069(4187)$ & $151(333)$ & $50(111)$ \\
\hline 160 & $23.0(0.906)$ & $0.055(3343)$ & $260(573)$ & $86(191)$ \\
\hline
\end{tabular}


The container quantities assume that all waste items are size reduced and placed in the sub-containers.

- Steel Type-A Box used for handling all waste. This box would be $1.2 \times 1.2 \times$ 2.4-m (4 x 4 x 8-ft) box with 25-mm (1-inch) walls.

○ 5 at cost to be determined based on requirements.

- Steel or aluminum 8-inch pipe 2.34-m (92-in.) long waste sub-containers of various wall thicknesses with compression end caps for one end and sealed caps on other. Final details (quantity of each material and schedule) to be determined.

○ Estimate between 120 - 125 sub-containers required at an estimated cost of $\$ 750$ each (unburdened). 


\subsection{Bibliography}

Baker, C.P., E-mail “Re: SMF Inventory”, PNNL-SA-37467, July 31, 2002.

Bauer, R.E. 1988. Test Design Description for the Fusion Materials Open Test

Assembly (Fusion MOTA-2A), Volume 1A, Part 1. WHC-SP-0224, Pt. 1, Westinghouse Hanford Company, Richland, WA.

Bitten, E. J., HNF-2849, Rev. 1, Alpha Contamination Levels in SMF South Cell and Compartments, August 20, 1998.

Boehnke, W. M., HNF-5079, Rev. 0, Specification for 22-Ton Steel Waste Disposal Box, 1999.

Boehnke, W. M., HNF-3723, Rev. 0, Packaging Design Criteria for the Steel Waste Package, 2000.

Boehnke, W. M., HNF-4763, Rev. 0-A, Safety Analysis Report for Packaging (Onsite) Steel Waste Package, 2001.

BWHC-646-0001-01, Profile Checklist \& Waste Stream Approval Checklist for Revision for Mixed LLW Debris from 324 Shielded Materials Facility (SMF) Storage, August 18, 1999.

Catalan, M.A., E-mail “MOTA Characterization”, PNNL-SA-37474, July 31, 2002.

Chilton, A.B., Shultis, JK, and Faw, RE, Principles of Radiation Shielding, Prentice-Hall, Inc., Englewood Cliggs, NJ, 1984.

Clements, E. P., 1998, Safety Analysis Report for Packaging (Onsite) for the GNS-12 Packaging, HNF-SD-TP-SARP-022, Rev. 0-B.

Crow, S. R., 1997, Safety Analysis Report for Packaging 21PF-1 Overpack/EBR-II Spent Fuel Storage Cask System, SD-RE-SAP-054, Rev. 3-B.

DOE, "Safety Evaluation Report: Safety Analysis Report for Packaging (Onsite) Steel Waste Package", Attachment to U. S. Department of Energy Letter No. 003553 from Knolllmeyer, P. M. to Hansen, R. D., June 22, 2000.

Ermi, A. M., August 25, 1994, MOTA Specimen Irradiation History Listings, Doc \# 9455040, Westinghouse Hanford Company, Richland, WA.

Ermi, Ruby. Personal interview. May 23, 2002.

Ethington, P. R., 31-SOP-SMF-A-63, Operation of Transfer Doors and Transfer Ports in the SMF, November 14, 2001.

Garner, Frank. Telephone interview. May 24, 2002. 
http://www.hanford.gov/safety/beryllium/suspect3.htm

http://www.hanford.gov/safety/beryllium/CBDPP.pdf

http://www.hanford.gov/safety/beryllium

http://www.hanford.gov/safety/beryllium/fctsheet/324.htm

Johnson, Norris. Personal interview. June 11, 2002.

Johnson, P. G., HNF-4763, Rev. 0-B, ECN 665608, Safety Analysis Report for Packaging (Onsite) Steel Waste Package, December 28, 2001.

Klueh, R.L. and Alexander, D.J. (Oak Ridge National Laboratory). "Heat Treatment Effects on Impact Toughness of $9 \mathrm{Cr}-1 \mathrm{MoVNb}$ And 12Cr-1MoVW Steels Irradiated to 100 dpa".

Lamarsh, J.R., Introduction to Nuclear Engineering, $2^{\text {nd }}$ Ed., Addison-Wesley Publishing Company, Reading, MA, 1983.

McCarthy, M. 2001. 324 Building Spent Fuel Segments, Pieces, and Fragments Removal Engineering Study. HNF-6197 Rev 0. Fluor Hanford, Richland, WA.

McDowell, A. K., April 2002, Hanford Site Solid Waste Acceptance Criteria, HNF-EP0063, Rev. 7.

McGaughey, S. D., 2000, Safety Analysis Report for Packaging (Onsite) Lead-Lined Drum/21PF-1 Packaging System, WHC-SD-WM-SARP-001, Rev. 1 through $1 \mathrm{G}$.

Oak Ridge National Laboratory, 1985. Alloy Development for Irradiation Performance. Semiannual Progress Report for Period Ending September 30, 1984. DE85010454, National Technical Information Service, Springfield, VA.

Peters, B.B., HNF-3788, Rev. 1, EDT 660216, Safety Analysis Report for Packaging (Onsite) ATG Nuclear Services 3-82B Cask, June 27, 2001.

PNL, 1988, Safety Analysis Report for the Steel Waste Package, PNL-MA-651.

PNL, 1988, 22-Ton Steel Waste Disposal Box Lifting Yoke, drawing H-3-56434.

PNL, 1996, 22-Ton Steel Waste Disposal Box Assembly/Details, drawing H-3-56431, Rev.1 (4 sheets) with Supplemental ECN numbers 650709, 650724, and 659023.

Puigh, Ray. Personal interview. June 4, 2002. 
Romano, T., 1997, Safety Evaluation for Packaging (Onsite) SERF Cask, HNF-SD-TPSEP-058, Rev. 0.

Serles, J. A., HNF-SD-TP-SEP-058, Rev. 0-B, Safety Evaluation for Packaging (Onsite) SERF Cask, December 28, 1999.

Steen, R. T., May 31, 2002, Email Correspondence, MOTA Specimen Disposition, This message describes the discussion between Dick Steen and Jeff Riddelle from 324 building and Dave Templeton of DOE regarding the status of the MOTA samples. DOE determined that the MOTA samples should all be considered as waste.

Yates, K. L., SMF-SOP-133, Waste Packaging and Handling in the SMF, June 1994.

\section{Drawings}

H-3-20162

H-3-33960

H-3-20156

H-3-20239

H-3-33973

H-3-38542

H-3-20273

H-3-20211

H-3-20212
Architectural floor plan

Architectural gas bottle storage station (has dwg list)

Architectural key plans

Hot cells crane and shield door

Long-term storage cabinet (two sheets)

SERF cask

SST liner details (hot cells)

Structural concrete (Hot cells)

Structural concrete (hot cells) 


\section{APPENDIX A}

\section{Shielded Material Facility Description}




\section{Appendix A. Shielded Material Facility Description}

The SMF consists of three cells, arranged in the shape of an "L", surrounded by an operating gallery. The cells include the air lock, the preparation or east cell, and the fabrication or south cell as seen in Figures A-1 and A-9. The air lock, located at the knee of the L-shaped arrangement, functions primarily as a transition and ventilation barrier for shielded material movement between the radioactivity-free areas and the two operating cells. The south cell has been subdivided into smaller work areas. The work areas include; the south cell proper, compartment 1, compartment 2, compartment 3, and compartment 4.

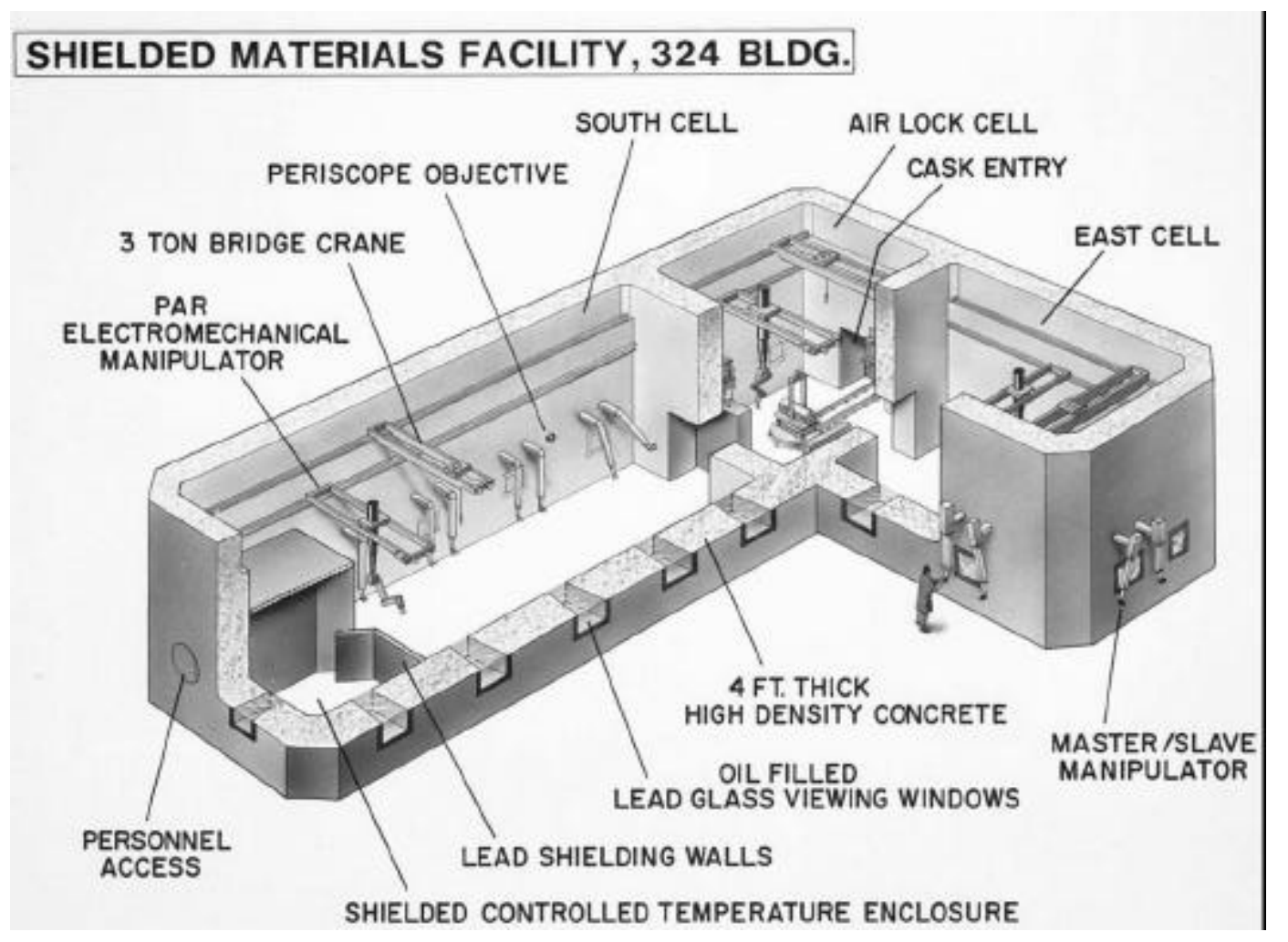

Figure A-1 Cutaway of SMF Before Compartments Were Constructed

The air lock cell dimensions are $6.0 \mathrm{~m} \times 4.9 \mathrm{~m} \times 5.5 \mathrm{~m}(20 \mathrm{ft} \times 16 \mathrm{ft} \times 18 \mathrm{ft})$ high. The east cell dimensions are $7.0 \mathrm{~m} \times 4.9 \mathrm{~m} \times 5.5 \mathrm{~m}$ high $(23 \mathrm{ft} \times 16 \mathrm{ft} \times 18 \mathrm{ft})$. The south cell dimensions are $15.2 \mathrm{~m} \times 4.9 \mathrm{~m} \times 5.5 \mathrm{~m}(50 \mathrm{ft} \times 16 \mathrm{ft} \times 18 \mathrm{ft}$ high). The cells all have 1.2$\mathrm{m}$ (4-ft) thick, shielded concrete walls with a specific gravity of 3.65. The cells also all have stainless floors and mild steel walls, with corrosion-resistant coatings. The operating gallery surrounding the SMF is approximately $464.5-\mathrm{m}^{2}\left(5,000-\mathrm{ft}^{2}\right)$ with $4.5-\mathrm{m}$ (15-ft) of headroom clearance. The operating gallery is used for cell operation and equipment mock-up.

SMF operations are conducted with 36 remotely operated MSMs located at or near 22 lead glass, oil-filled windows (see Figures A-2 through A-4). A remotely operated 
overhead crane and a PAR manipulator service each cell. However, both the south cell crane and PAR are currently inoperable and inaccessible for hands on repair because of the elevated dose rates.

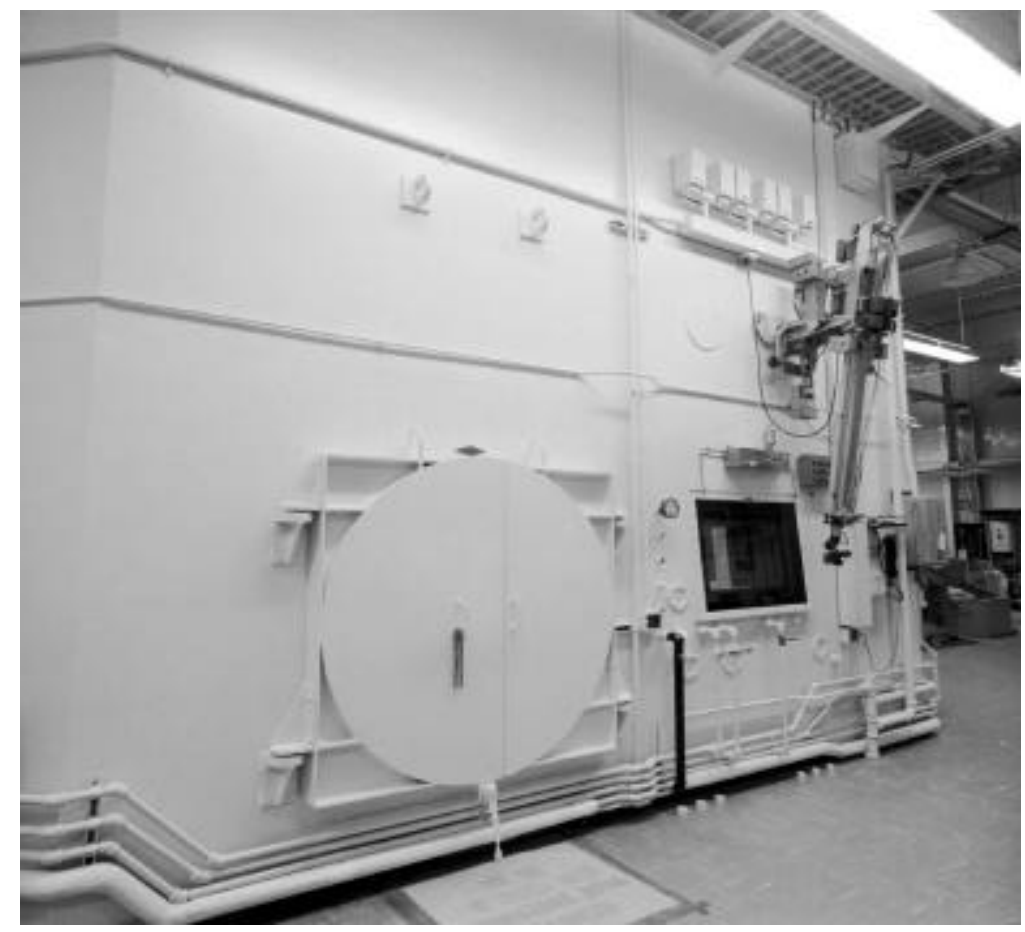

Figure A-2 Compartment 2 Exterior Pass-Through

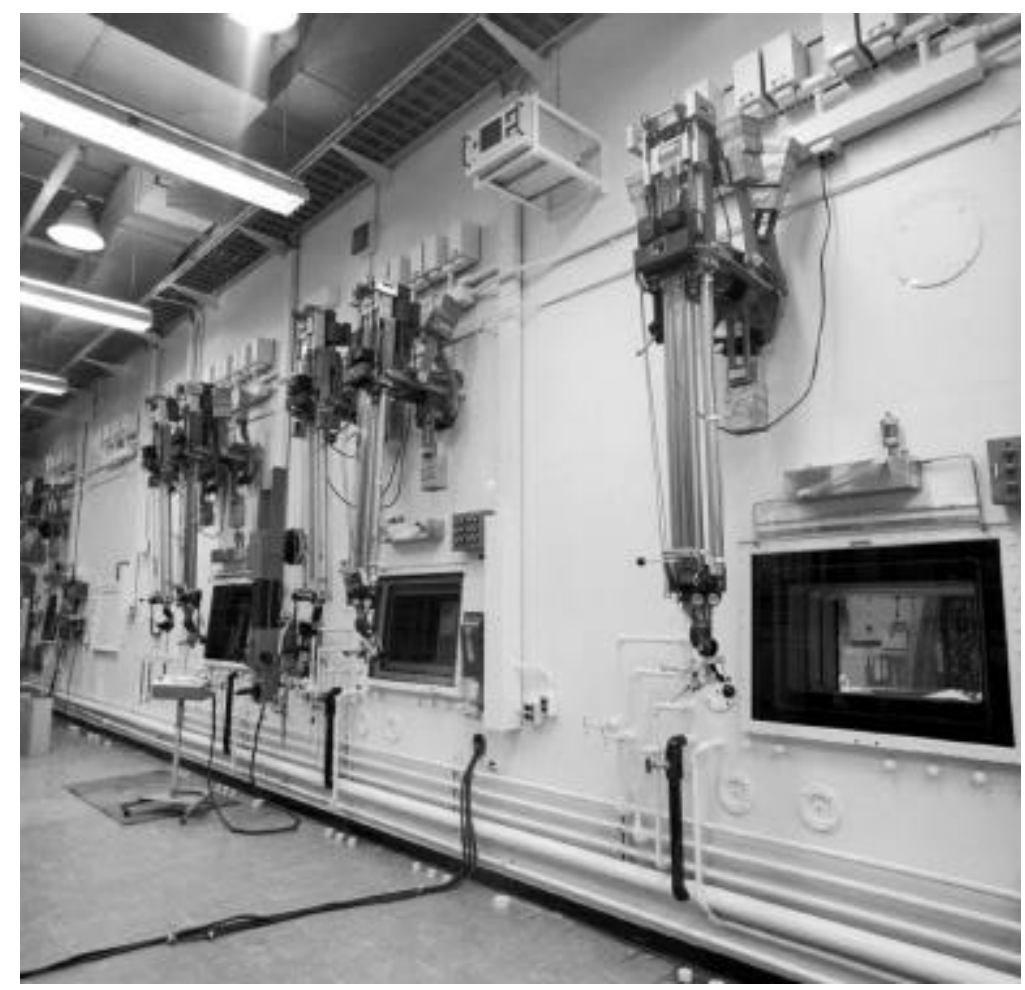

Figure A-3 SMF Exterior View Manipulators 


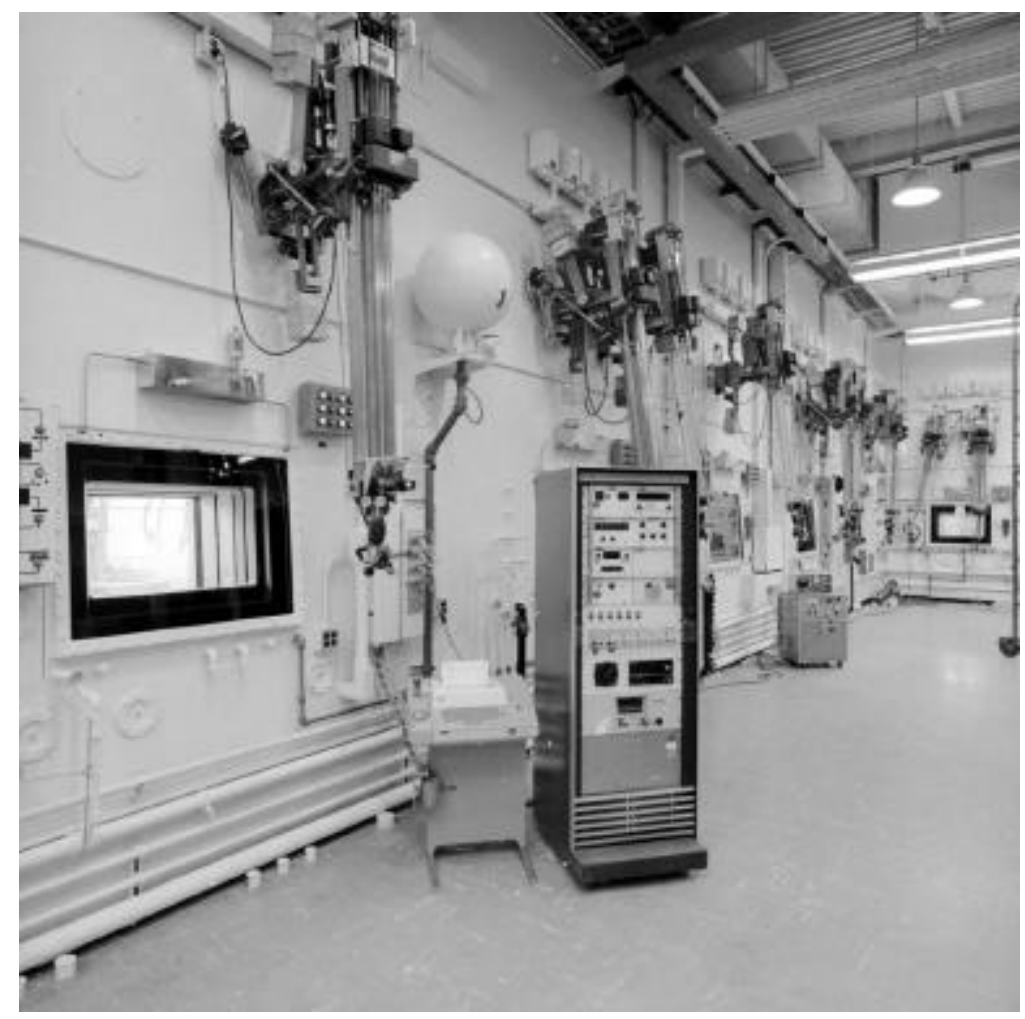

Figure A-4 South Cell East Wall (Exterior)

In the mid-1970s, two shielded long-term storage cabinets (see Figures A-5 and A-8) were installed at the north end of the south cell near Stations \#3 and \#13. Each cabinet contains 13 drawers with $19532.8 \mathrm{~cm}^{3}\left(2.0 \mathrm{inch}^{3}\right)$ storage cubicles with a $13 \times 15$ array in each drawer. There are 5070 storage cubicles between the two cabinets. Lifting a lead-filled lid provides access to the cabinets, which are attached to the lids. The lid dimensions are 108.6-cm (42.75-in.) x 100.3-cm (39.50-in.) x 20.0-cm (7.78-in.) thick and weighs $2268-\mathrm{kg}(5000-\mathrm{lb})$. Figures $\mathrm{A}-6$ and $\mathrm{A}-7$ provide an overall view of the cabinet lids. 


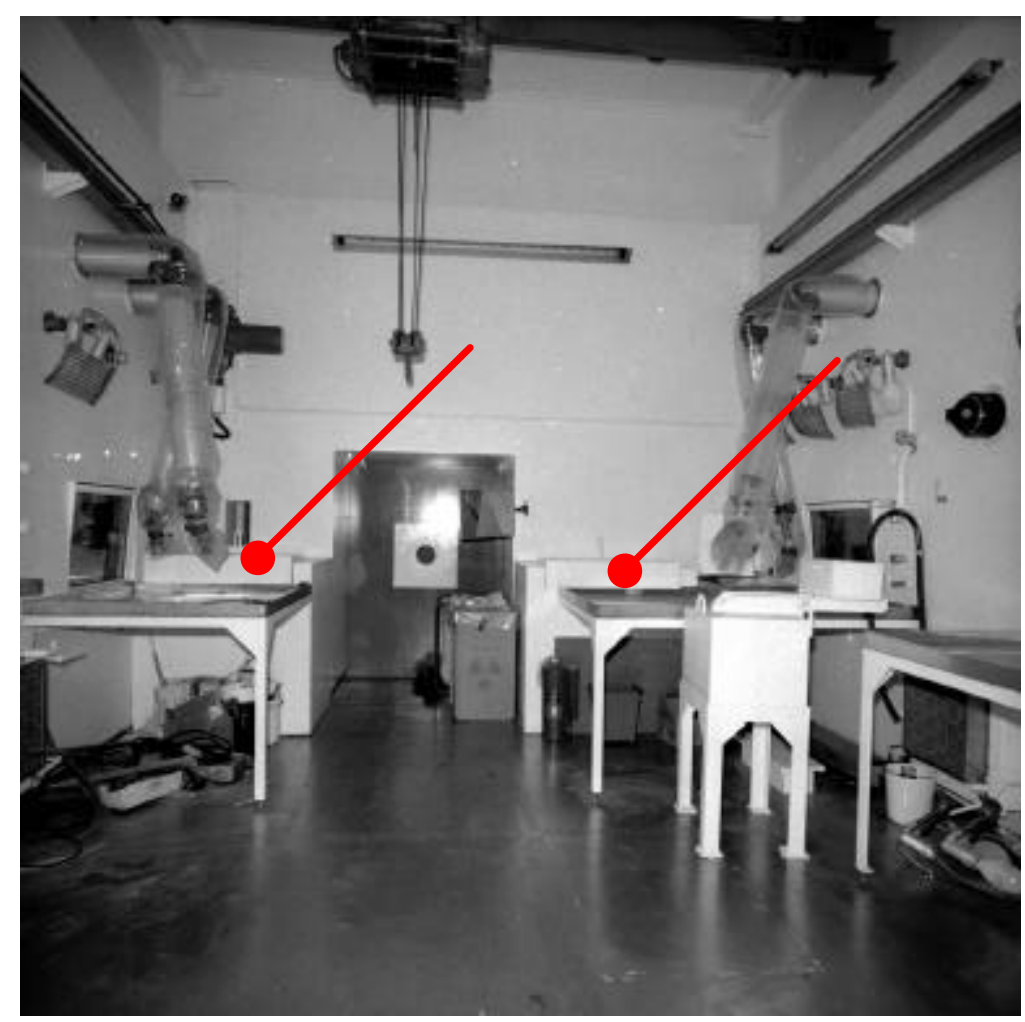

Figure A-5 South Cell with Long-Term Storage Cabinets Indicated

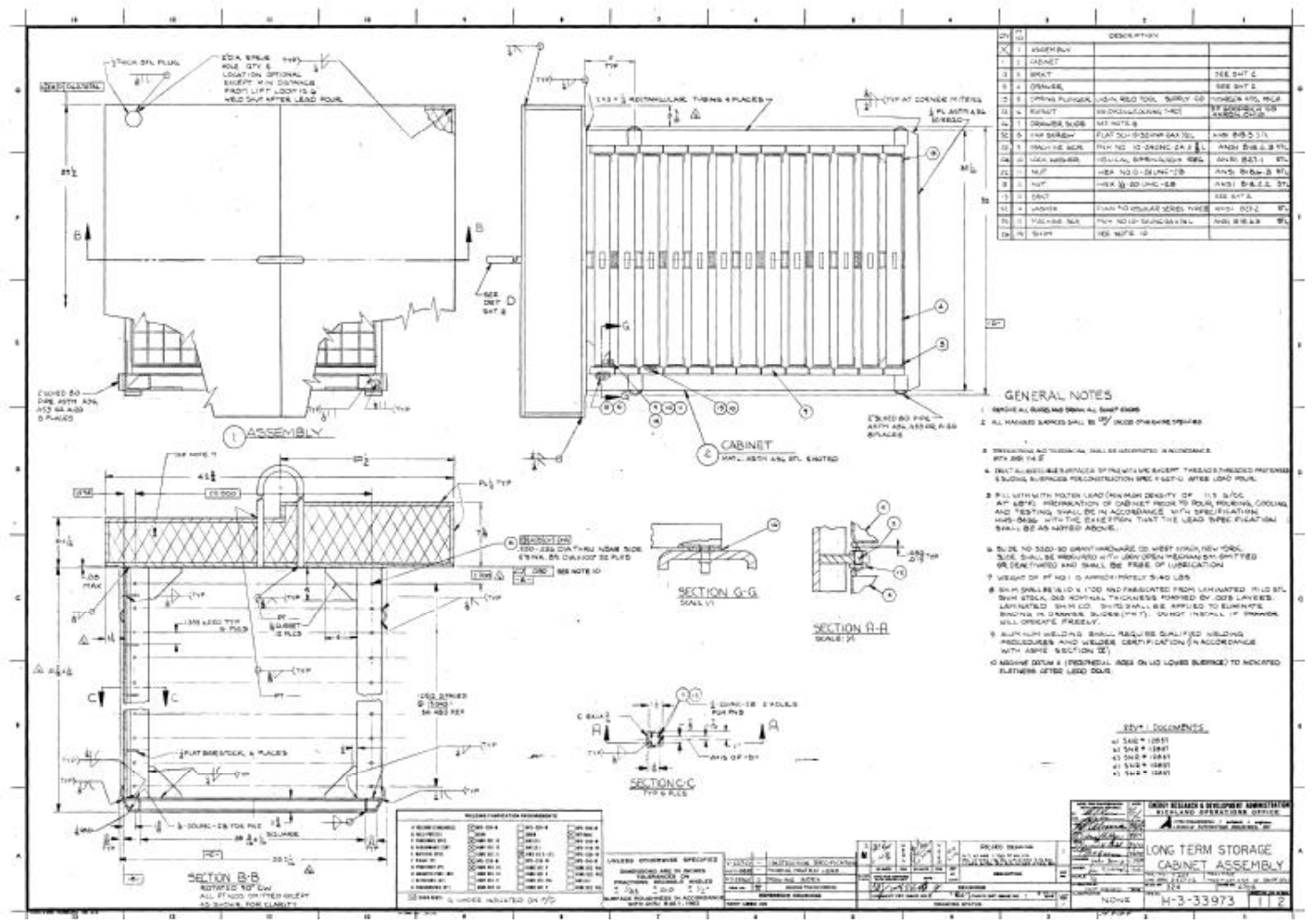

Figure A-6 Long-Term Storage Cabinet Lid 


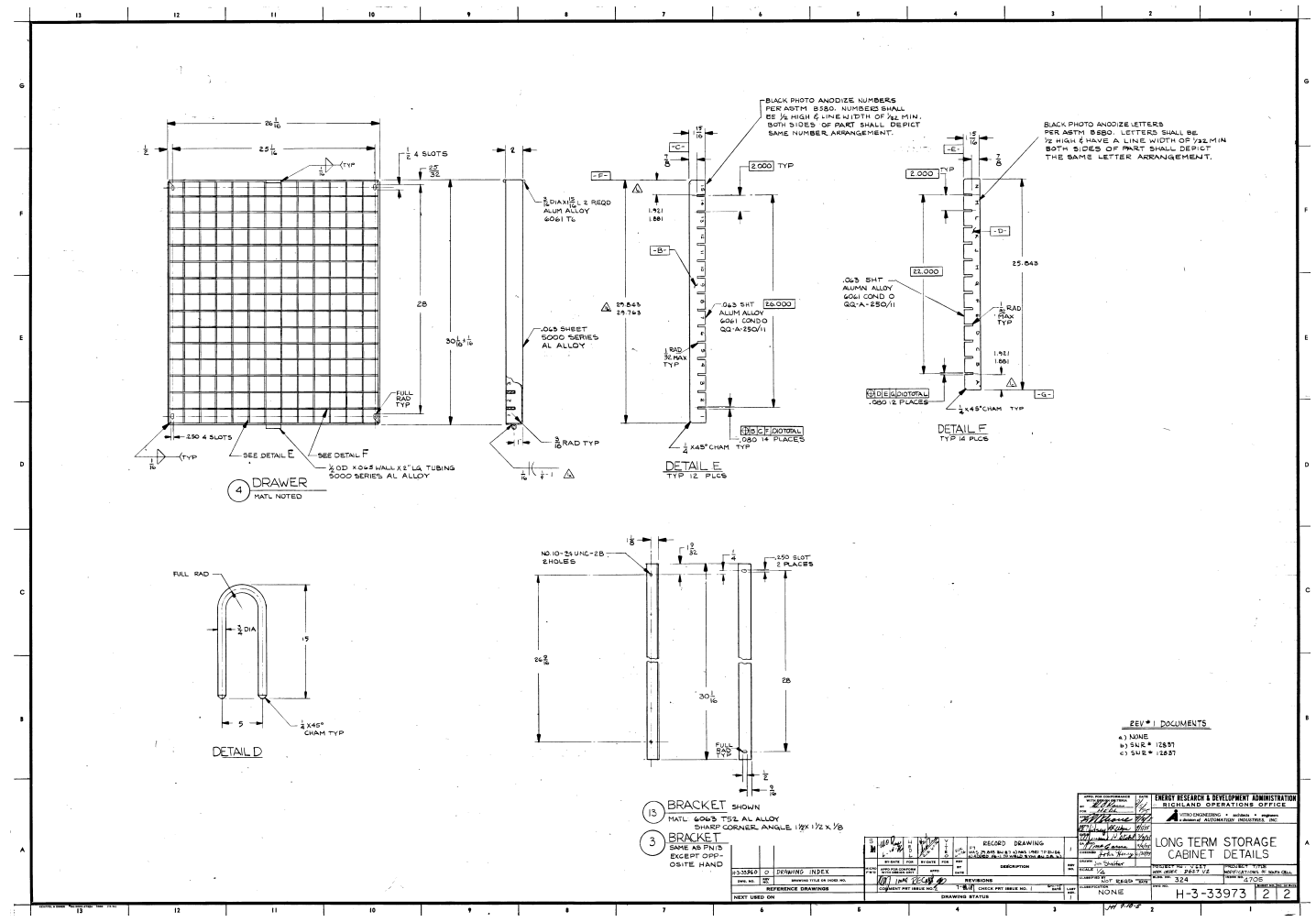

Figure A-7 Long-Term Storage Cabinet Dividers

\section{South Cell Compartmentalization}

Each of the four compartments located inside of the south cell are equipped with at least two pass-through ports, one to the south cell proper and another to the adjacent cell. Compartment 1 and compartment 2 are roughly $2.4-\mathrm{m}(8-\mathrm{ft})$ wide by $3.5-\mathrm{m}(11.5-\mathrm{ft})$ long by 3.2-m (127-in.) high. Compartment 3 and compartment 4 are roughly $2.4-\mathrm{m}$ (8ft) wide by 3.0 (10-ft) long by 3.2-m (127-in.) high. Process knowledge suggests that all smaller pass-through ports (intra-compartmental and between the compartments and south cell proper) are functional. The large doors between the compartments and south cell proper have not been operated in the recent history and may be rusted, which would limit their ability to be opened.

Compartment 1 is equipped with one 35.6-cm (14-in.) diameter pass-through for material transfers between the compartment and the south cell proper. The passthrough is equipped with a tray, which is removable depending on the size of the item being transferred. Compartment 1 is also equipped with a 10.2-cm (4-in.) diameter port for transfers with compartment 2 . The maximum length of material that can be normally placed in the $35.6-\mathrm{cm}$ (14-in.) diameter transfer port is approximately $78.7-\mathrm{cm}(31-\mathrm{in}$.) long. The maximum length of material that can be normally placed in the $10.2-\mathrm{cm}$ (4in.) diameter port is approximately $76.2-\mathrm{cm}(30-\mathrm{in}$.$) long.$ 


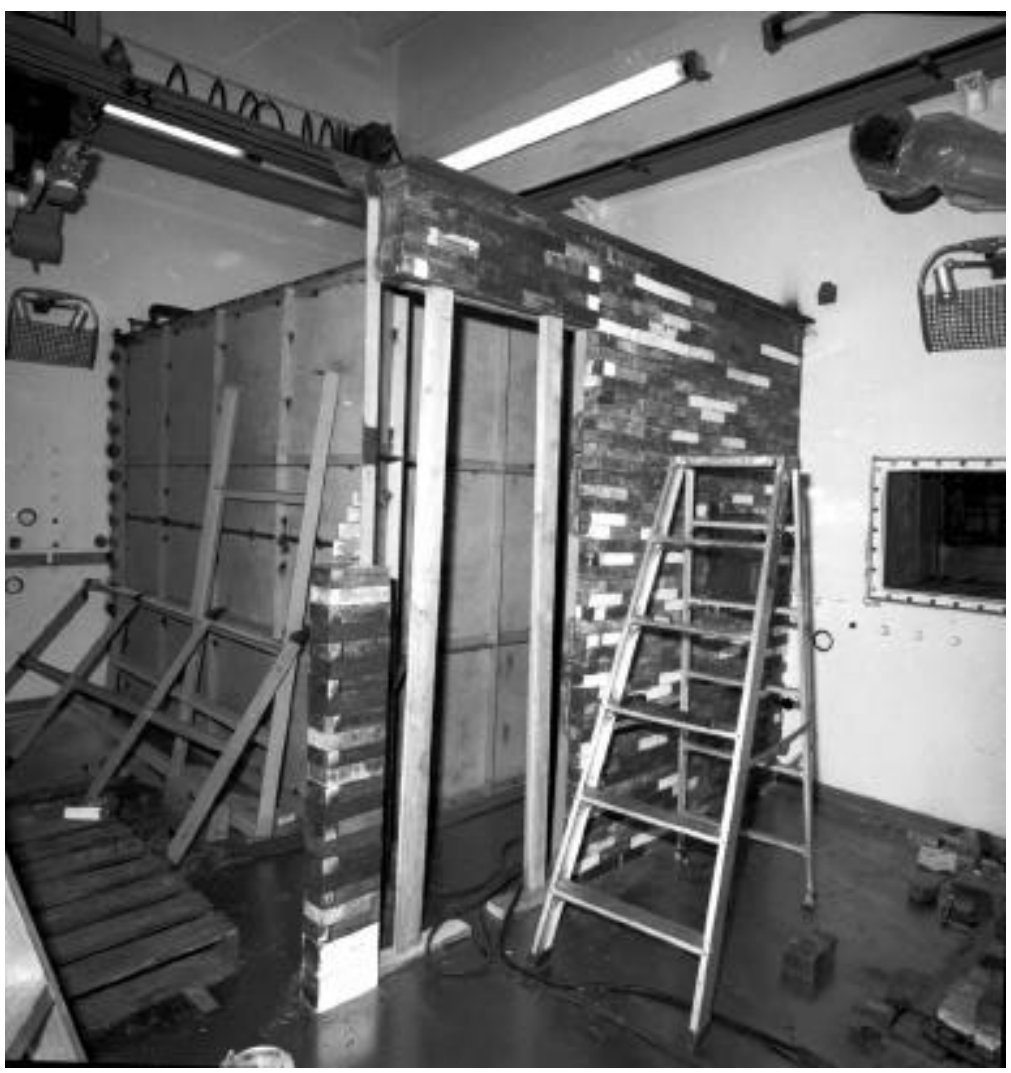

Figure A-8 Compartment 2 Under Construction (Interior)

In addition to the 10.2-cm (4-in.) diameter port common with compartment 1 , compartment 2 is equipped with one 35.6-cm (14-in.) diameter pass-through and one 10.2-cm (4-in.) diameter port for transferring to or receiving material from compartment 3. Compartment 2 is also equipped with a 10.2-cm (4-in.) port for receiving material or transferring items to the south cell proper. The maximum length of material that can normally be placed in the 35.6-cm (14-in.) diameter transfer port is approximately $61.0-$ $\mathrm{cm}$ (24-in.) long. The maximum length of material that can be normally placed in the 10.2-cm (4-in.) diameter transfer port (common to compartment 3 ) is approximately $61.0-\mathrm{cm}(24-\mathrm{in}$.) long. The maximum length of material that can be normally placed in the $10.2-\mathrm{cm}(4-\mathrm{in}$.) transfer port (common to the south cell proper) is approximately 147.3-cm (58-in.) long.

Compartment 3 is equipped with a 10.2-cm (4-in.) diameter port and a 35.6-cm (14-in.) square port for material transfer to or receipt from compartment 4 , as well as the 10.2$\mathrm{cm}$ (4-in.) diameter transfer port common with compartment 2. Compartment 3 is also equipped with a 35.6-cm (14-in.) square port for material receipt or transfer to the south cell proper, and a 10.2-cm (4-in.) pass-through for material transfer to the south cell proper. The maximum length of material that can be normally placed in either the 35.6$\mathrm{cm}$ (14-in.) diameter transfer port is approximately $30.5-\mathrm{cm}(12$-in.) long. The maximum length of material that can be normally placed in the $10.2-\mathrm{cm}$ (4-in.) diameter transfer port is approximately $91.4-\mathrm{cm}(36-\mathrm{in}$.) long. 
In addition to the 10.2-cm (4-in.) diameter port and 35.6- $\mathrm{cm}$ (14-in.) square transfer port common with compartment 3 , compartment 4 is equipped with a $35.6-\mathrm{cm}$ (14-in.) square port for material transfer to and/or receipt from the south cell proper and a 10.2$\mathrm{cm}$ (4-in.) pass-through for material transfer to the south cell proper. The maximum length of material that can be normally placed in the 35.6-cm (14-in.) diameter transfer port is approximately $30.5-\mathrm{cm}(12-\mathrm{in}$.) long. The maximum length of material that can be normally placed in the $10.2-\mathrm{cm}$ (4-in.) diameter transfer port is approximately $91.4-$ cm (36-in.) long.

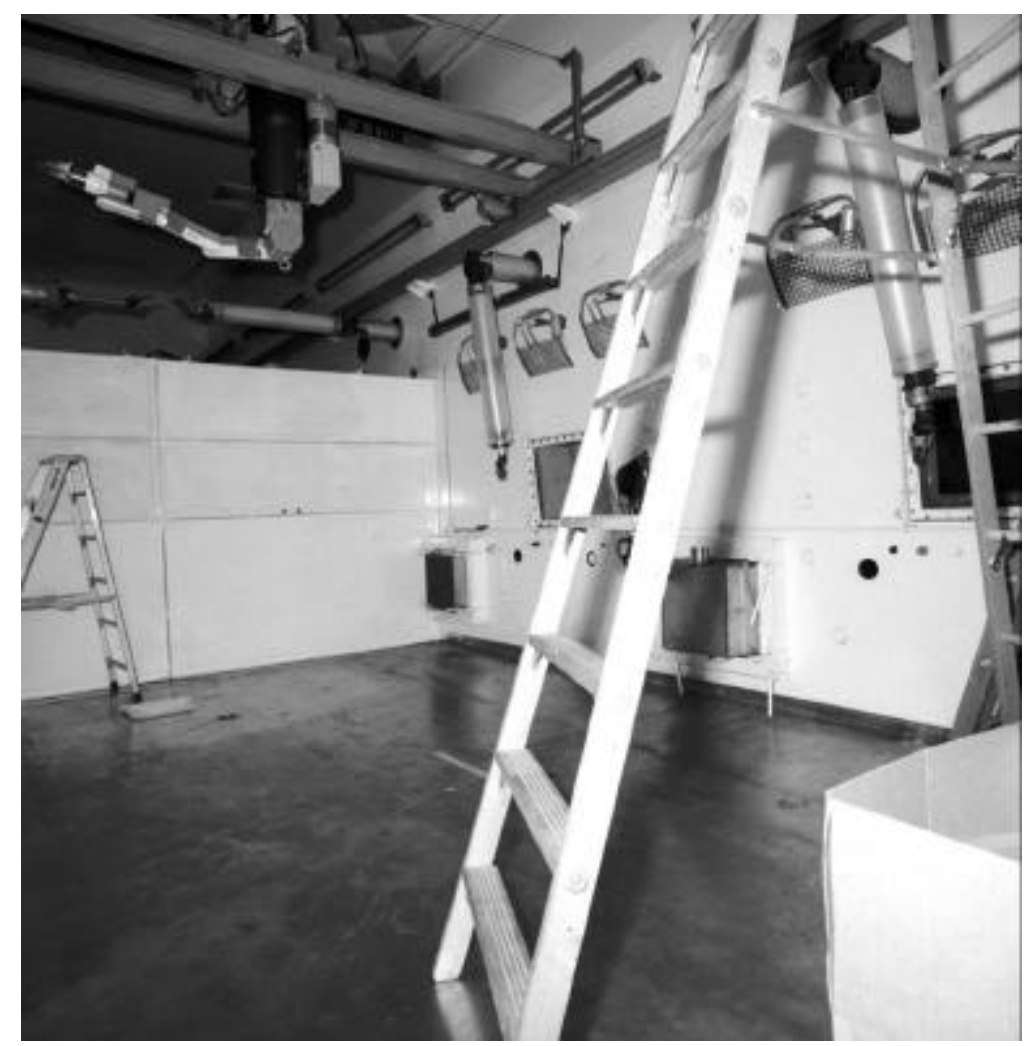

Figure A-9 South Cell View (Interior) 


\section{APPENDIX B}

\section{Personnel Interviews and Data Source Reviews}




\section{Appendix B. Personnel Interviews and Data Source Reviews}

5/14/2002 - Patrick Valdez met with Dick Steen and Bruce Sasser. The following documents were provided:

- MOTA storage cabinet/misc. SMF drawings

- Safety Analysis Report for Packaging (SARP) list with Don Fritz contact number for waste packaging

- SMF transfer door/port procedure (odd pages only)

- Long-term storage cabinet 1 inventory (hardcopy 08-07-89)

- Contact list of former MOTA staff

- Example study (HNF-8197) - spent fuel removal

- MOTA semi-annual progress report (9-30-84)

- RMIS document search list.

Shannon Crowell and Patrick Valdez went through the 70 pages of the inventory and found a few interesting problems. The inventory seems to only have samples for one of the storage units, and the closest date we can find for the inventory is sometime after the middle of January 1988 (those were the last recorded sample shipments). However, there are a dozen or so samples that appear to have been sent out for re-irradiation that we have no record of where they went after that. There are also numerous samples with no owner and no storage location.

We also got some drawings of the cell, a sample study, miscellaneous irradiation documents, and a few drawings of the cells and the storage cabinets.

The contact list contained the names of former MOTA managers and operators. Each had been contacted by Fluor and a summary of each contact was listed. The following is that list of people and Fluor's summary of their telephone interview:

Larry Greenwood - He was one of the primary scientists on the MOTA projects. $\mathrm{He}$ is very willing to help and has a lot of information. He indicated that there is a small possibility that some of the unopened containers might contain liquid lithium or sodium.

Augie Ermi - He was the project manager. He said that he disposed of all the records that he had.

Ray Puigh - He was one of the primary engineers on the project. He had input on some other people to contact. (Frank Garner or Al Farabee, DOE at FFTF) $\mathrm{Al}$ is the director of the fusion program at FFTF. Ray also confirmed that sodium may be present in the unopened containers and that the pressure tubes may contain xenon or krypton gases.

Frank Garner - May want 18 creep test specimens for testing 


\section{Ruby Ermi - (No interview data from Fluor)}

5/17/2002 - Patrick Valdez met with Dick Steen. The following document was provided:

- Long-term storage cabinet 2 hand copy of laminated cards

Fluor provided us a hand copy of the drawer layout cards they found for MOTA storage unit 2. The original cards are $2-\mathrm{ft} \times 2$-ft cards that are laminated. The operators used to put stickers on them and write sample IDs and limited notes on the stickers. This apparently is the most well kept record of what went in and out of the drawers and should be the most recent because it was used right up until the end of the project. There are a few sample types listed, a few names of contacts or businesses, but lots of ambiguity. Most of the listings in the second unit appear to just be ID numbers, which without more information in a database somewhere won't tell us anything about what it is or who owns it. It appears some stickers were removed (samples shipped out?) or had fallen off. Some of the stickers were illegible and others had question marks next to the samples. They have a similar set of sheets for unit 1 that they will be copying for us. They are also taking video and still photographs of each sheet for us, but those are not completed yet.

Dick Steen also said that from talking to some of the operators he believed most of the specimens in any given drawer slot were put into a vial that was sealed at both ends with rubber stoppers. So if slot A7 of drawer 2 has seven samples, they should all be contained in a single vial, provided pressure build up didn't push out the rubber stoppers or radiation didn't degrade the rubber so much that it melted, cracked, etc.

Dick Steen also showed Patrick what is apparently a roof access to the south cell. All Patrick could see was a metal cover about $10-\mathrm{ft} \times 10$-ft in dimension, but Dick Steen said that from the drawings he saw, there were two, tapered concrete cover blocks below it. To get access, the rain cover would have to be pulled, then the outer concrete one, then the inner concrete block. This may not be a viable option for environmental reasons.

After examining some drawings, Dick Steen appears to think that the disabled crane in the south cell has continuous rails into the air lock. Looking at the 1975 picture Patrick found in RMIS, it appears as if this may be possible, but there is a wall of some sort that has been constructed since then. It does not appear to be a load bearing wall, but maybe just a false wall for contamination control. Depending on what it would take, Dick Steen mentioned maybe being able to completely remove the wall long enough to replace the crane completely. This is probably an ideal case.

In a document (doc\# 9455040 - MOTA Specimens Irradiation History Listings) found yesterday on RMIS, it appears as though there was a comprehensive list of all the samples from the MOTA irradiations and that a final database of this information was left with PNNL (contact listed as Ruby Ermi) and with Westinghouse. Ruby Ermi is 
still with PNNL in 3730 and is one of the key contacts Fluor gave us. They may still have a record, either electronic or paper (although the document states that the paper record would be thousands of pages if printed out), that would help us with the second cabinet.

5/22/2002 - Shannon Crowell called Al Farabee, Steve Hiller

Al Farabee said that we should talk to Steve Hiller about tracking down records and specimen owners. He also mentioned Chuck Carlilse as a possible contact related to the LMR program.

Steve Hiller directed us to Ray Puigh. Steve said he handled irradiating the MOTA assemblies but never dealt with the samples as individual items (so he had no useful information).

5/23/2002 - Shannon Crowell/Patrick Valdez met with Ruby Ermi. Given the following documents:

- MOTA 1A-2B summary fluence listings (big binder)

- MOTA specimens storage and shipping records (big binder)

From our meeting with Ruby Ermi, we obtained some more understanding of what went on during the MOTA testing. We showed her the inventory of cabinet 1 and she seemed to recognize the sample IDs as being MOTA samples. The sample IDs were typically created using a letter and number to designate an alloy or material and then a number for the sample. So an ID of T323 would be sample 23 of the T3 alloy. This numbering scheme was also used on some samples in the \#2 cabinet even though they were not necessarily MOTA specimens. She was unsure of a master list identifying all of the different alloys. She did show us a list with sample IDs for several metals. As for storage unit 2, she was unsure about much of what was in there, although most of what she did recognize was not MOTA. Apparently a lot of the contents in that cabinet may be similar types of samples irradiated at different places (Idaho Falls was mentioned -- EBRII Breeder Reactor program. The Idaho Falls reactor was used before and after FFTF was used for irradiation). She was pretty sure though that none of the $2 \mathrm{~B}$ (and possibly $2 \mathrm{~A}$ ) MOTA stuff went to 324. Her recollection was that MOTA 2B was shipped to 327.

We brought back some binders containing shipping records and other specimen information for MOTAs 1A through 1D. According to Ruby, 324 was supplied with a set of binders that were to be the master list. Of course, whether or not they were ever filled out, she doesn't know. But they would contain sample ID, description, and ultimately storage location. The binders sent to 324 had only the storage location blank. The electronic versions of the database were stored on a tape drive and discarded a couple of years ago. There are also three cabinets of binders in the 326 basement that may or may not contain any interesting information.

Ruby also seemed convinced that all of the identifiable Oak Ridge National Laboratory (ORNL) samples were shipped back to ORNL in the late 80 s and early 90s. She gave us records for samples shipped to ORNL, so we may be able to use 
those records to update the spreadsheet. She did say though that they spent considerable time trying to identify a lot of samples and some were never found. There also was a copy of a standard sample ID selection process outlined after MOTA 1C. It mentioned trouble finding samples requested for shipment. Whether this convention was followed or not was entirely up to the scientist who was preparing the samples.

She gave us a couple of potentially resourceful contacts in Dave Greenslade (who worked on MOTA 2), G. Hollenberg (who worked on the Idaho Falls project), and Norris Johnson (who was the 324 technician who worked with storing the MOTA specimens). She also gave us the names of a couple of project managers in Russ Jones (PNNL) and Rick Kurtz (PNNL Fusion Group). Apparently Ray Puigh is the guy to talk to about the Japanese samples.

It was also determined that the shielding around the MOTA sample storage units was to shield the cell from the specimens. At the time they were doing this work, the south cell was fairly clean and they routinely made manned entries to set up test equipment. The shielded storage cabinets allowed them to work in the area.

Regarding the dose from the specimens: They have material and irradiation records that would allow her to do analyses for individual samples to say how much dose they should have at this point, but it sounded like this would clearly be cost prohibitive. She is currently planning to clean her own hot cell and will have to dispose of similar types of samples.

\section{5/24/2002 - Patrick Valdez called Frank Garner, Augie Ermi}

Frank Garner, who worked directly on some of the MOTA research, said that Augie Ermi would be the best person to talk to about any sort of comprehensive database for what happened after transfer to 324 . He said most of the samples in the storage bins would be either broken tensile or Charpy specimens or pressurized tubes (for creep study). He didn't think we'd be allowed to dispose of the pressurized tubes without puncturing them.

Augie Ermi said he didn't have any records.

6/4/2002 - Patrick Valdez/Shannon Crowell met with Ray Puigh

We showed Ray Puigh the cabinet 2 floor plan and he went through explaining what some of the samples were. He mentioned the presence of sodium (and possibly lithium) in some of the specimens. He could not positively identify materials/alloys from the ID numbers and said that a master list of all those materials used to be kept, but most likely was destroyed. He also furnished us a report with the attachments related to his samples, although some of the information doesn't have specimen IDs to relate the information to. As Ruby said earlier, the database was so large that only the specimen information related to a scientist's samples were sent to them. All the information was kept in one big database, which Ruby reported had been destroyed and Fluor staff reported that 
Augie Ermi had destroyed. We should call to confirm this. Because of its size, he doubts that any of the actual information would have been archived, just the letters and reports without the attachments. Ray also thought that this task of identifying all the samples was a huge job and that even if you found records, you may not know what you had until you opened the cabinet and looked. Also, some of the IDs on the cabinet 2 floor plan could actually be whole batches of samples, not individual specimens. He did positively identify some programs/projects from irradiations at the EBR-II reactor. He gave us a couple of names of people to ask about specific samples/programs, but pointed to Augie Ermi as being "the MOTA guy". But he also made it sound unlikely that Augie would be able to help.

Ray also mentioned some other names but followed each one by saying "he wouldn't have reason to keep the records". As for irradiation information, he said that if we could find it, we would also have to know materials, and then by cross referencing each sample with radiation charts, could only make a ballpark guess as to what the actual number was for each sample. If we intend to search any more databases, he would recommend coming up with a list of keywords that would pertain to all irradiation tests, not just MOTA, because there were several programs that didn't look familiar to him.

Shannon Crowell's additional notes/comments:

The report copy we got from Ray Puigh doesn't have the data attachments even for just his samples. There is just some "example" data with no sample identification. So far, we have zero data for detailed physical information and irradiation data on samples. Ray thinks our task is not practically achievable.

Names given as possible contacts:

Steven Chastain

Ron Baker

Bruce McKenna

Frank Huang

Glen Massey

Other projects that might have published sample data:

LRM Program

Fusion Program

Multi Megawatt

Ray Puigh gave us some specific information as to what he thought some of the notes on the inventory sheets mean. These are listed below:

"TED" - Thermal Expansion Device, about 0.2-in. diameter by 1.5-in. long.

These were tubes filled with sodium or possibly (in special cases) lithium.

"WL HU": This is the name of an experimenter, W.L. Hu. 
"B-281": This is an experiment that was irradiated at EBRII in Idaho (EBRII operated 1964-1994). B-234 and other similar notations are for EBRII irradiation experiments. This typically used a B7 capsule that was 1.25 -in. diameter by 7 or 8 -ft long with spacers to locate the samples at the right height.

"AAXV, AAXIV": EBRII irradiation experiments

"SP-100": SP-100 was a space power reactor program. Lithium may have been used in these samples

"PWC-11": This indicates an alloy of niobium and zirconium.

"HMO 13": The name of an experiment

"GW": Gradient wire, a thin wire specimen

"SS": Spectral sample, 0.14 -in. diameter by 1 -in. long

"Fermi": This refers to a type of specimen, cylindrical tensile specimen.

"Bettis": Naval reactor program

"Control": Control samples would not have been irradiated.

"ACO 1-3": FFTF fuel assemblies

"Phoenix": There is a Phoenix reactor in France maybe this sample from drawer 11 is from there.

6/11/2002 - Patrick Valdez/Shannon Crowell met with Norris Johnson

Norris Johnson worked in 324 Building from around 1970-1992. He worked primarily in SMF south and east cells. On MOTA, he said that the MOTA assemblies were cleaned off and disassembled into their baskets/capsules at FFTF for shipment to 324 . There, they were loaded through the 7.5-in. port in the door onto a cart and pushed to the cleaning stations. There they were cleaned of remaining sodium at wash stations set up under the windows on the compartment 1 side. He said all of these sodium-cleaning stations should be gone, but if not, the only things that may be a little warm would be the cleaning pots. Norris also said that he would expect most (if not all) of the MOTA specimens to be very hot because some were irradiated up to five times at varying levels. He also said that up until the time he left, the south cell was kept relatively clean and all the automated testing equipment was removed between MOTA campaigns and stored elsewhere, and then re-assembled when it was needed. Norris also said that the laminated cards were the absolute best records kept as to where samples were within a cabinet. He also said sometime near the end of his time there (circa 1990), the cabinets were both opened and inventoried on those cards. 
On the cabinets, Norris said that the drawers had stops (like a file cabinet) that prevented them from being pulled all the way out. He also said that some drawers may be damaged from not being closed completely before dropping the whole cabinet back into its shielded case (the drawers would then hang on the edge and deform). He is unsure if these drawers will pull out or whether there is anything in them. He did think that the whole cabinet would pull out of the shielded case though. Norris also seemed to recall that everything in cabinet 1 was supposedly MOTA related and everything in cabinet 2 was "other" (possibly pre-MOTA stuff irradiated at Idaho Falls, and shipped in T2 or T3 casks to 324). Some samples in cabinet 1 and 2 are stuffed into aluminum or stainless steel tubing and capped with plastic or rubber end caps. He said when inventoried some of these caps had melted, cracked, etc. and he did not know what state they would be in today. When dividers in the drawer were removed, they were generally removed all the way across the drawer. He also remembered some samples that may contain europium and gadolinium.

On cesium, Norris said the four compartments were built to be an assembly line where the cesium capsules would be put into compartment 1 cleaned somewhat, repackaged part way, put into compartment 2, cleaned, repackaged a bit more, into compartment 3, cleaned, assembled some more, and into compartment 4 for final assembly and then out into a cask for shipment. Apparently most of what went into compartment 1 was cesium powder from ORNL. Some of this powder leached into compartment 2 at one point, which required that cell to be cleaned and the door/window seals refitted. Apparently some of the capsules put into compartment 1 were taken back out into the south cell and most of the contamination (while Norris was still there) would be related to cesium powder contamination getting out of compartment 1 . Norris did not believe there were any cesium capsules remaining, but was not positive of this. Norris also mentioned that there was some bend testing of some irradiated zircaloy tubes. Shannon Crowell thought maybe she saw some of them still lying on the workbenches, but Norris thought they had been disposed of.

Norris also did not know anything about other document storage. He did mention the unfilled sheets Ruby had and that Augie Ermi was the guy to talk to. He also seemed to think that other than the laminated sheets, records went by the wayside.

7/25/2002 - Search of 326 basement cabinets

Patrick Valdez and Jim Alzheimer spent a couple of hours going through the cabinets in room $1 \mathrm{~A}$ in the basement of 326 . There were over a dozen cabinets with various materials in them.

The largest volume was left over materials used to make MOTA specimens. There was a lot of strip material from which 1/8-in. diameter discs had been punched. There were sections of small diameter tubing that must have been 
used for thermal creep and pressure rupture tests. Interesting but not useful for us.

There were about two shelves of laboratory notebooks that we went through fairly completely. Most of these were of no use for our purposes. We were able to glean a little insight into what had been conducted but most of the notebooks were just page after page of tabular data or notes that did not seem to relate to what we were looking for. Some notebooks contained copies of memos and correspondences but nothing very revealing.

There were a few boxes that contained old manuals for equipment and other items removed from a lab when the project was closed down. Interesting but not very useful.

There were numerous HEDL and PNL reports but mostly from early on in the project. There were QA plans, Project Management Plans, and other planning documents. We saw nothing of the 15 or so final reports that have been lost.

There were binders of specimen traveler cards but they appear to only go as far as specimen preparation before being put into the reactor and do not track exposure. 


\section{APPENDIX C}

MOTA Waste Forms, Characterization, and Inventories 


\section{Appendix C. MOTA Waste Forms, Characterization, and Inventories}

The identification and characterization of the wastes located in the long-term storage cabinets consisted primarily of speaking with several individuals who were familiar with the cabinets (and their contents), and then attempting to cross-reference card information with other data sources to determine a 'master' list of what is stored in the cabinets. For cabinet 1 , limited data was provided concerning samples and their locations within the cabinet. For cabinet 2 , it was simply not possible to find additional information to cross reference the card information against to more accurately determine characterization data. The data was not sufficient to cross-reference what was in the cell with an experiment. It is believed that many of the samples within this cabinet are not MOTA samples (the description of the cell contents and what little experiment descriptions we could find do not match available MOTA information). Research efforts attempted to match the available experiment information with laboratory notebooks from the irradiation experiments; however, no beneficial information was found. Based on process knowledge information, it is believed that the cabinet 2 samples were from experiments similar to MOTA, but not irradiated at the FFTF.

The cabinet 1 information is provided mainly as 'MOTA' and 'MOTA Basket', but not IDs. In some circumstances, there is sample ID information on the storage unit cards. It is believed that it would be an unnecessary task to cross-reference the entire sample IDs from the irradiation documentation with the card data. This is for several reasons. The MOTA samples (and what is in cabinet 2) are small pieces of various alloy metals. The dimensions of these samples are about the same size and should have similar activities (except for the special samples detailed below) when compared to the other SMF wastes. The only items that could pose a problem when it comes to disposal are those containing trace amounts of liquid metals (the liquid metals were there for thermal conductivity and were supposed to be cleaned off the samples) and the sealed/pressure tubes. Another reason is that in many cases, it is simply not possible to know if an individual sample is in a particular cubicle location. The cubicle description often only contained a single MOTA basket, not what samples were actually in that cubicle.

\section{Physical Characteristics}

Of the roughly 14,700 MOTA specimens (See Table C-1) listed in the documentation, all but about 9000 were from the Japanese programs. Roughly 5700 specimens were supposed to have been shipped back to Japan.

Around 8304 of the remaining samples are mainly copper, steel, or stainless steel alloys (with a sprinkling of other metals). These samples weigh an estimated 18.4-kg (40.5-lb) total with a $100 \%$ packed volume of $8.75 \mathrm{E}-3 \mathrm{~m}^{3}\left(534 \mathrm{in}^{3}\right)$. Actual packed volume will be dependant on many process factors, especially compaction of the pressure and open tube samples. 
There are an estimated 1500 occupied cubicles in the two cabinets (based on examination of the available records). Assuming that cabinet 2 contains items similar to cabinet 1 , each cubicle can hold at least 10 samples (no statistically rigorous average could be determined). Because cabinet 2 likely does not contain MOTA samples, there could be a total of 15,000 samples in the two cabinets.

Using the card information, assumed to be the most accurate, an estimate was made that around 1500 cells are at least partially filled with materials. Assuming the maximum case of 13 Fermi samples, this provides an upper bound of $108 \mathrm{~kg}(238 \mathrm{lb})$ of material with a $100 \%$ packed volume of $0.031 \mathrm{~m}^{3}\left(1892 \mathrm{in}^{3}\right)$. It is important to note, that the total mass and volume of all the MOTA and related samples does not reach this mass or volume.

Table C-1 MOTA Characterization

\begin{tabular}{|c|c|c|c|}
\hline Description & Picture & Dimensions (mm) & $\begin{array}{l}\text { Mass } \\
(g)\end{array}$ \\
\hline Fermi Tensile & 111 & $\phi 6.32 \times 47.6$ & 5.5 \\
\hline $\begin{array}{l}\text { 2.25-in. NCD Ductile } \\
\text { Tensile (no Grip } \\
\text { Holes) }\end{array}$ & & $57.1 \times 12.7 \times 3.17$ & 11.4 \\
\hline $\begin{array}{l}\text { 2.25-in. NCD Notched } \\
\text { Ductile Tensile }\end{array}$ & & $57.1 \times 12.7 \times 3.17$ & 10.6 \\
\hline $\begin{array}{l}\text { 1.75-in. x 0.030-in. } \\
\text { Tensile Sheet } \\
\text { Specimen }\end{array}$ & 7 & $44.4 \times 4.95 \times 0.76$ & 0.74 \\
\hline $\begin{array}{l}\text { 1.00-in. x 0.030-in. } \\
\text { Tensile Sheet } \\
\text { Specimen }\end{array}$ & & $25.4 \times 4.95 \times 0.76$ & 0.48 \\
\hline
\end{tabular}




\begin{tabular}{|c|c|c|c|}
\hline Description & Picture & Dimensions (mm) & $\begin{array}{l}\text { Mass } \\
(g)\end{array}$ \\
\hline $\begin{array}{l}1 / 3 \text { Size Charpy } \\
\text { (Hanford) } \\
\text { (ORNL) } \\
\text { (Japanese) }\end{array}$ & ONE THIRD SIZE CHARPY & $\begin{array}{l}23.6 \times 3.3 \times 3.3 \\
25.4 \times 3.3 \times 3.3 \\
23.0 \times 3.3 \times 3.3\end{array}$ & $\begin{array}{l}2.08 \\
2.24 \\
1.97\end{array}$ \\
\hline $\begin{array}{l}\text { 1/2 Size Charpy } \\
\text { (Hanford) } \\
\text { (ORNL) }\end{array}$ & ONE HALF SIZE CHARPY & $\begin{array}{l}23.6 \times 5.0 \times 5.0 \\
25.4 \times 5.0 \times 5.0\end{array}$ & $\begin{array}{l}4.70 \\
5.06\end{array}$ \\
\hline $\begin{array}{l}\text { Believed to be } \phi 0.630- \\
\text { in. Compact Tension }\end{array}$ & & $\phi 16.0 \times 2.54$ thk & 3.50 \\
\hline $\begin{array}{l}1.00 \text {-in. } \times 0.5 \text {-in. } x \\
0.024 \text {-in. FCP Coupon }\end{array}$ & & $25.4 \times 12.7 \times 0.61$ & 1.56 \\
\hline $\begin{array}{l}\text { Believed to be } 0.87 \text {-in. } \\
\text { x 0.78-in. x } 0.12 \text {-in. } \\
\text { Compact Tension }\end{array}$ & & $22.2 \times 19.8 \times 3.05$ thk & 9.10 \\
\hline $\begin{array}{l}0.625 \text {-in. } x 0.375 \text {-in. } x \\
0.080 \text {-in. Hard } \\
\text { Coating Coupon }\end{array}$ & COATING COUPON & $15.9 \times 9.52 \times 2.03$ & 2.44 \\
\hline $\begin{array}{l}\text { High Heat Flux Disk } \\
\phi 0.39 \text {-in. to } \phi 0.71 \text {-in. } \\
0.04 \text {-in. to } 0.55 \text {-in. } \\
\text { thick }\end{array}$ & HIGH HEAT FLUX & Various & $\mathrm{N} / \mathrm{A}$ \\
\hline $\begin{array}{l}\phi .230 \text {-in. Diameter x } \\
0.86 \text {-in. Split Cladding } \\
\text { Section }\end{array}$ & SPUT CLADDING SWELING & $\begin{array}{l}\phi 5.84 \times 21.8 \times 0.38 \mathrm{wd} \\
1 / 4 \text { Sections }\end{array}$ & 0.28 \\
\hline
\end{tabular}




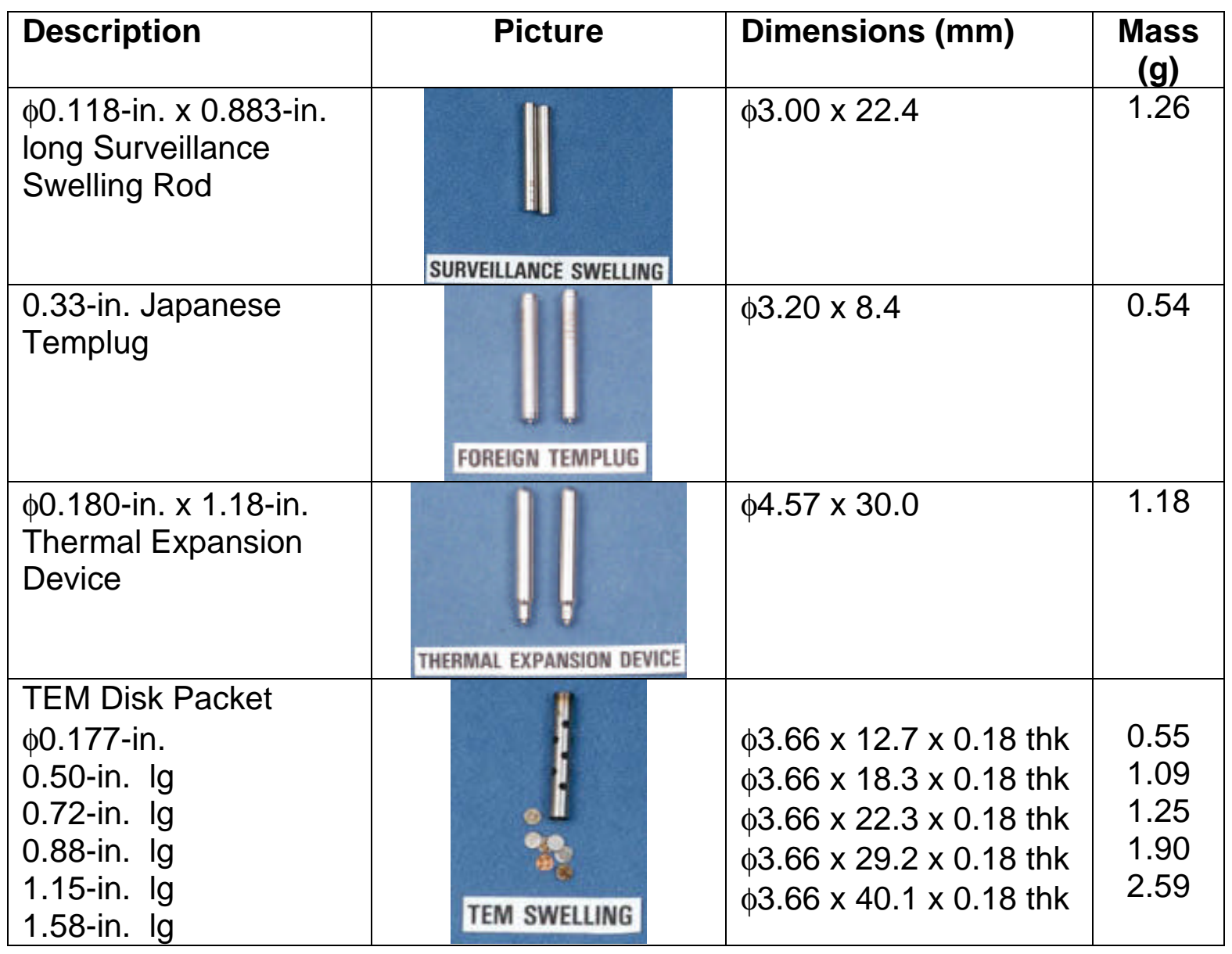

\section{Simplified Activity Calculation}

Based on shipping documentation from 1995, about 300 grams of samples had a total activity of $67.5 \mathrm{Ci}$. We took the maximum isotope activation, per alloy element, $(\mathrm{Ci} / \mathrm{g})$ for the metals listed in our calculations. After applying an adjustment of 10 additional decay years, these values were used to calculate the activity of the bulk of the samples. This activity level is considered to be conservative. Material composition (especially the trace elements) could not be found for more than $60 \%$ of the samples (many samples like TEM disks did not have any material description other than ferritics or austenitics). Without these material compositions and the FFTF spectrum for the irradiation, it is not possible to accurately calculate the activation levels.

According to the above activation calculations, for the entire $18.4 \mathrm{~kg}$ of material, we are expecting less than $1000 \mathrm{Ci}$ of activity from the metals, $822 \mathrm{Ci}$ of Fe-55, $2 \mathrm{Ci}$ of Mn-54, $66 \mathrm{Ci}$ of Mo-93, $59 \mathrm{Ci}$ of $\mathrm{Co}-60$, and $7 \mathrm{Ci}$ of Tc-99. The following table (C-2) provides a summary of the emitted gamma energy from the various isotopes and the estimated activity. Any gamma emission that would occur less than $1 \%$ of the time was ignored. The average for Mo-93 does not take into account the weak $0.263 \mathrm{MeV}$ gamma. 
Table C-2 Radioactivity Data

\begin{tabular}{|c|c|c|c|c|c|}
\hline Isotope & Percentage & $\begin{array}{c}\text { Gamma } \\
\text { Energy } \\
\text { (MeV) }\end{array}$ & $\begin{array}{c}\text { Specific } \\
\text { Activity } \\
\text { (Ci/g) }\end{array}$ & $\begin{array}{c}\mathbf{5 ~ g} \\
\text { Sample } \\
\text { (Ci) }\end{array}$ & $\begin{array}{c}\mathbf{1 0 5 . 4} \text { g } \\
\text { Sample } \\
\text { (Ci) }\end{array}$ \\
\hline Fe-55 & N/A & N/A & $4.47 \mathrm{E}-2$ & $2.22 \mathrm{E}-1$ & 4.71 \\
\hline Mn-54 & 100 & 0.834 & $1.14 \mathrm{E}-4$ & $5.70 \mathrm{E}-4$ & $1.20 \mathrm{E}-2$ \\
\hline Mo-93 & 56.7 & 0.263 & $3.56 \mathrm{E}-3$ & $1.78 \mathrm{E}-2$ & $3.75 \mathrm{E}-1$ \\
& 99.8 & 0.684 & & & \\
& 99.1 & 1.477 & & & \\
& Average & 1.081 & & & \\
\hline Co-60 & 100 & 1.173 & $3.22 \mathrm{E}-3$ & $1.61 \mathrm{E}-2$ & $3.39 \mathrm{E}-1$ \\
& 100 & 1.332 & & & \\
\hline Tc-99 & Average & 1.252 & & & \\
\hline
\end{tabular}

As can be seen in Table C-2, the largest gamma dose contributors would be from the Co-60 and the Mo-93. Both of these isotopes have high-energy gamma emissions as well as significant activity. While the total activity of the Fe-55 dwarfs all the other estimated isotopes, it is a pure beta emitter $(3.45 \mathrm{MeV})$ and should not be as much of a dose concern once within the disposal container.

To simplify our analysis of these items, we decided to ignore the dose contributions from the Tc-99, Fe-55, and Mn-54 because their gamma contributions would be small compared to those from the Mo-93 and Co-60. Another simplification was to combine the activities from the Mo-93 and Co-60. The Co-60 has a higher gamma energy, which should lead to a more conservative estimate. Additionally, activity-exposure data is readily available for the Co-60. This analysis is based on the equations found on pages 168 and 169 of Chilton (Chilton 1984).

Table C-3 Expected Exposure Rates at 100-cm

\begin{tabular}{|l|l|l|l|}
\hline $\begin{array}{l}\text { Sample Mass } \\
(\mathbf{g})\end{array}$ & $\begin{array}{c}\text { Combined } \\
\text { Activity (Ci) }\end{array}$ & $\begin{array}{c}\text { Exposure } \\
\text { Rate (R/hr) }\end{array}$ & $\begin{array}{c}\text { Exposure } \\
\text { Rate (mR/hr) }\end{array}$ \\
\hline 1 & $6.78 \mathrm{E}-3$ & $8.784 \mathrm{E}-03$ & 8.78 \\
\hline 5 & $3.39 \mathrm{E}-2$ & $4.392 \mathrm{E}-02$ & 43.9 \\
\hline 105.4 & $7.14 \mathrm{E}-1$ & $9.250 \mathrm{E}-01$ & 925 \\
\hline $\begin{array}{l}\text { Maximum } \\
\text { Upper Bound }\end{array}$ & 125 & $1.619 \mathrm{E}+02$ & 162,000 \\
\hline
\end{tabular}

As can be seen in the Table C-3 individual samples are quite capable of providing measurable exposure at $100-\mathrm{cm}$. These calculations assumed a mono-energetic point source in air. The gamma of the Co-60 is quite energetic; therefore an attenuation factor of 810 is required to reduce the dose rate to $200 \mathrm{mRad} / \mathrm{hr}$ at $100-\mathrm{cm}$ (39.4-in.). This corresponds to about 14-cm (5.5-in.) of lead shielding (Chilton 1984, Lamarsh 1983), if all the samples are to be placed in a single container. Therefore it is our 
conclusion that standard lead-lined drums have sufficient shielding for the majority of the MOTA samples.

\section{Special Samples}

In addition, a total of 419 'special' samples were identified containing unusual materials or metals like Ni-59 or Co-59, which are expect to have higher activation than the bulk of the samples. Research efforts concentrated on these special samples, attempting to locate them within the storage cabinet records. Less than $45 \%$ of these samples were found within the records. All 419 samples weigh an estimated 6.0-kg (13.2-lb) total, with a $100 \%$ packed volume of $1.23 \mathrm{E}-3-\mathrm{m}^{3}\left(75-\mathrm{in}^{3}\right)$. Estimated activities were not calculated for these samples because we could not find their material composition. Some of these samples may contain metal beryllium; however, it is not expected that there will be any airborne beryllium. This corresponds with the current 324 Building Fact Sheet on beryllium (http://www.hanford.gov/safety/beryllium/fctsheet/324.htm).

\section{Estimated Disposal Volume}

The estimated disposal volume is based on assuming the upper bound of 108-kg (238lb) of material with a $100 \%$ packed volume of $0.031-\mathrm{m}^{3}\left(1892-\right.$ in. $\left.^{3}\right)$. A $75 \%$ packed volume was used, although it is believed that close to $100 \%$ packed volume is realistically attainable. The resulting volume is then $0.041-\mathrm{m}^{3}\left(2502-\mathrm{in}^{3}\right)$ Further assuming $14-\mathrm{cm}(5.5-\mathrm{in}$.) of shielding constrained to fit in a lead-lined drum; the available waste diameter is $33-\mathrm{cm}(13 \mathrm{in}$.) with a total possible length of $58-\mathrm{cm}(22.8-$ in.). This would correspond to $0.050-\mathrm{m}^{3}\left(305-\mathrm{in}^{3}{ }^{3}\right)$ of waste within the drum. This implies that the entire volume of the MOTA storage cabinets would fit within a single, lead-lined 55-gallon drum.

Because of the unknowns with the potential volume, weight, and activity calculations, it is recommended that the entire volume of the long-term storage cabinets is not placed in a single, lead-lined drum; rather the samples are placed in two shielded drums. 
For copies of MOTA spreadsheets contact the Hanford Technical Library 509-372-7430 or pnl.techlib@pnl.gov

\section{MOTA 1 Inventory}

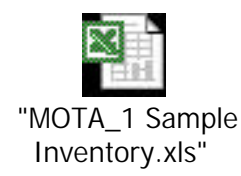

\section{MOTA 1 Drawer Listing}

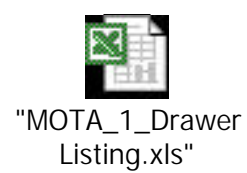

\section{MOTA 2 Inventory}

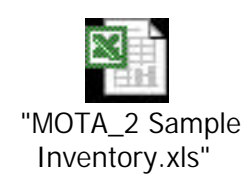

MOTA 2 Drawer Listing

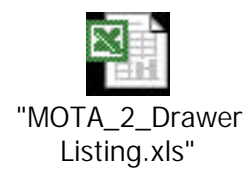




\section{APPENDIX D}

SMF South Cell Waste Forms, Characterization, and Inventory 


\section{Appendix D. SMF South Cell Waste Forms, Characterization and Inventory}

The SMF waste forms were obtained by looking through the existing cell windows (cell entries were prohibited). The following figures (D-1 through D-22) provide digital photographs of what is visible through the SMF windows. These photographs have been digitally enhanced to make the images clearer. The numbers after the description correspond to the SMF inventory IDs provided later in this section (Baker 2002).

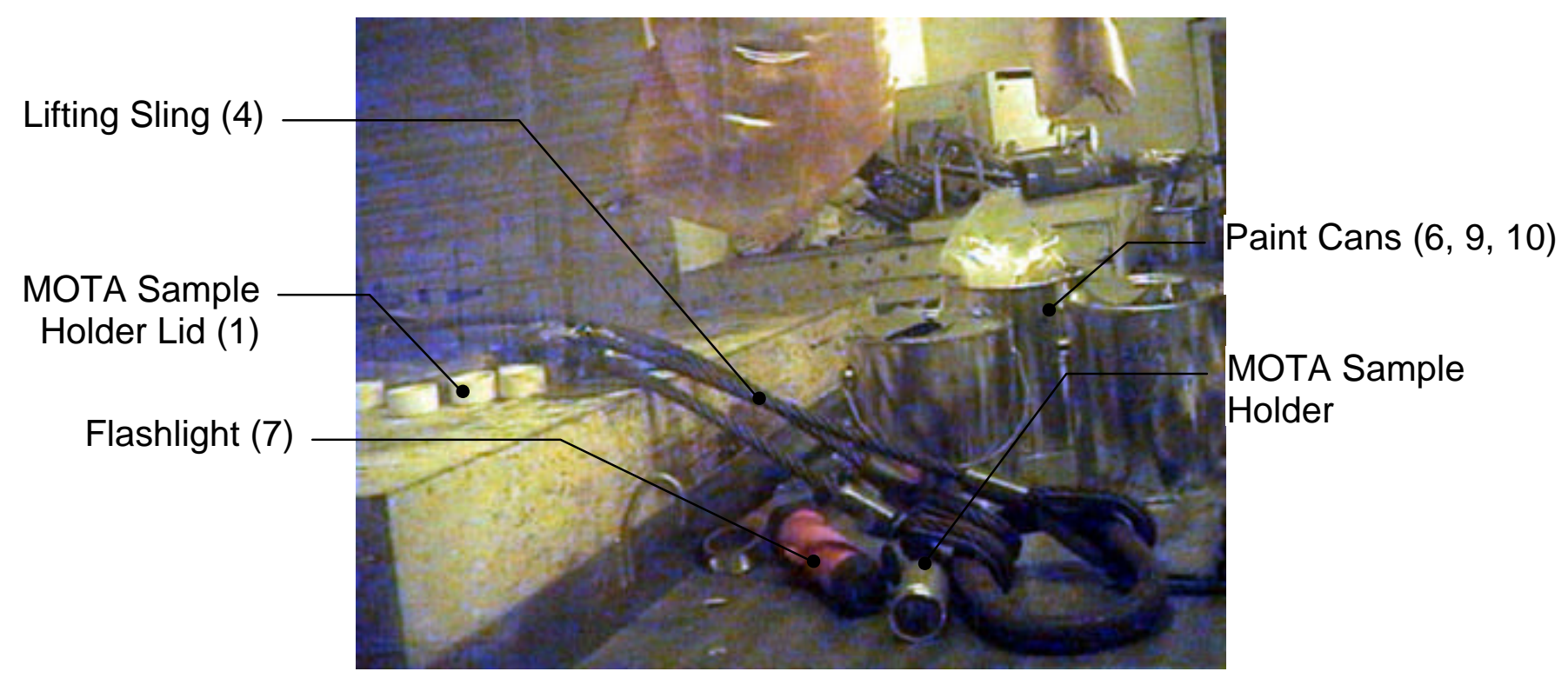

Figure D-1 Station 3

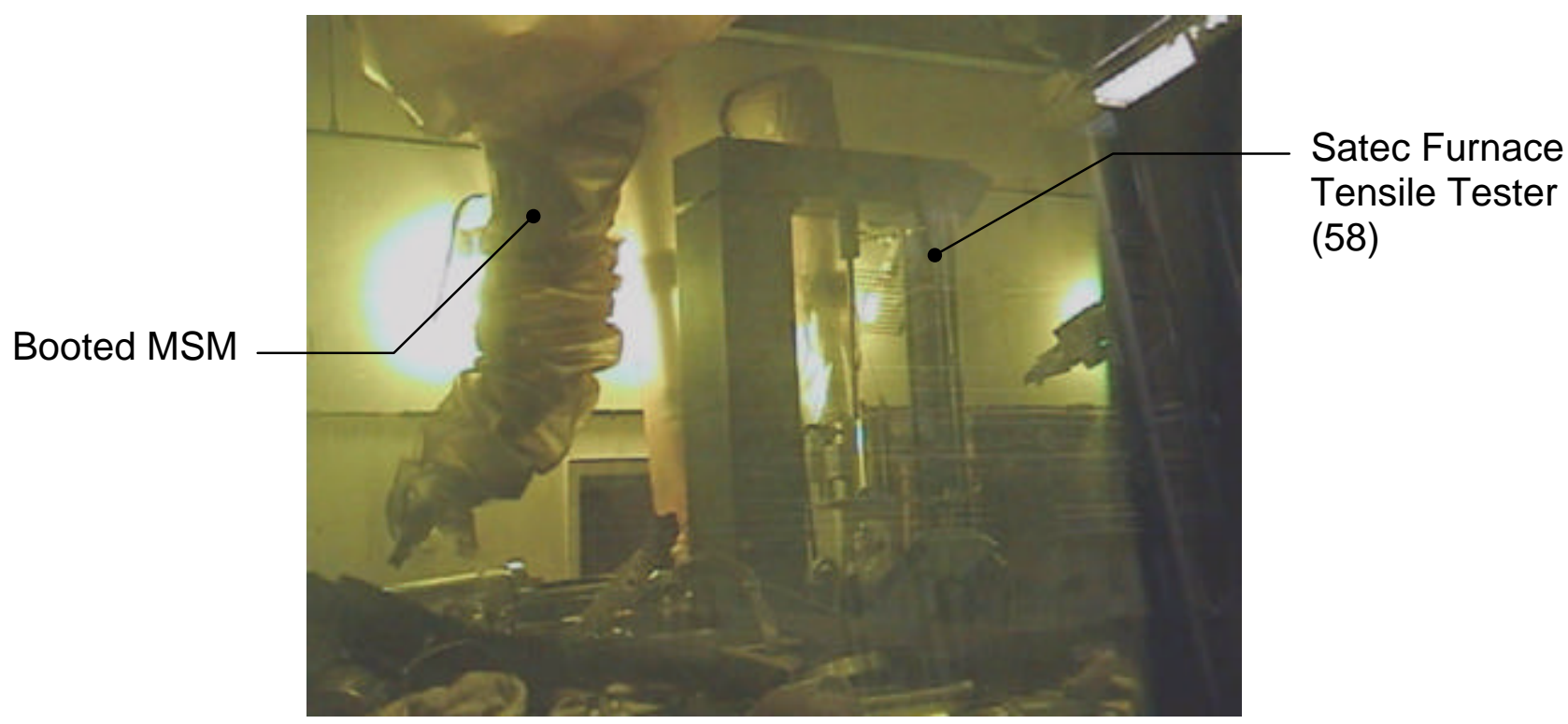

Figure D-2 Station 3 


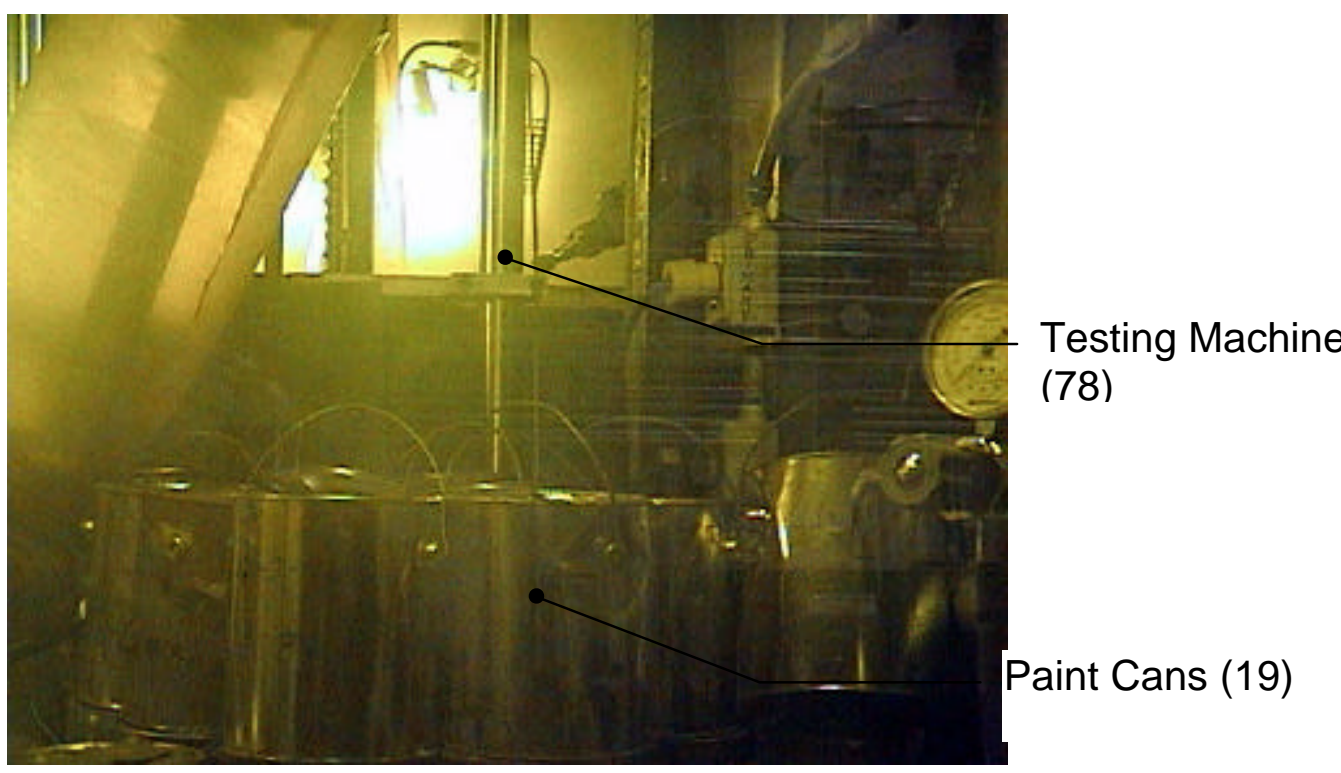

Figure D-3 Station 4

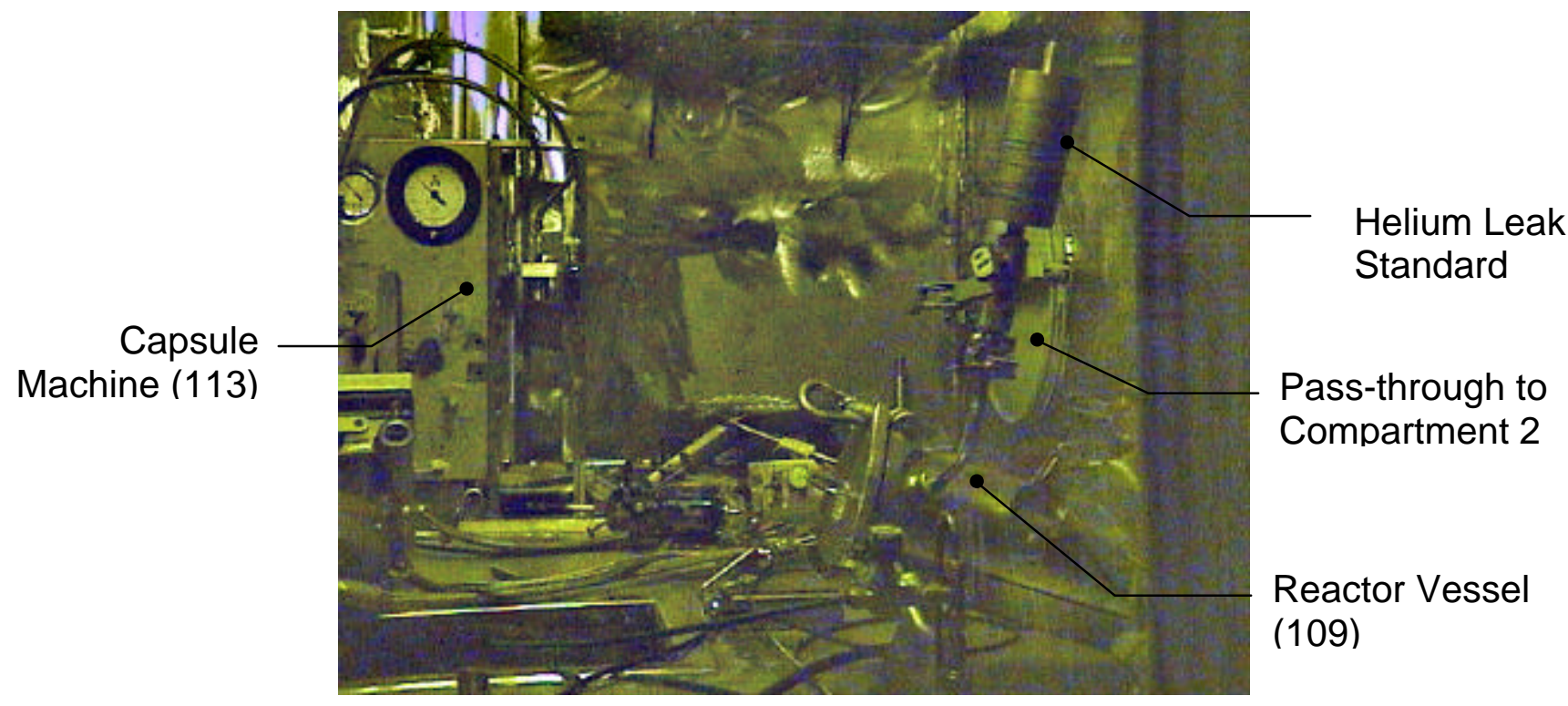

Figure D-4 Station 6 (Compartment 3) 


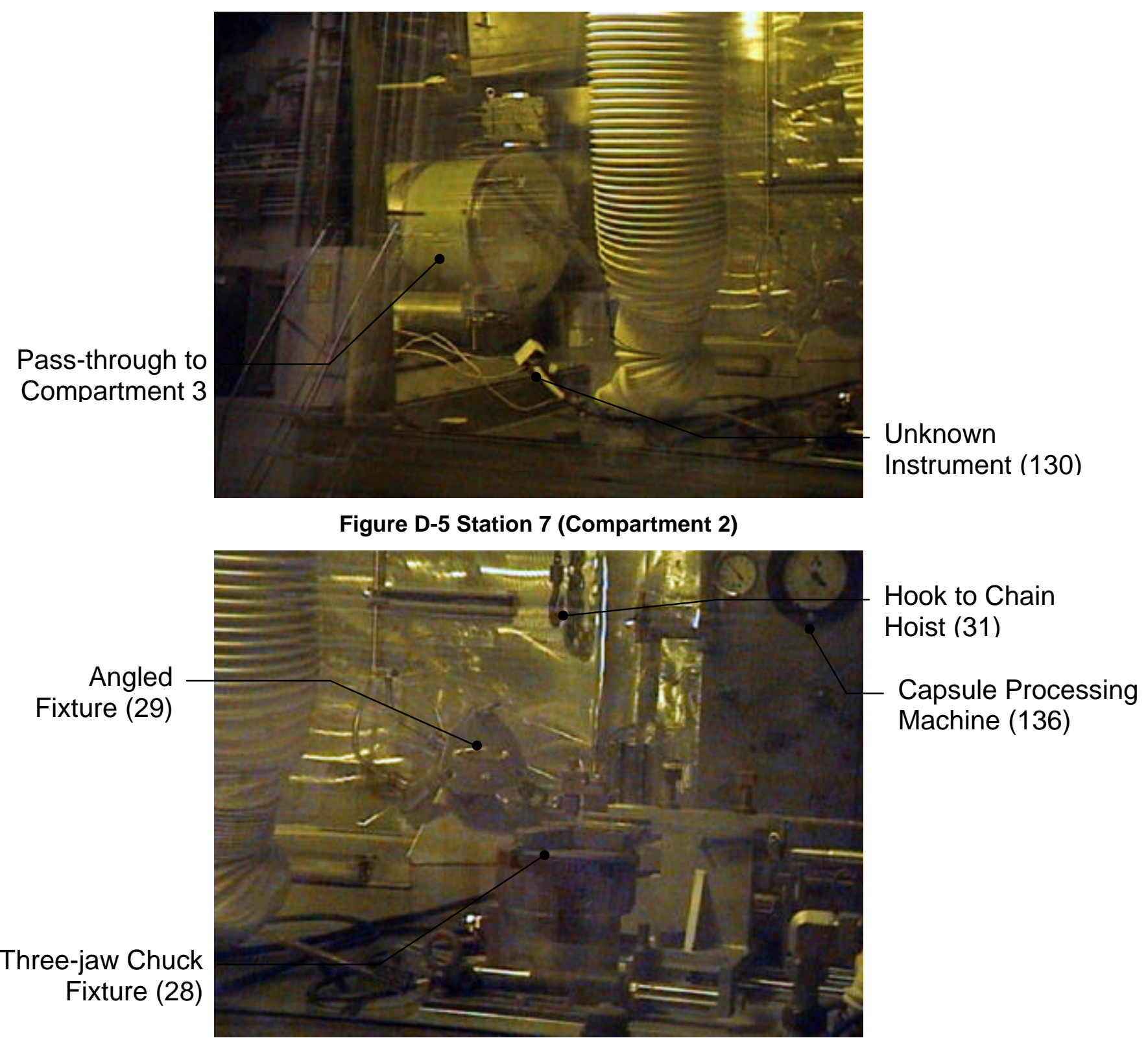

Figure D-6 Station 7 (Compartment 2) 


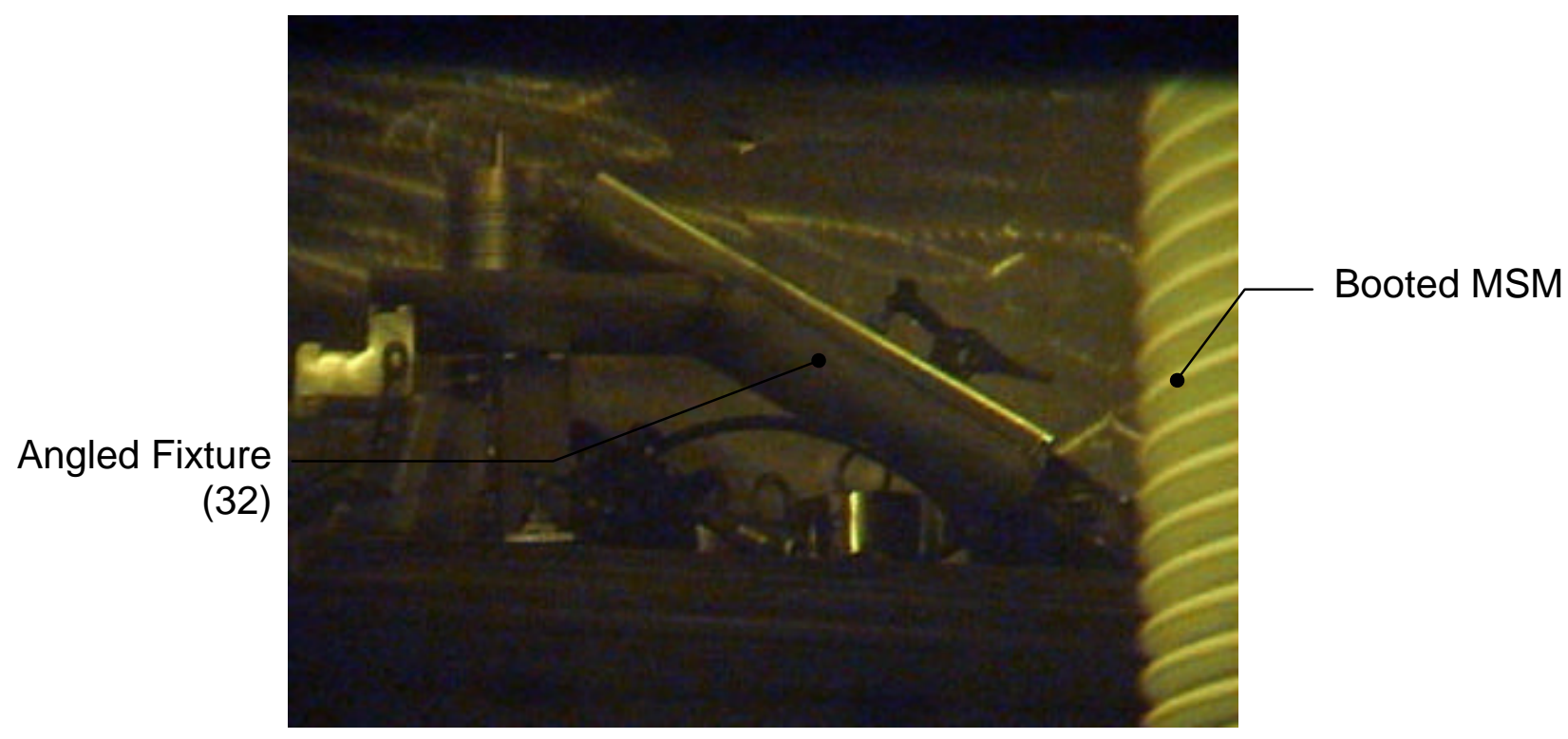

Figure D-7 Station 7 (Compartment 2)

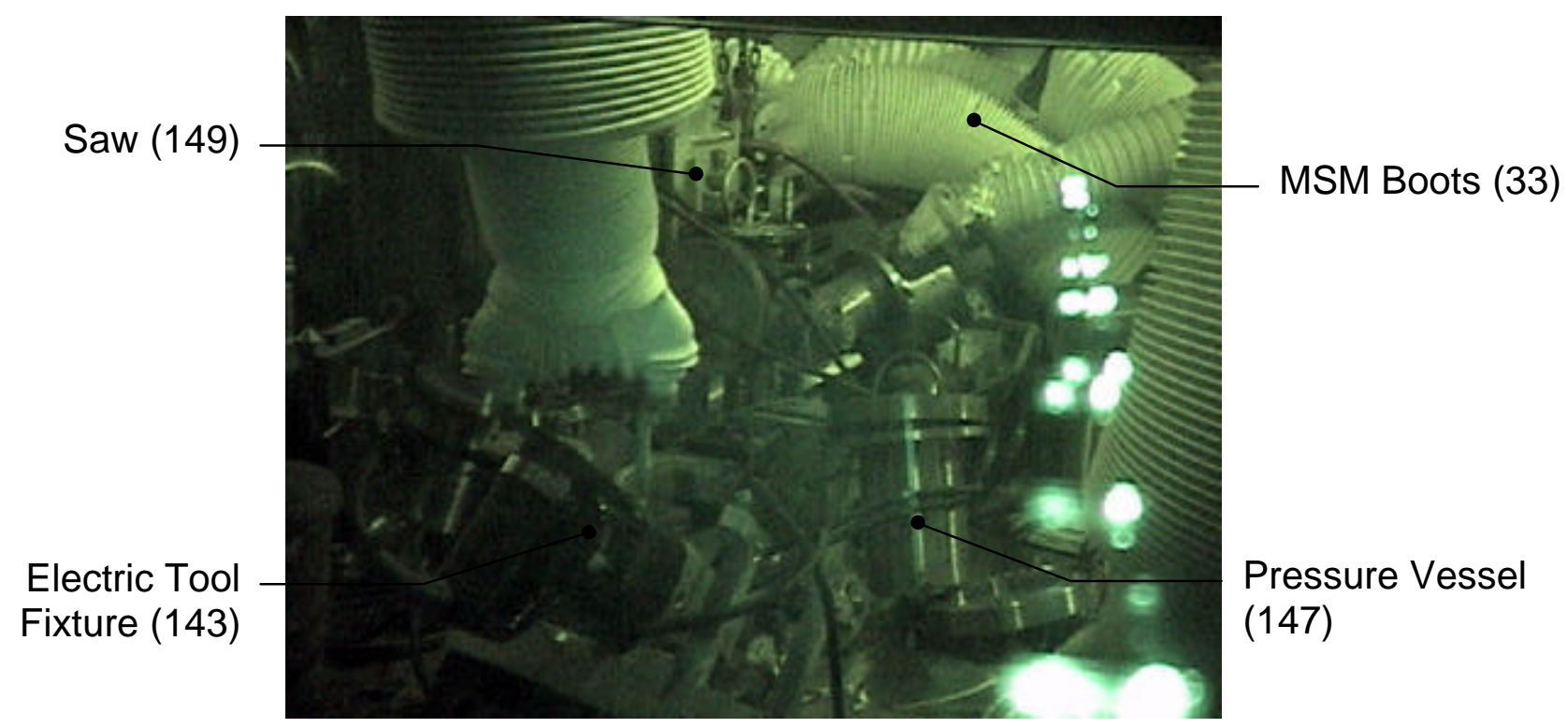

Figure D-8 Station 8 (Compartment 1) 

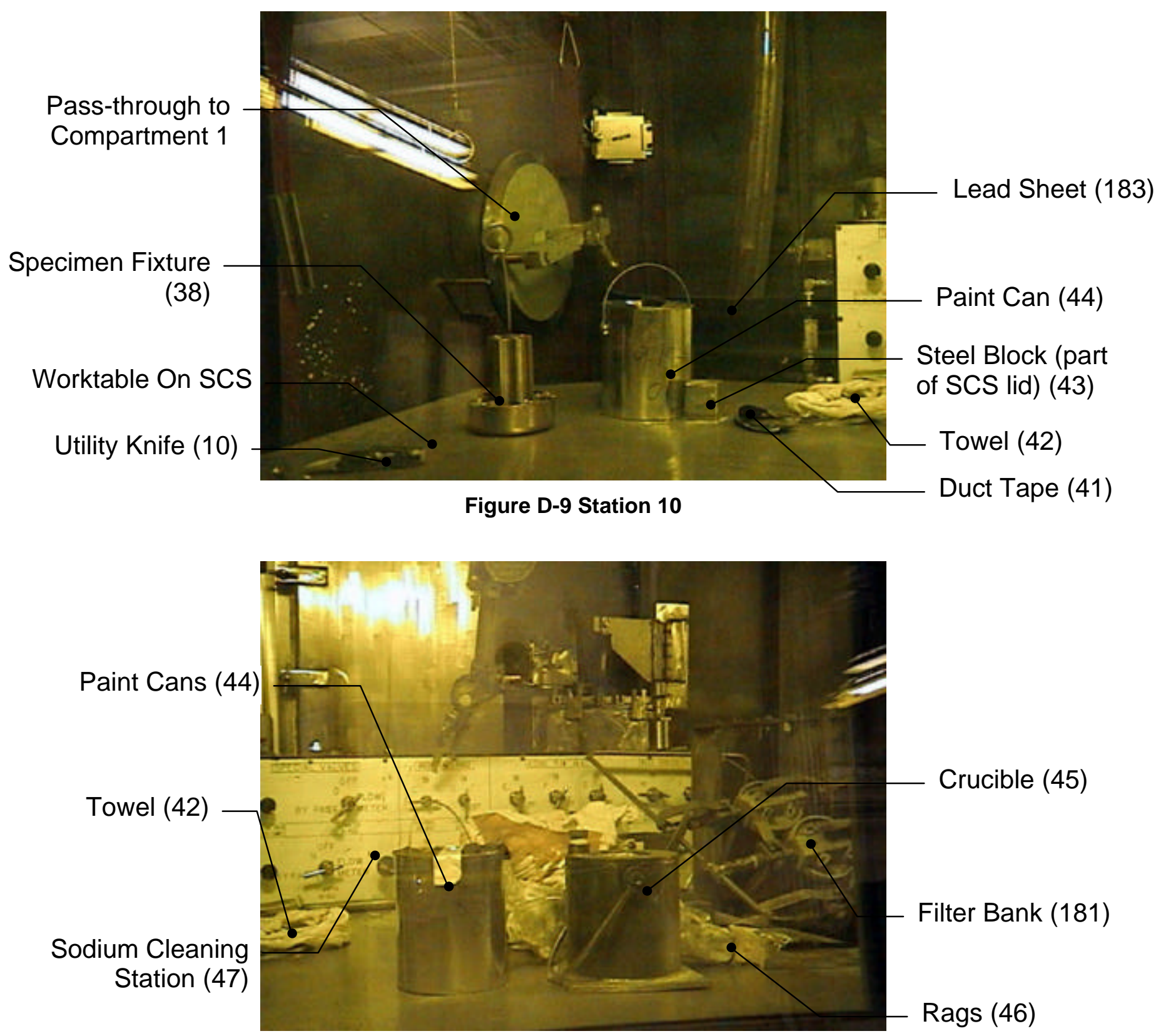

Figure D-10 Station 10 


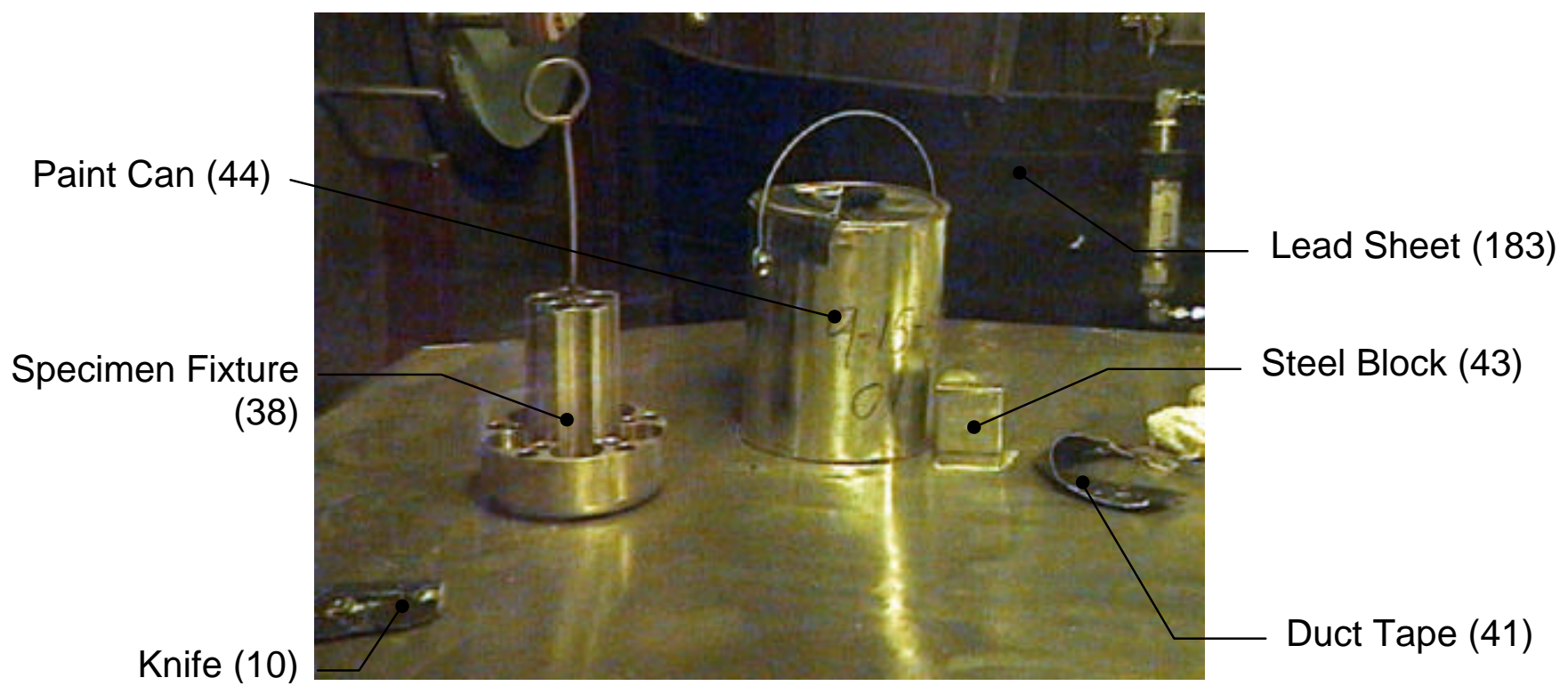

Figure D-11 Station 10

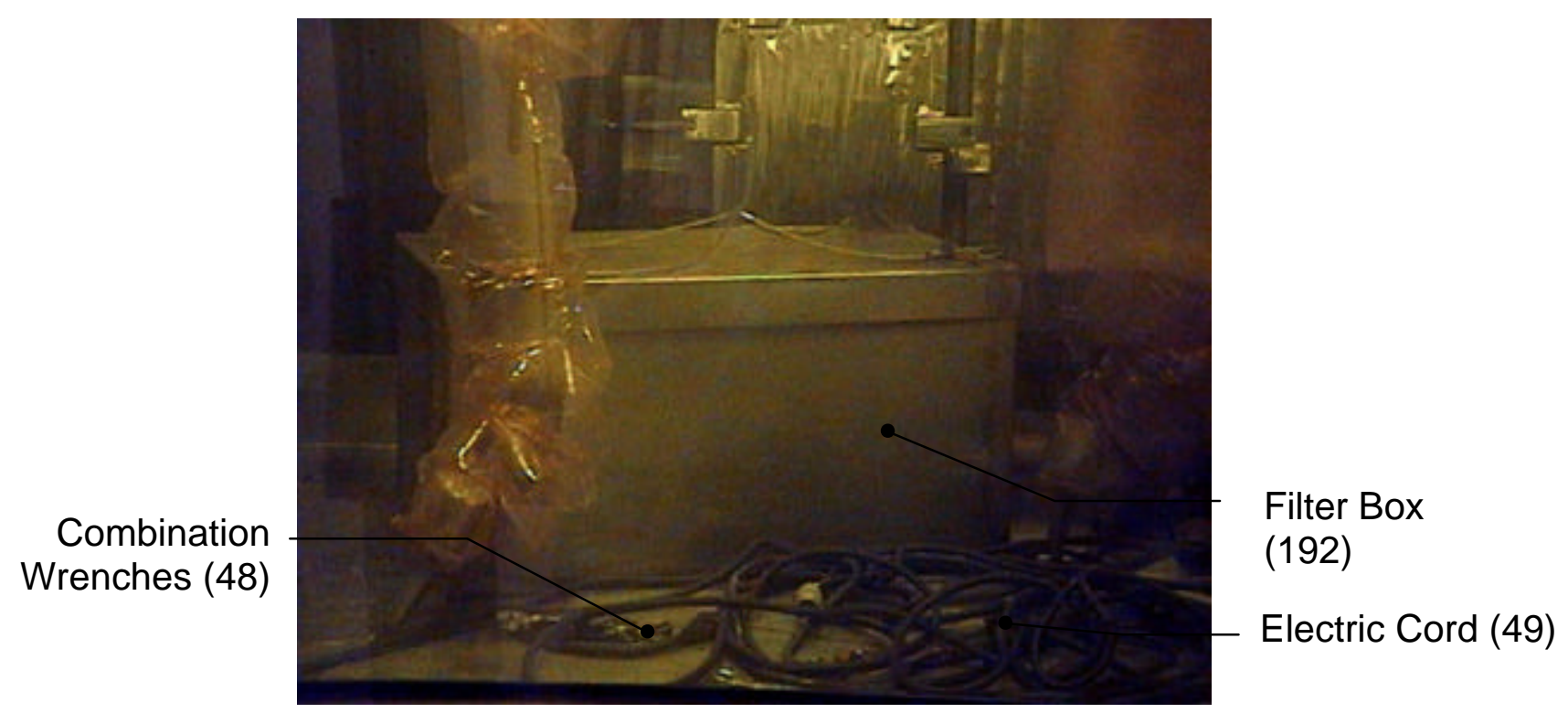

Figure D-12 Station 11 


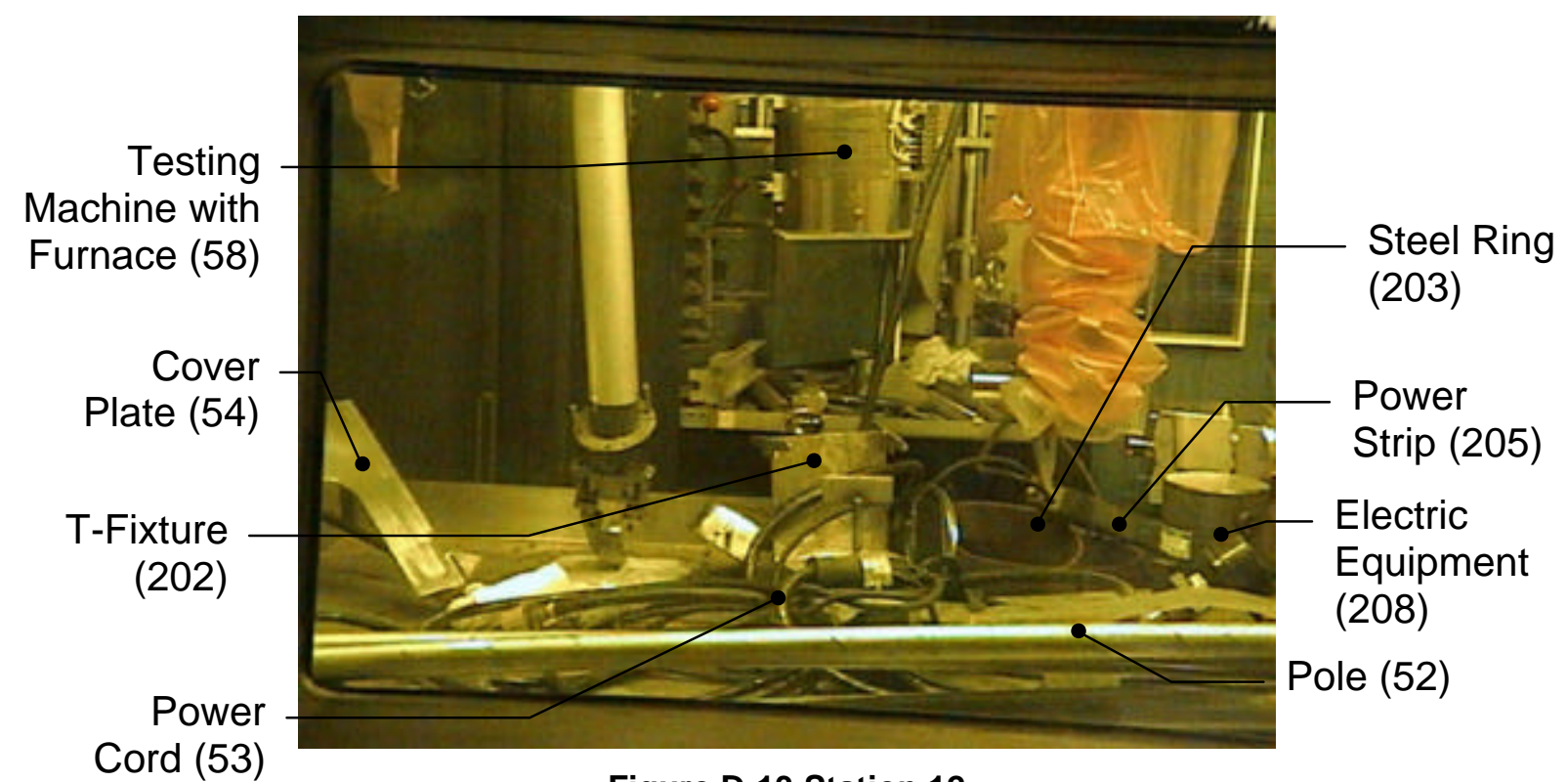

Figure D-13 Station 12

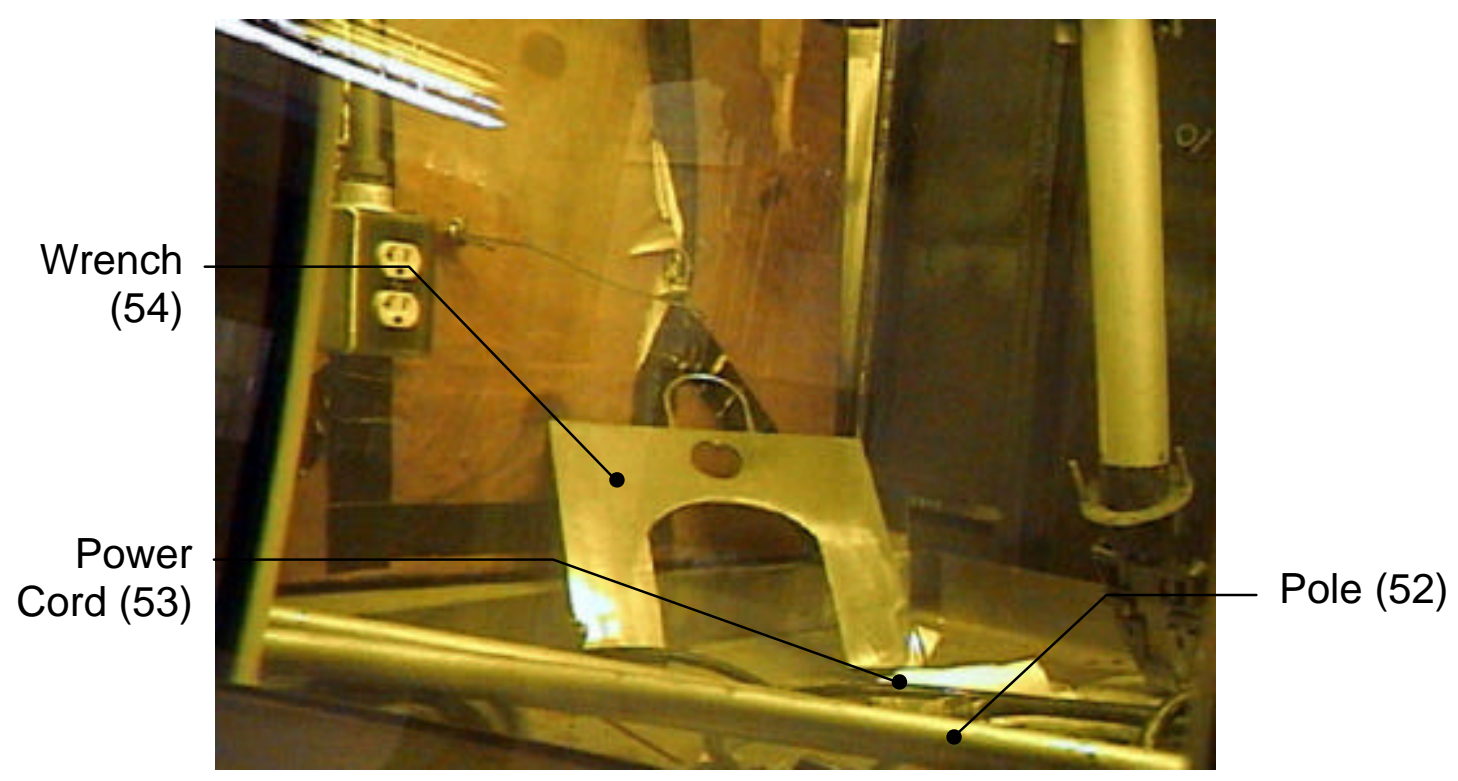

Figure D-14 Station 12 


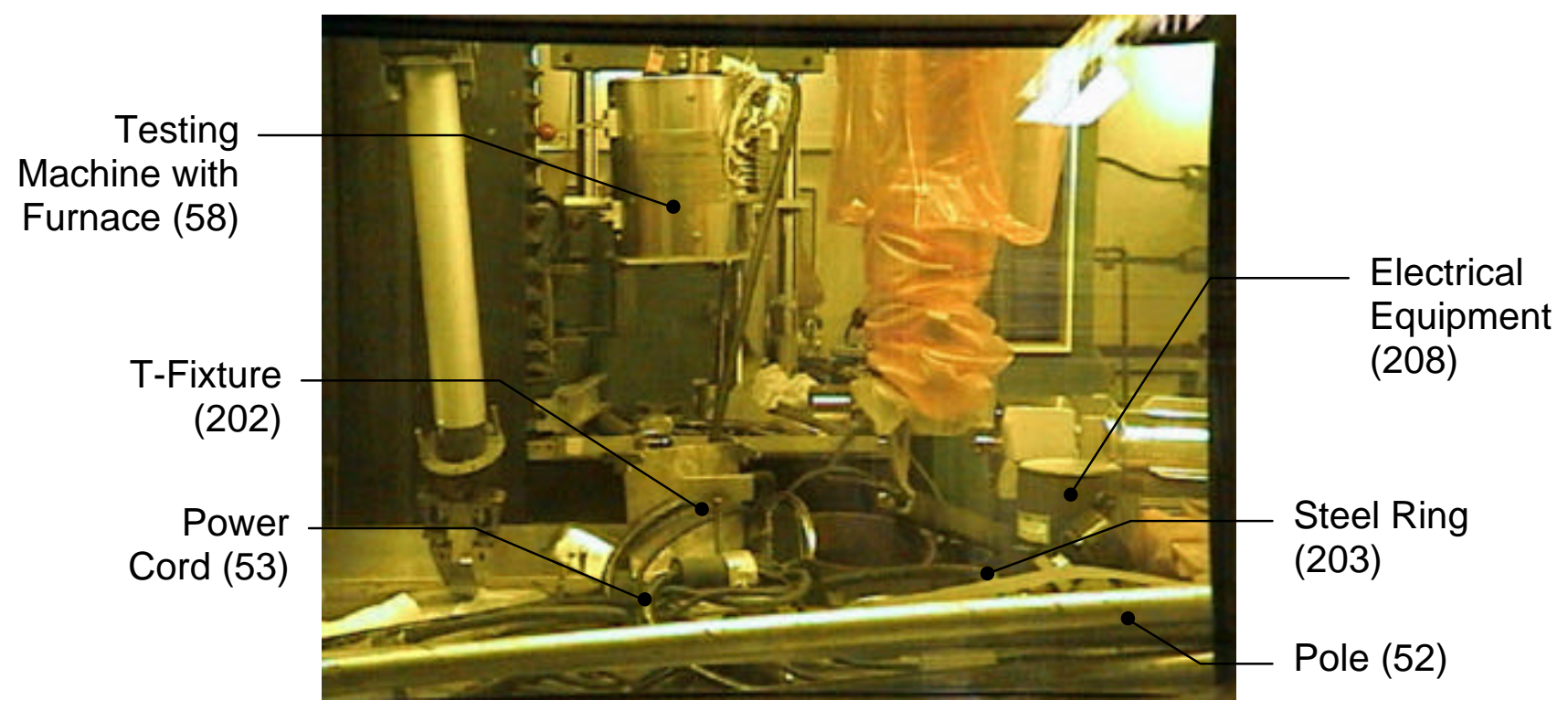

Figure D-15 Station 12

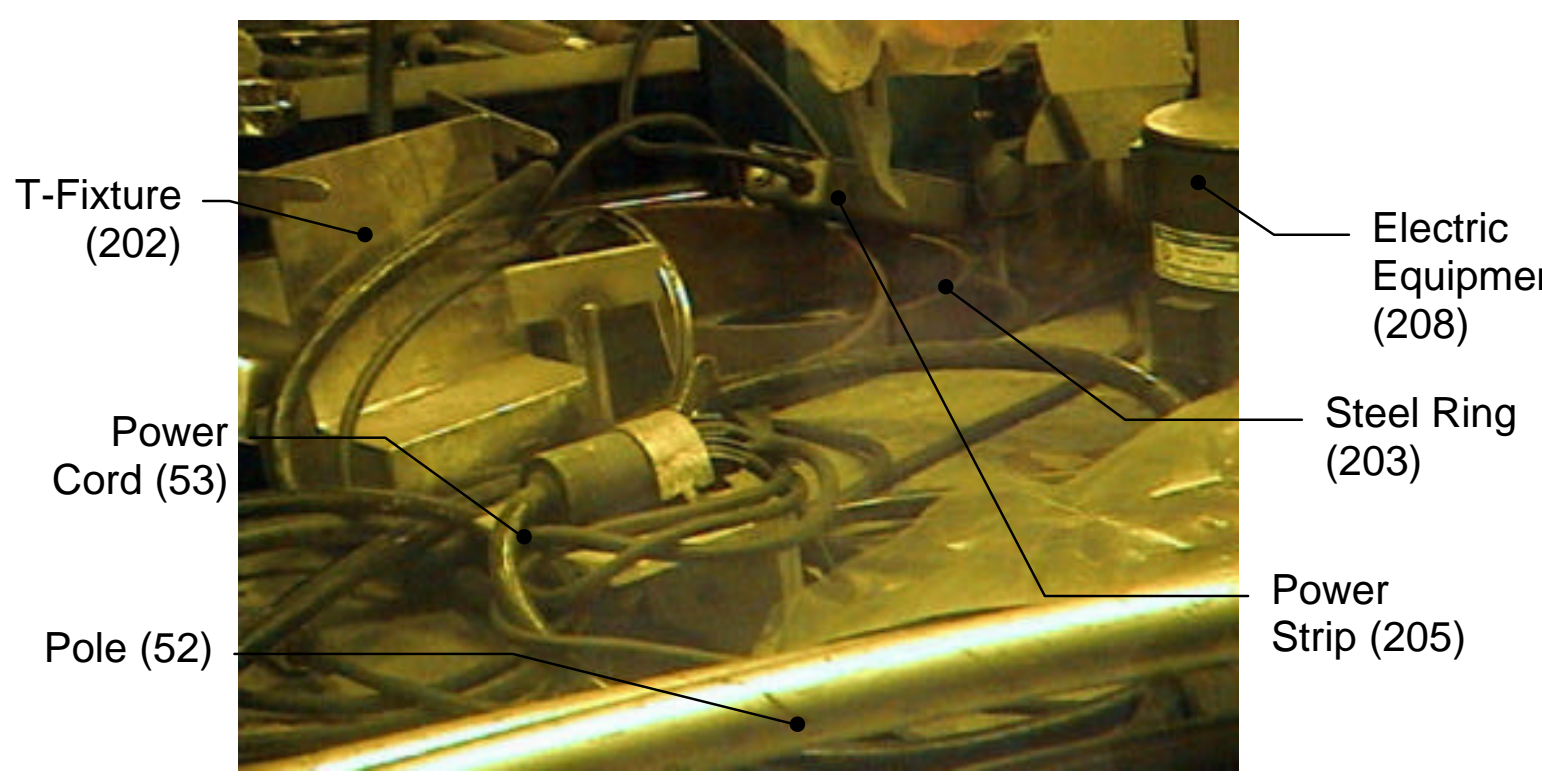

Figure D-16 Station 12 

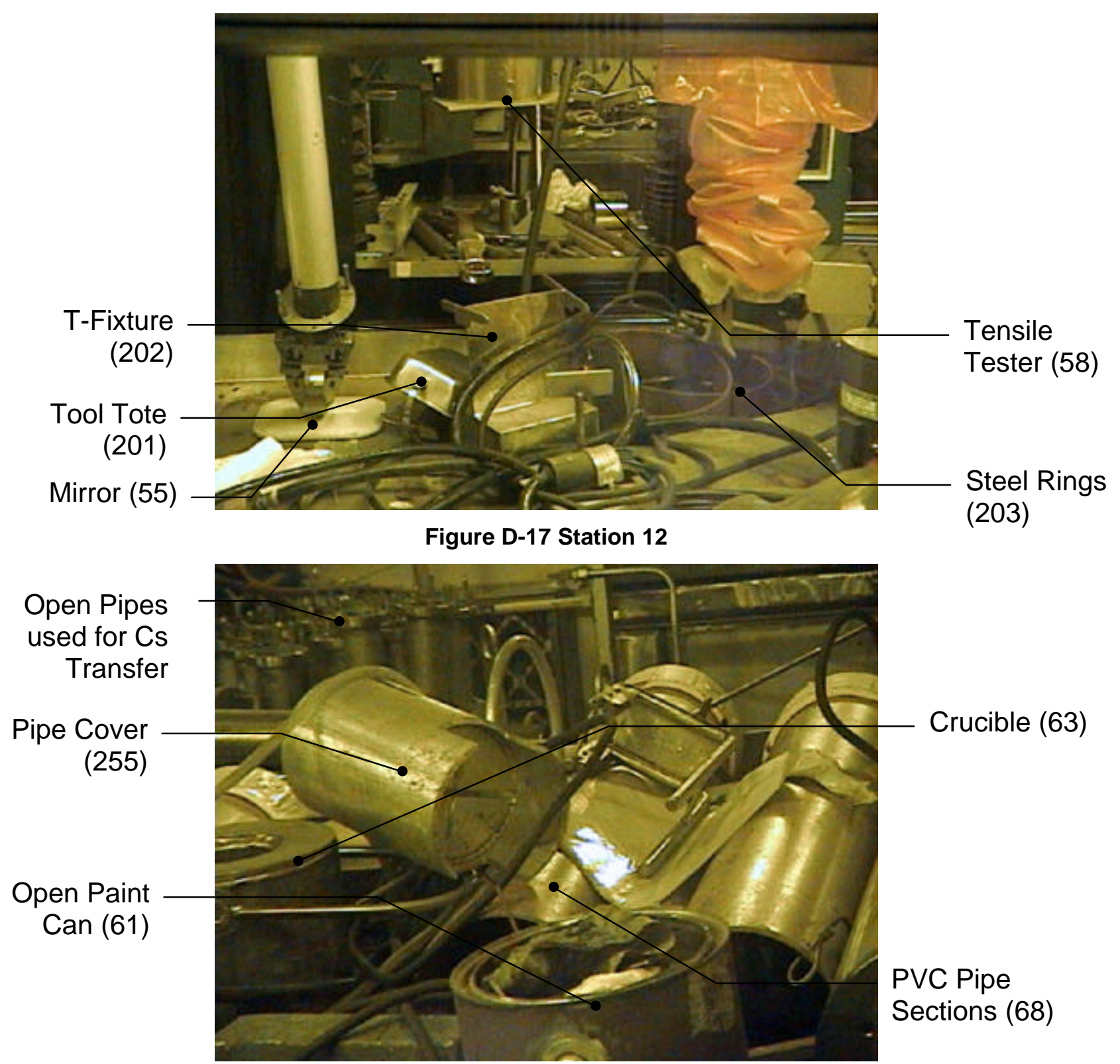

Figure D-18 Station 13 


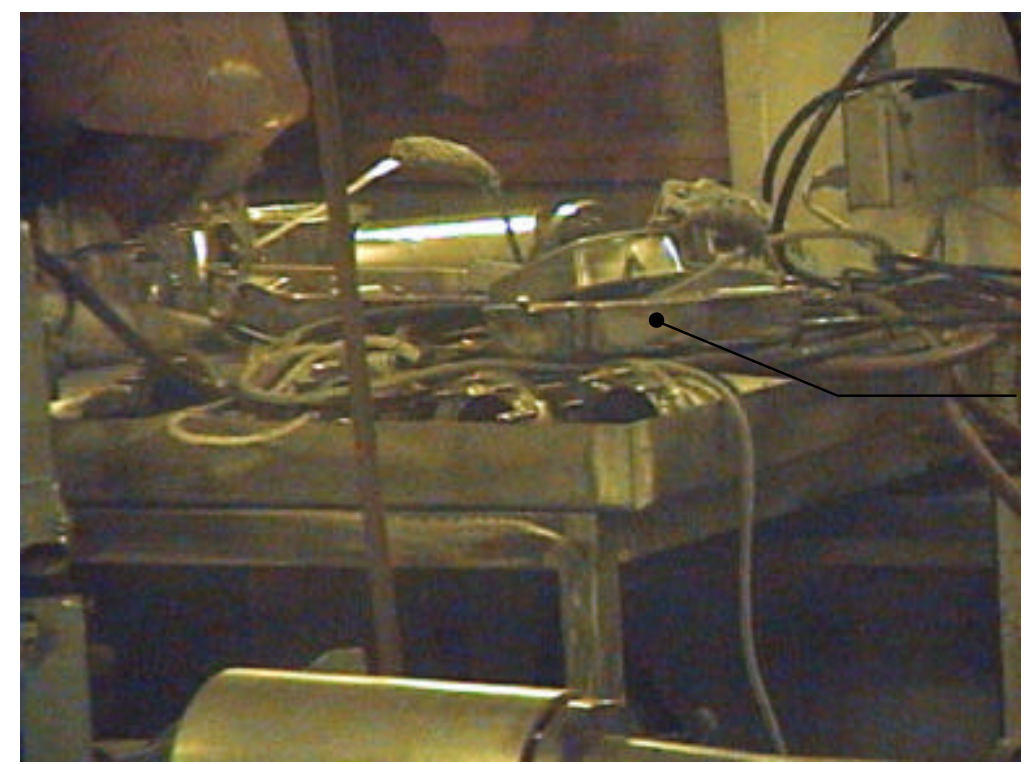

Tool Tote (20)

Figure D-19 Station 13

Window view of Station 4 worktable

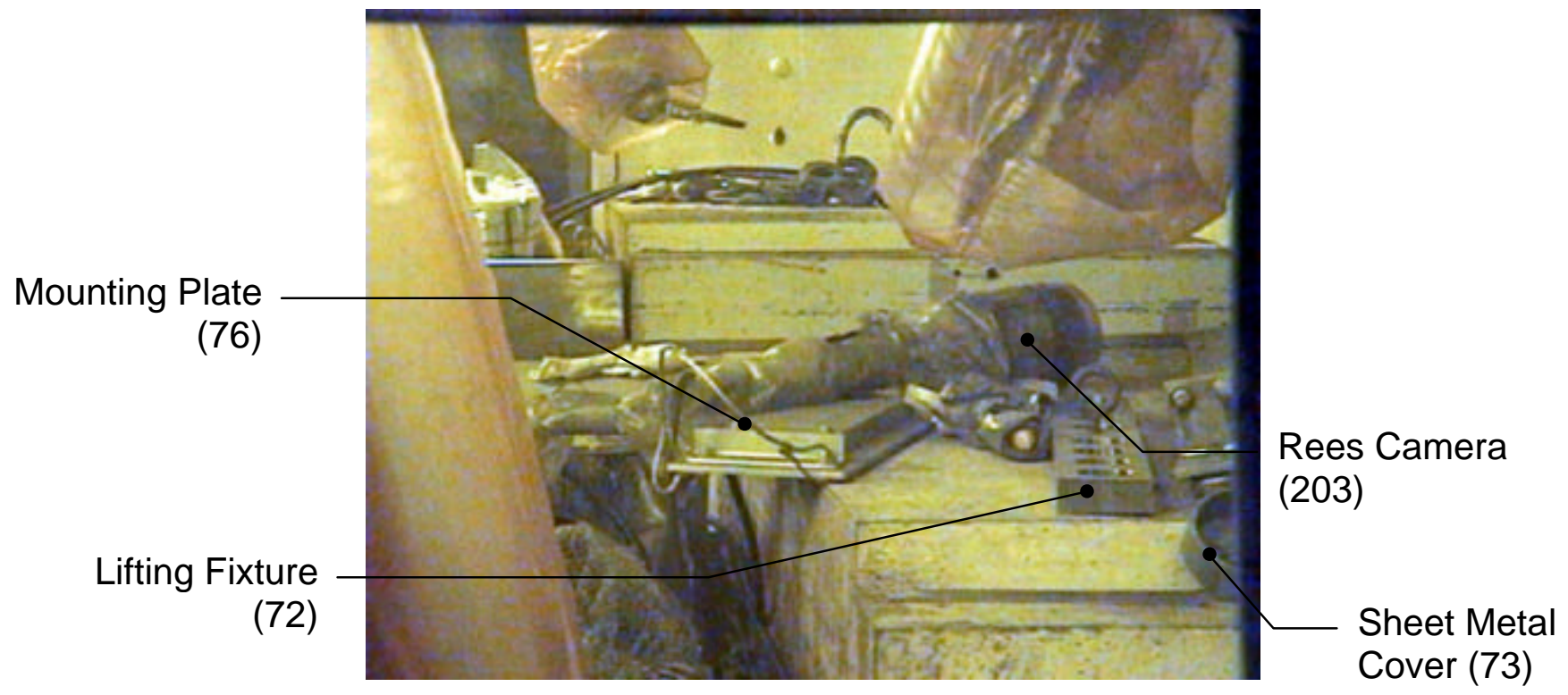

Figure D-20 Station 13

Top of long-term storage cabinet 1 


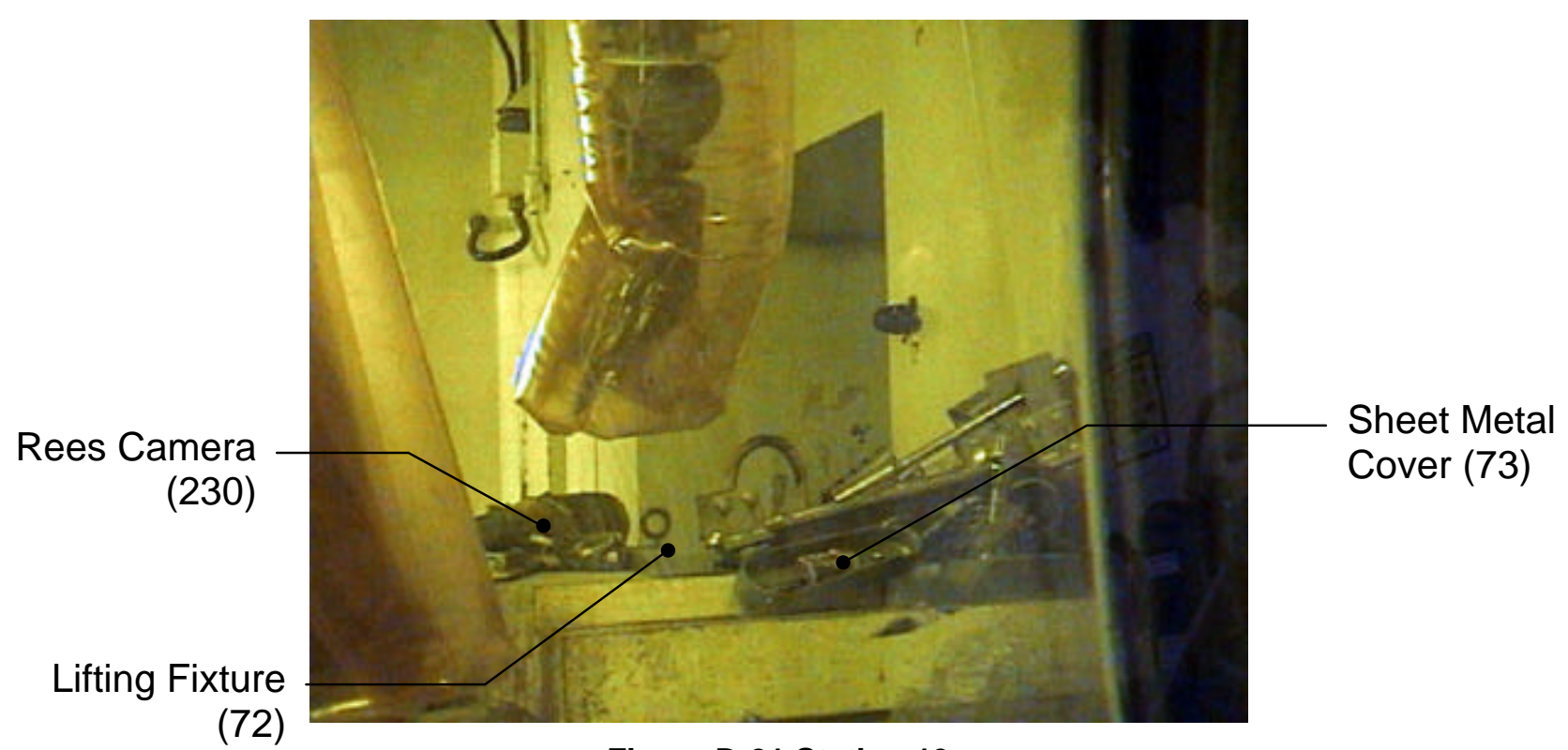

Figure D-21 Station 13

Top of long-term storage cabinet 1

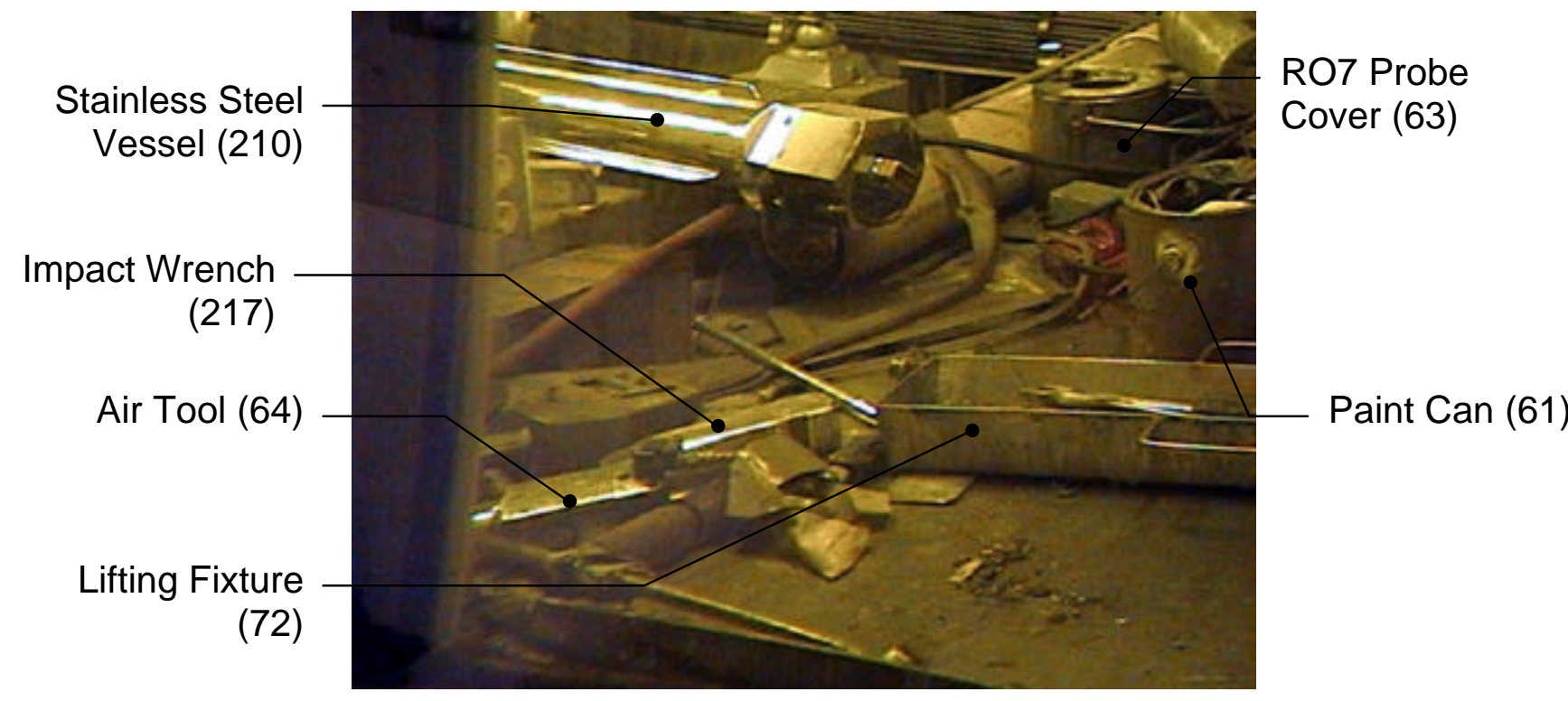

Figure D-22 Station 13

\section{Waste Database Inventory}

The inventory database (Baker 2002) comprises a physical inventory of the contents of the south cell. The database does not include any suspected unseen items on the floor under the worktables or any other unseen items. It also does not include the utility carts in the cell. The data collected included the following:

Item Number

Item Name

Item Description 


\author{
Quantity \\ Window Number (through which item is most readily seen) \\ Location Description \\ Location \\ Material \\ Length \\ Width \\ Height \\ Volume $\left(L^{*} W^{*} H\right)$ \\ Large \\ Weight \\ Container (TRUE if item may contain significant source-term waste) \\ Mechanical Properties \\ Radiological \\ Notes
}

The item numbers were assigned sequentially. Some numbers were skipped as a result of clerical errors (entering the same item twice) during the database creation. Numbers were not reused once assigned. Location Description is a narrative (detailed) description of the item's location; Location is a general location. Materials listed are estimated or based on a priori knowledge. Length, Width, and Height are estimated unless better information was available. Volume is length $\mathrm{x}$ width $\mathrm{x}$ height; so it is the maximum volume an item might occupy. An item is noted as "large" if it is more than $1.52-\mathrm{m}(5-\mathrm{ft})$ long and has a significant volume, or if it's more than $0.21-\mathrm{m}^{3}\left(13000-\mathrm{in}^{3}\right)$, about a $0.61-\mathrm{m}(2-\mathrm{ft})$ cube. The idea is to identify those items that will be difficult to package. An item is noted as a "container" if it may contain significant source-term waste. Mechanical Properties is a loose classification of the ease with which an item might be folded or size-reduced into a smaller container. No radiological data is included at this point, because none was available. The Notes field contains markings, guesses as to purpose or description of the object, or other pertinent information.

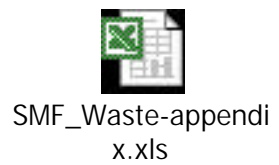

For copies of SMF Waste Appendix.xls contact the Hanford Technical Library 509-372-7430 or pnl.techlib@pnl.gov. 


\section{APPENDIX E}

Crane Repair Options 


\section{Appendix E. Crane Repair Options}

The south cell overhead crane is currently not fully functional. Based on a recent function test, only a single axis, the bridge trolley, is not functional (faulty electric motor). The crane is currently capable of north-south and up-down motion. However, it should be noted that the crane is old and has not had regularly scheduled maintenance.

The recommended path forward is to replace the overhead bridge crane (Union Machine Co., from Seattle, circa 1963). The crane bridge rides on two I-beams that run the length of the south cell. These I-beams appear to be bolted to the ceiling, which is 5.5-m (18-ft) above the floor. Extension I-beams can be added in the air lock to move the crane into the air lock. This was done in the past but the extensions have been lost. This would require removing the partition wall near the ceiling between the south cell and the air lock. It would also require removing the northern stop(s) on the rails in the south cell.

Some of the personnel interviewed believe that the contamination inside the south cell from the cesium powder release is very high and manned entry into the south cell will not be possible, even after removal of all the other waste materials from the cell. However, others and the contamination report (Bitten 1998) indicate that this might not be the case.

\section{Crane Options}

The bridge crane is required for lifting the long-term storage cabinet lids. It also would be used to aid in removing other large items in the cell, such as the tensile test machines, the SCS, and the large sheet metal box (Inventory Item 211). In addition, the crane would likely be useful in installing the lids onto shielded waste packages such as the box for the SCS. It may be possible to work around the failed trolley motor for those lifts. However, replacing the crane is the most efficient and likely the most cost-effective method to completing the work. The following options have been evaluated.

\section{Backdrive With Hoist}

If the hoist is hooked to the payload (long-term storage cabinet lid) or other fixture, the hoist motor can be used to backdrive the trolley. For example, if the bridge is positioned over the long-term storage cabinet lifting bail, hoist cable is paid out, and the hook attached to the bail. When the hoist is raised, it should pull the hoist so it centers over the long-term storage cabinet. This assumes that the trolley brakes (if any) can be released, and that there is little friction in backdriving the hoist. A serious shortcoming of this method is that it is probably not possible to position the hoist directly over the long-term storage cabinet. It would probably not be possible to return the long-term storage cabinet lid once it was lifted. 


\section{Backdrive With AEA Manipulator}

If the AEA manipulator can reach the trolley (or the hook), it may be strong enough to backdrive the trolley and position it correctly for lifting the long-term storage cabinets.

\section{Backdrive with Engineered Device}

It may be possible to add an engineered device to the bridge that will backdrive the trolley. This could be added using the AEA manipulator if it can reach the correct locations. This approach presents significant technical risk and cost; repairing or replacing the hoist is clearly a preferred alternative.

\section{Add Manual Trolleys to Bridge}

It may be possible to add unpowered hoists and trolleys to the existing bridge - one on each side of the existing trolley. These hoists could then be positioned and operated with MSMs and/or the AEA manipulator to lift the long-term storage cabinet lids.

\section{Lift Cabinet Lids With Engineered Device}

An engineered device could be designed and fabricated outside the SMF. It could then be inserted and used in the south cell to lift the long-term storage cabinet lids. This would probably be some type of A-frame hoist structure on casters with beams extending beyond the supports. A hoist on each end could be used to lift both long-term storage cabinet lids simultaneously, one counter weighting the other.

\section{Installation of Chain Hoists}

Heavy-duty chain hoist trolley units are available that could be mounted on the existing bridge for lifting the long-term storage cabinet lids and other large heavy items. When lifting a 2270-kg (5000-lb) load, the operator of a manually-operated hoist would need to exert forces on the order of $27-\mathrm{kg}(60-\mathrm{lb})$ to the primary chain. This type of use would be very demanding of both the MSM and the operator. A pneumatically or electrically operated hoist would definitely be recommended.

An additional consideration is trolleying the payload. The bridge motors still work (as of this writing), so positioning the load with the bridge may not a problem. However, positioning it in the trolley direction by manually pushing on it will be very challenging for the operator and potentially damaging to the MSMs. It is important to note that the existing bridge motors have not had preventive maintenance may fail at anytime.

\section{Down Selection}

Back-driving the trolley presents an unacceptable technical risk. While the activity could be practiced and tested in the east cell, the consequences and likelihood of failure are too high for these alternatives to be considered further. All of the alternatives in which an engineered system is introduced into the south cell present roughly equal concerns as far as ALARA is concerned. Engineering and fabrication costs for any engineered system are likely to be high. 
If the dose levels in the cell are too high to permit entry, the crane will either have to be repaired or replaced via the crane access port in the air lock, or an engineered system developed to lift the long-term storage cabinet lids. The other lifting needs will need to be met by engineered systems or other methods may need to be developed.

\section{Recommended South Cell Crane Option}

We recommend the complete replacement of the south cell crane trolley, with a manned entry, after removing the high source term wastes (with the MSMs and AEA manipulator) from the south cell, reducing the background to a level permitting manned entry. It is believed that there would be a good chance that with the removal of the majority of the highly active items and some preliminary decontamination, manned entry would be possible.

Vendor cost estimates range from $\$ 10,000$ to replace the motor, $\$ 38,000$ to replace the trolley, and $\$ 50,000$ to replace the entire crane. These price estimates reflect the unburdened hardware costs. A full crane replacement is recommended because the old crane has not had its preventive maintenance, and of particular concern is the possibility that the high radiation levels during operations may have destroyed the insulation of the electrical cables. The preliminary diagnostics test has indicated a failed trolley, but it is suspected that there will be additional components that will fail once the trolley has been replaced. 


\section{APPENDIX F}

\section{Packaging Systems}




\section{Appendix F. Packaging Systems}

There are two factors to include when developing and evaluating options for packaging the wastes from the south cell. First, we need to consider the size and source term of the wastes so that the appropriate size and type of container is used. Items must be able to fit into the containers, and the external radiation levels must be low enough for acceptance at the CWC. Second, we need to be sure that the contamination on the waste items and in the cell does not get on the outside of the containers. We need to keep the contamination inside the south cell (i.e., prepackaging within the south cell or as the waste is leaving the south cell) or sealed inside the shipping containers.

Two options for packaging have been considered. First is to package waste items inside the south cell and remove the packages through the air lock. Second is to move the waste items out of the south cell for packaging. Variations on this second option are to package in the east cell or package in the air lock.

\section{Packaging Within the South Cell}

The advantages of packaging in the south cell proper include the fact that items do not have to be moved through the pass-through or dealt with in the air lock. Items would be handled a minimal number of times. If feasible, packaging in the south cell proper would be the fastest approach, especially for the larger items. However, the cesium powder contamination in the south cell presents special challenges with respect to keeping the outside of the waste containers radioactively clean.

A variation of the option to package in the south cell is to create a "clean" area in the north end of the south cell near the air lock door and the pass-through to the east cell. Setting up such an area would entail first removing waste items in the area to locations farther south in the cell. The surfaces in the area would be decontaminated as much as possible using the manipulators and whatever other tools are available. A greenhouse or other barrier would be installed around the clean area. This barrier would include a pass-through from the south cell proper. This pass-through could include a decontamination function where the cesium powder and other loose contamination could be removed. Waste items could then be bagged into the "clean" area and moved through the pass-through to the east cell. A similar concept might be possible that would permit filling of a waste box or other shipping container in front of the air lock door, and then moving this container into the air lock for removal.

\section{Packaging Outside of South Cell}

For items small enough to be moved through the pass-through to the east cell, packaging into shipping containers in east cell is possible. Potentially, some larger items could be size reduced so that they could be moved through the pass-through. Because the inside of the east cell is accessible by workers, setting up equipment for packaging in the east cell is possible. The cesium powder that makes packaging in the south cell difficult also complicates packaging in the east cell. The loose contamination needs to be removed or fixed in the south cell before items are moved to the east cell to avoid contaminating the east cell. It may be possible to bag items in the south cell 
before transfer to prevent contamination spread. An advantage of doing the final packaging in the east cell as opposed to final packaging in the south cell is that the low background radiation levels will permit monitoring of the packages during filling to assure that they are below CWC limits but are also as full as possible. It will also be possible to select the best packaging options for waste items if their source terms can be measured before packaging.

Using the air lock for packaging of some larger items might be feasible, but this concept is probably not very favorable. Again, control of the cesium powder complicates the options.

Whatever waste packaging approach is selected, we need to deal carefully with the cesium powder contamination issue. Contamination of the air lock or the east cell, such that they are not appropriate for manned entry would be a significant setback. Our waste removal activities to date have focused on removal and packaging of the wastes, whether they are MOTA specimens or other wastes. One approach is attempting to decontaminate the cell by collecting (i.e., vacuuming) or fixing the cesium powder.

\section{Compartment 1 Issues}

Compartment 1 has significant wastes and source term (cesium chloride) issues. This is the compartment from which the cesium powder was released and is expected to present the only real challenges for compartment cleanup. Two options are seen for packaging wastes from compartment 1 cleanup, namely packaging in the compartment or removal of wastes from the compartment and packaging somewhere else.

Packaging inside compartment 1 does not appear to be a good option because of the large amount of waste present and the expected high levels of very mobile contamination. Packaging outside compartment 1 will require the wastes to be either moved into the south cell proper through the pass-through or into compartment 2 through the interconnecting pass-through. Either option requires careful consideration of contamination control.

\section{Containers}

The primary component of each waste packaging system is the actual container in which the waste will be placed. This is the container the waste will be disposed in at the CWC. For most contact-handled type-A wastes, no other packaging system components are needed. However, for remote-handled wastes, a cask or other shielded container will be required to hold the primary container for its transport to the CWC. The optimum approach for packaging remote-handled wastes is to use the REC air lock for a package filling location. Therefore, the SERF cask or other shielded container will be required to move wastes to the REC air lock from SMF. It is also possible; depending on the amount of radioactive materials present in certain items and the size of these items, that some remote-handled wastes will have to be loaded into shielded containers either in the south cell proper or perhaps in the SMF air lock. Packages exist that would be appropriate for such activities; however, moving such a heavy package into the south cell proper has not been done previously using only remote means. Moving heavy objects into the south cell was not done in the past 
without a manned entry. In the event that the dose in the south cell proper cannot be lowered enough for manned entry, a new method or equipment for moving a heavy container in and out of the south cell will have to be developed. The method for moving the waste container will need to ensure that it can handle the expected gross weight of the container.

Following is a list of the known shipping containers that might be used to transport remote-handled wastes from SMF, within 324 Building, and to the CWC.

- SERF cask

- ATG-3-82B cask

- Steel waste package

- Lead-lined drum

- EBR-II cask

- GNS-12 cask.

\section{SERF Cask}

The SERF cask is used to transport irradiated fuel and other materials between 323 , 324, 325, 326, 327, and 3270 Buildings. Use of the SERF cask is governed by HNFSD-TP-SEP-058, Safety Evaluation for Packaging (Onsite) SERF cask (Serles 1999). Only dry, solid materials shall be shipped in the cask. Liquids, either absorbed or unabsorbed, are not authorized. Organic materials are not authorized except plastic bags or wrapping. All materials shall be enclosed in an inner container because the cask is not considered a containment boundary. One example of a permissible inner container is a 1-gallon container with friction fit lid (paint can) that is wrapped in plastic. Items too big for a paint can may be placed in the SERF cask if certain criteria are met relative to the amount of smearable contamination that is present.

The SERF cask consists of an outer cylindrical shell with an outer diameter of $66-\mathrm{cm}$ (26-in.) and a wall thickness of $1.59-\mathrm{cm}(0.625$-in.), an inner shell with an outer diameter of $21.9-\mathrm{cm}(8.63-\mathrm{in}$.) with $20.3-\mathrm{cm}(8-\mathrm{in}$.) of lead between.

Both the inner and outer shells are 300 series stainless steel with wall thickness of 1.27$\mathrm{cm}(0.5$-in.). The internal cavity is $258-\mathrm{cm}$ (101-in.) long with a diameter of $19.4-\mathrm{cm}$ (7.6-in.). The cask has an empty weight of $11,800 \mathrm{~kg}(26,000 \mathrm{lb})$. There is a sliding scoop-shaped tray within the cask that is used in loading and unloading. The cask is loaded, transported, and unloaded horizontally.

The front end of the SERF cask has a lead-filled rotating cylindrical valve, and the other end has a removable plug with a hole for a push rod. Both ends have a provision for bolted, gasketed cover plates.

To load and unload the cask, the front of the cask is first mated to a cell opening and a push rod is connected to a tray (called the "boat") that slides into the cell. The "boat" is a 14-gauge stainless steel tube with an outside diameter of 188 -mm (7.38-in.) and a 
length of 2.54-m (100-in.). The rear end of the boat is a $9.5-\mathrm{mm}(0.38$-in.) thick carbon steel disk.

For removing wastes from SMF, the SERF cask will be mounted on the SERF cask selfpropelled, heavy duty cart. Wastes from the south cell proper will be loaded into the SERF cask, which will be sitting on the cart in the SMF air lock. Waste items will be transferred into the cask through the pass-through in the door between the air lock and the south cell using the "boat".

The SERF cask will then be used to move the wastes to the REC air lock, where the wastes will be transferred to their final waste container (i.e. grout container) before shipping to the CWC.

Drawing of the SERF cask and its self-propelled cart are included/shown in Figures F-1 and F-2.

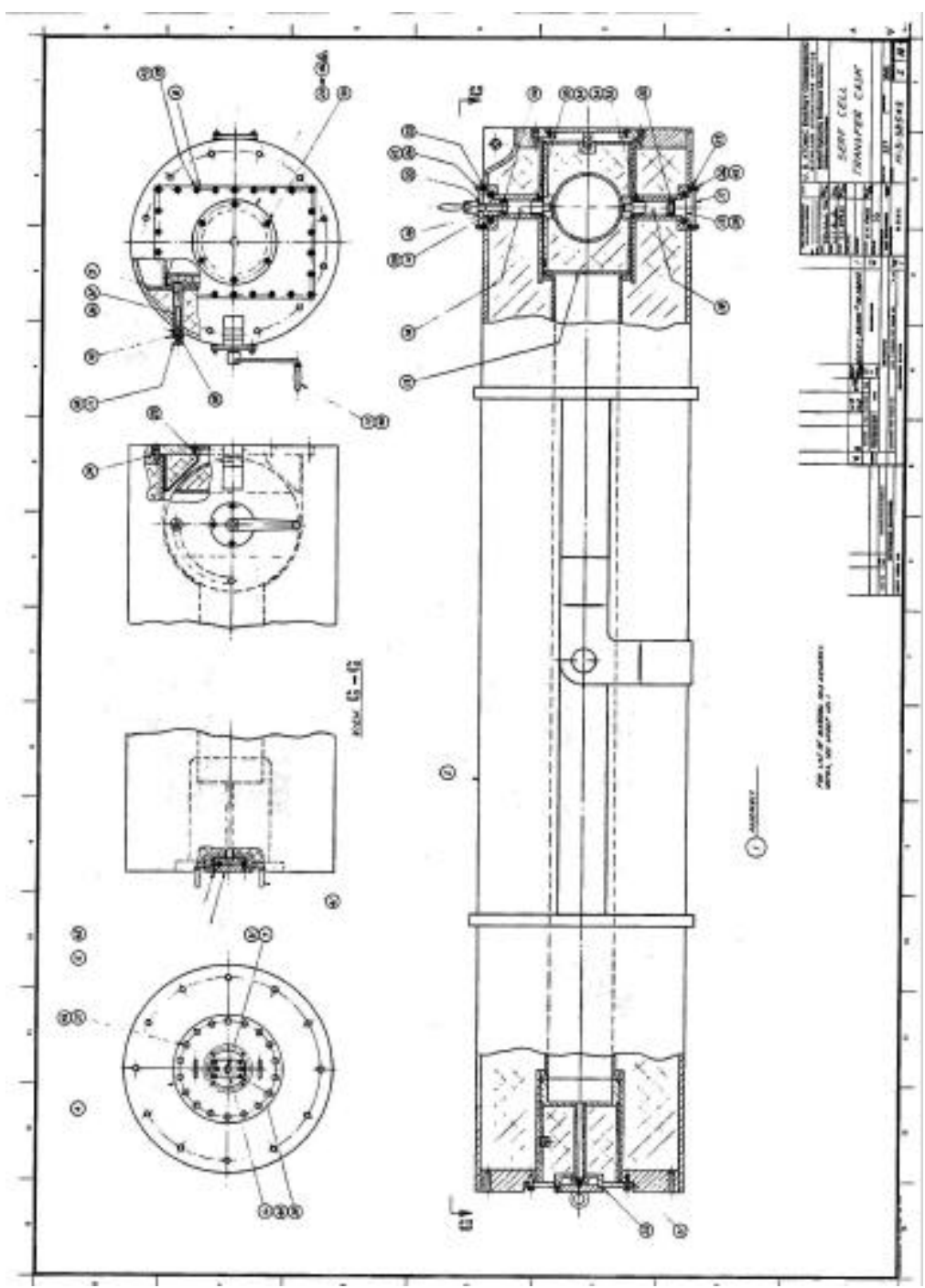

Figure F-1 SERF cask 


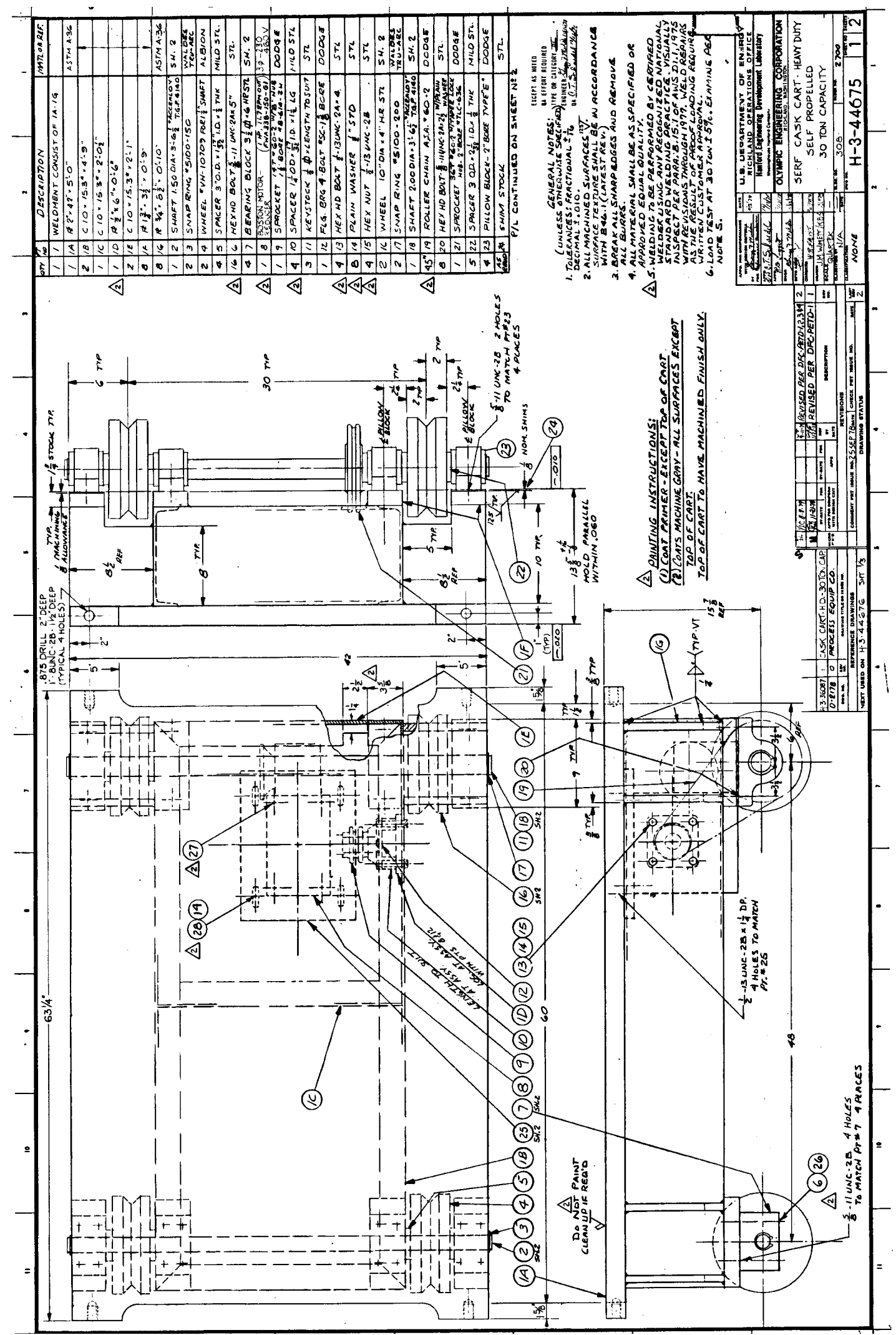

Figure F-2 SERF Cask Cart 


\section{ATG-3-82B Cask}

The ATG-3-82B cask (Figure F-3) is a steel and lead composite cask, fabricated in the form of an upright circular cylinder. The shielded cask, closed at one end with a lid closure at the other, has an outside diameter of 168-cm (66-in.) and an outside height of $189-\mathrm{cm}(74.5$-in.). The cask wall consists of a $0.95-\mathrm{cm}(0.375$-in.) inner steel shell, 9.53-cm (3.75-in.) of lead, and a $2.54-\mathrm{cm}(1-\mathrm{in}$.) outer steel shell. The outer shell is surrounded by a $2.54-\mathrm{cm}$ (1-in.) layer of insulating material and is canned in 11-gauge steel. The cask is too large in diameter to fit into the south cell through the door, however it would not be necessary for it to enter the south cell.

The cask primary lid, sealed by a silicone gasket, is bolted to the cask body. A secondary lid is located in the center of the cask primary lid. Lifting and tie-down devices are attached to the cask body. Impact skirts, consisting of removable rings of shock-absorbing foam, are attached to the ends of the cask. Gross weight of the package is $22,680-\mathrm{kg}(50,000-\mathrm{lb})$. A grout container drawing is show in Figure F-4.

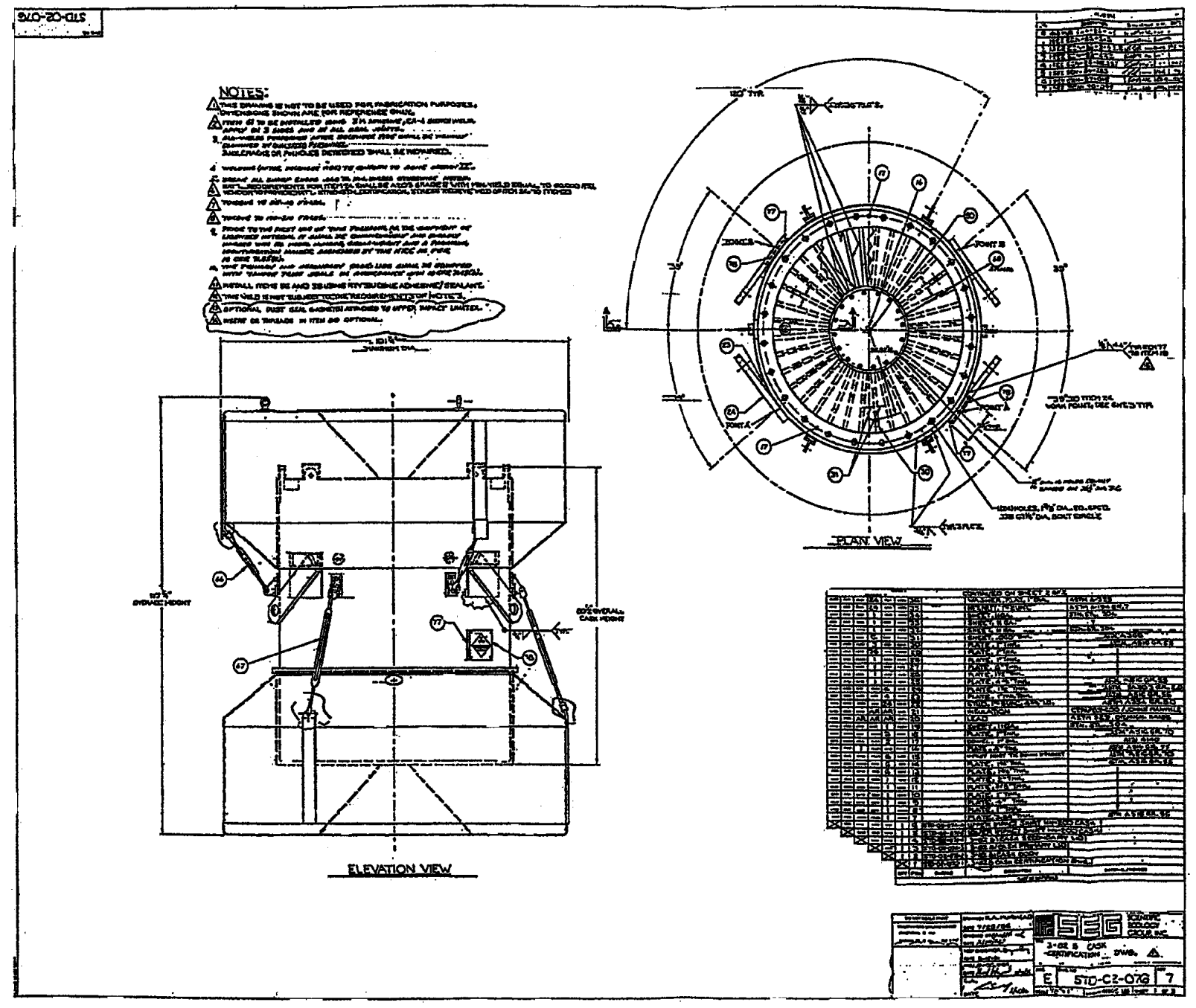

Figure F-3 ATG-3-82B Cask 
The waste is placed in an open-top HN-200 grout container, which has a height of 140$\mathrm{cm}$ (54-in.) and an internal diameter of $116.5-\mathrm{cm}$ (45.9-in.). The contents may be grouted. Both grouted and ungrouted payloads are authorized. If grouted, the open-top grout container is filled with grout ( $94 \%$ flyash, $6 \%$ Portland cement) up to a maximum of $7.6-\mathrm{cm}$ (3-in.) from the top. A drawing of the $\mathrm{HN}-200$ grout container is provided in Figure F-5.

The grout container is then placed in an $\mathrm{HN}-200 / 3-82 \mathrm{~B}$ liner (Figure F-5), which has a height of $147.7-\mathrm{cm}(57.38-\mathrm{in}$.) and an internal diameter of $121.6-\mathrm{cm}(47.88-\mathrm{in}$.). The liner's lid, containing a $2-\mathrm{cm}(0.75$-in.) threaded vent hole, is bolted into the liner. A high-efficiency particulate air (HEPA) filter is secured in the vent hole. The liner is then placed in the ATG-3-82B cask.

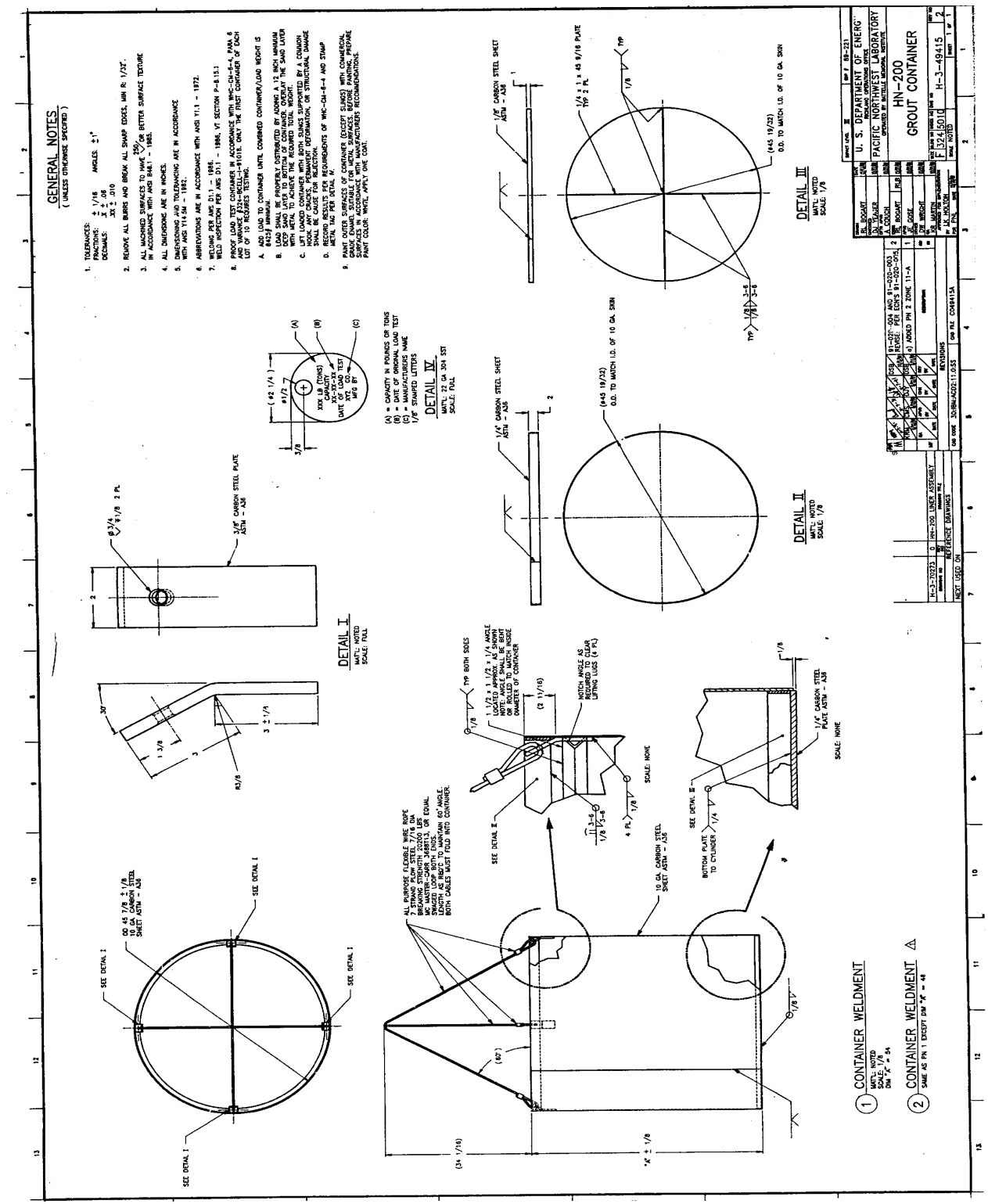

Figure F-4 HN-200 Grout Container 


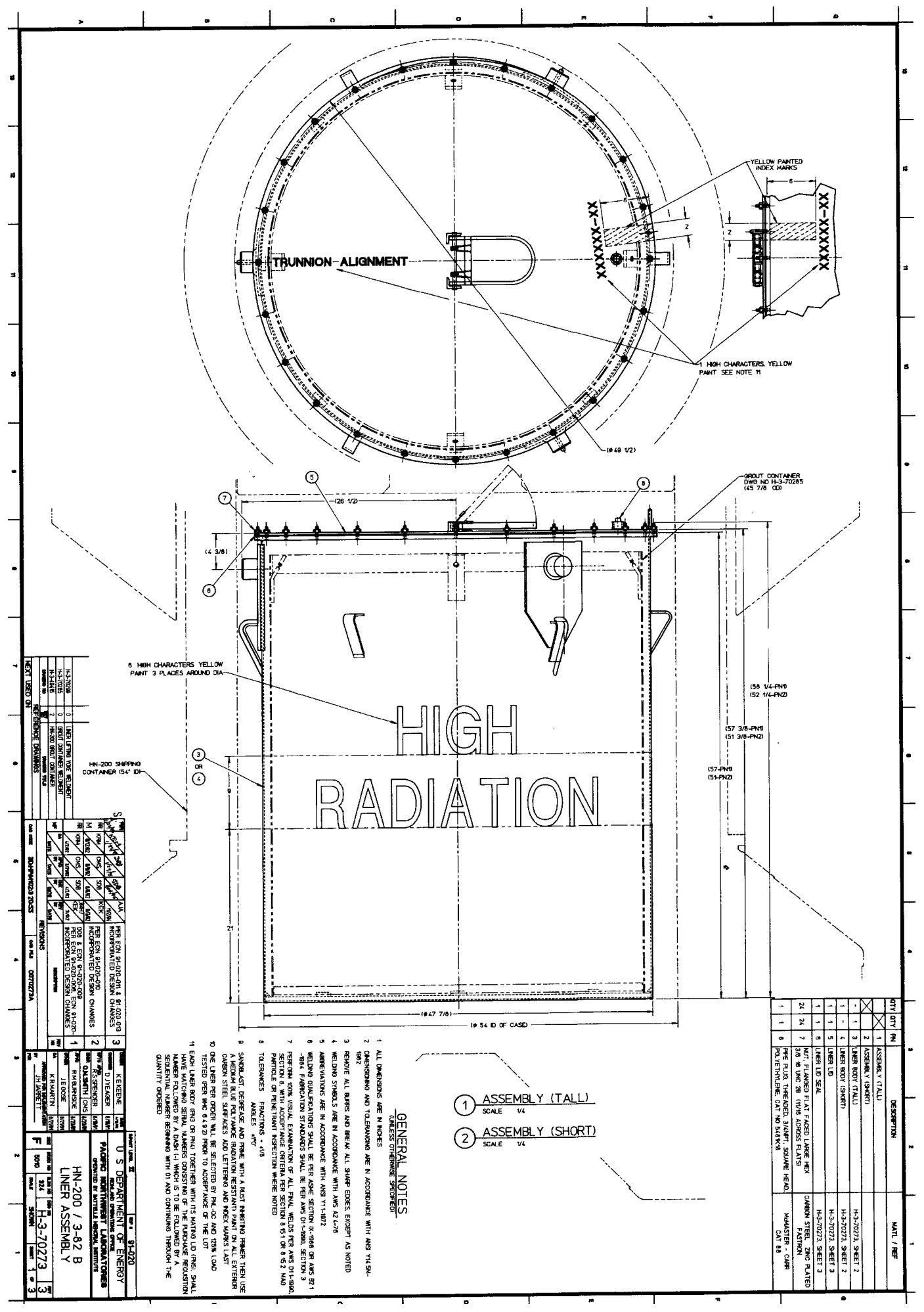

Figure F-5 HN-200/3-82B Liner 


\section{Steel Waste Package}

The Steel Waste Package (SWP) consists of six components (Figure F-6). A seventh component, Engineered Container Assembly (ECs), may be included as an option for dispersible materials, but is considered part of the payload and not a component of the packaging. The components are as follows:

- EC (optional for dispersible debris, drawing H-3-308699, Engineered Container Assembly)

- Rectangular Grout Container (RGC) (drawing H-3-70454, Rectangular Grout Container Weldment/Sling Assembly)

- Rectangular Overpack Disposal Container (RODC) (drawing H-3-70453, Rectangular Overpack Disposal Container /Weldment/Details)

- 22-Ton Steel Waste Disposal Box (SWDB), (drawing H-3-56431, 22-Ton Steel Waste Disposal Box Assembly/Details)

- 22-Ton SWDB Overpack Assembly (Drawing E-D-003)

- 22-Ton SWDB Shield Plate (drawing E-D-005)

- 22-Ton SWDB Impact Limiter (drawing H-3-56433, 22-Ton Steel Waste Dspl Box Impact Limiter Assy/Det).

The SWP has a maximum payload capacity of $3,860-\mathrm{kg}(8,500-\mathrm{lb})$. The fully loaded weight of the package is $41,700-\mathrm{kg}(92,000-\mathrm{lb})$.

The RGC is a rectangular box made of 11-gauge carbon steel with an open top (no lid). The RGC is the primary container for dispersible and non-dispersible waste. When ECs are used, the RGC is the container used to handle up to eight loaded ECs. The RODC is a rectangular box made of $0.476-\mathrm{cm}(0.187 \mathrm{in}$.) thick steel with a sealed lid and filter for ventilation. The RODC serves as the first confinement boundary.

The 22-ton SWDB is a rectangular box made of steel plates that are bolted together and sealed to provide shielding and confinement for the SWP. The SWDB has a sealed lid with a filter for ventilation. The 22-ton SWDB over pack surrounds the SWDB inside the SWDB impact limiter and serves as the containment boundary. It is a rectangular box made of $1.3-\mathrm{cm}(0.5$-in.) thick stainless steel that is "leak tight". The 22-ton SWDB shield plate is installed beneath the 22-ton SWDB inside the bottom of the SWDB impact limiter and provides additional shielding. The 22-ton SWDB is too wide to fit into the south cell through the air lock door. 

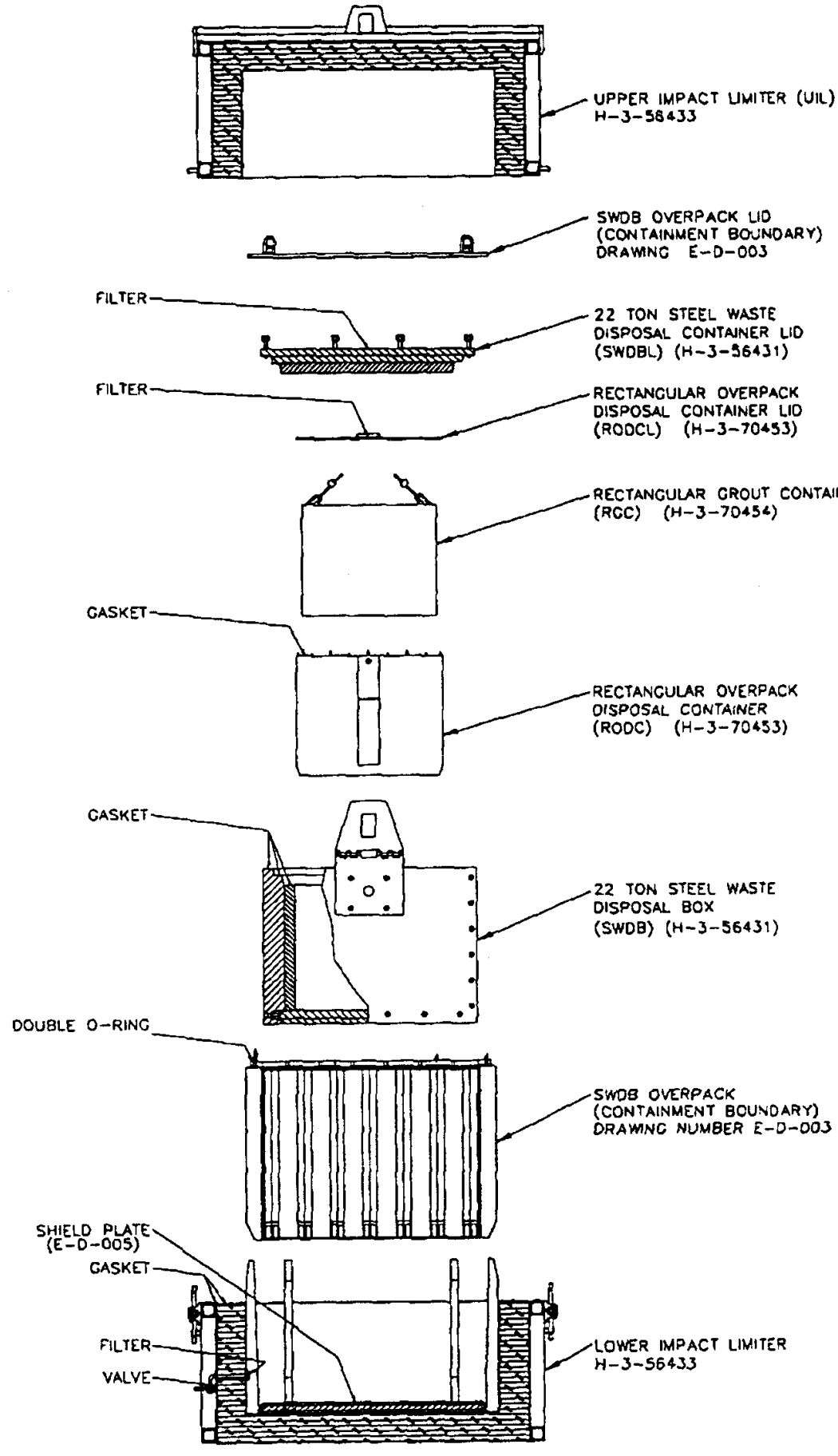

Figure F-6 Steel Waste Package (SWP) 


\section{Lead-lined Drum}

The lead-lined drum (LLD)/21PF-1 over pack (LLD/21PF-1) packaging system is an approved onsite packaging system for the transport of radioactive material. The contents of the LLD are restricted to solids or absorbed liquids. The LLD is the first part of the packaging system, provides the containment and shielding, and is comprised of a 55-gallon drum that confines the lead shield. The lead shield surrounds the containment vessel except for the top. On the top, the lead shield plug is placed within the containment vessel. The containment vessel is fitted with a load canister. The load canister is welded to the inner surface of the shield plug to facilitate loading in a horizontal position. The containment vessel is constructed of carbon steel. A filter is used to vent the containment vessel. The LLD is closed with a standard lid, gasket, and bolted closure ring.

The second part of the packaging system is the over pack, which provides impact and thermal protection for the LLD. Three different over packs can be used. The models authorized for use are the $21 \mathrm{PF}-1 \mathrm{~A}, 21 \mathrm{PF}-1 \mathrm{~B}$, and a minor variation on the $21 \mathrm{PF}-1 \mathrm{~A}$ known as the JWP over pack.

The cylindrical cavity for holding the payload is attached to the shielding plug. The cavity has a $21.6-\mathrm{cm}(8.5$-in.) inside diameter and a $44.5-\mathrm{cm}$ (17.5-in.) length. The cavity volume is $16,300-\mathrm{cm}^{3}\left(0.58-\mathrm{ft}^{3}\right)$. Maximum authorized payload weight is $45 \mathrm{~kg}$ (100 lb).

The LLD would fit through the door into the south cell and might be appropriate for removal of some remote-handled waste items (i.e., MOTA specimens). Drawings of the LLD and impact limiters are shown in Figures F-7 and F-8. 


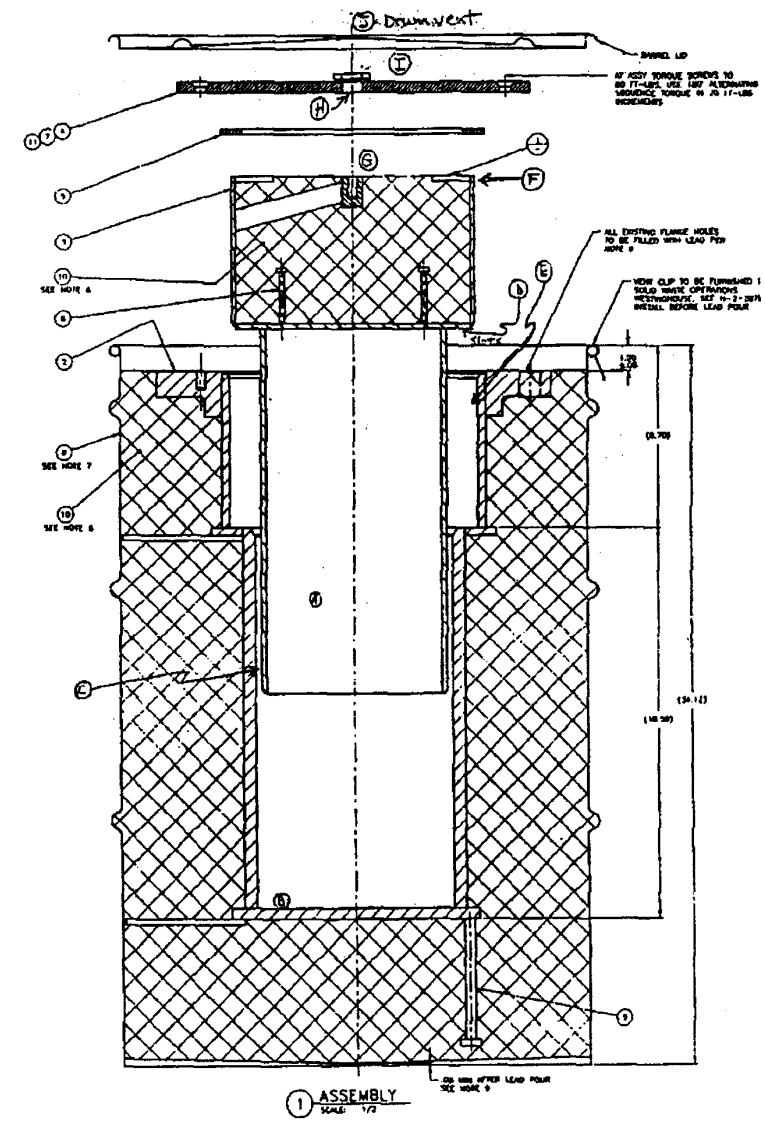

Figure F-7 Lead-Lined Drum

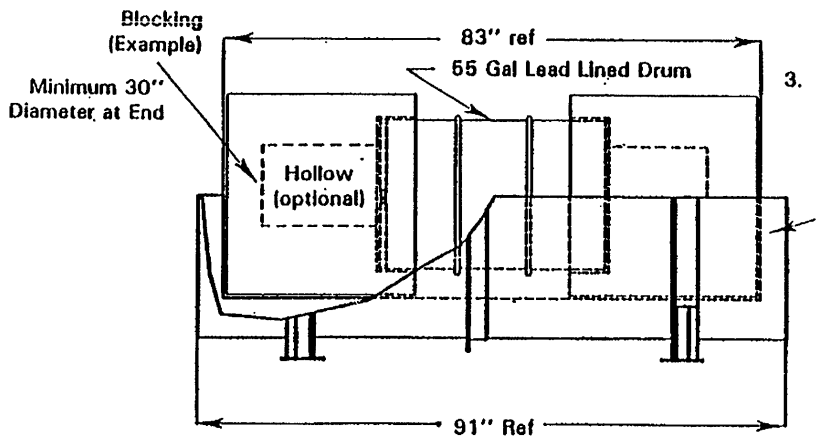

2. Block and brace to wilhsland a slallc force applted to the center of gravity of the package having a vertical component of 2 times the weight of the package (14,800 lbs.), a horlzontal component along the directlon in which the velicle travels of to times the weight of the package (74,000 lbs.). and a horizontal component in the transverse direction of 5 limes the welght of the package (3) 7,000 ibs.)

3. Load the Lead-Lined Drum wilh blocking and bracing in contact with the overpack neoprene pads.

Figure F-8 Lead-lined Drum Overpack 


\section{EBR-II Cask}

Drawings of the EBR-II cask are shown in Figure F-9. Documentation on the specifics of the EBR-II cask has not been identified. The EBR-II cask does not appear to be very useful as part of a SMF waste disposal package because it is intended for transport of fuel rods and is of an incompatible geometric configuration.

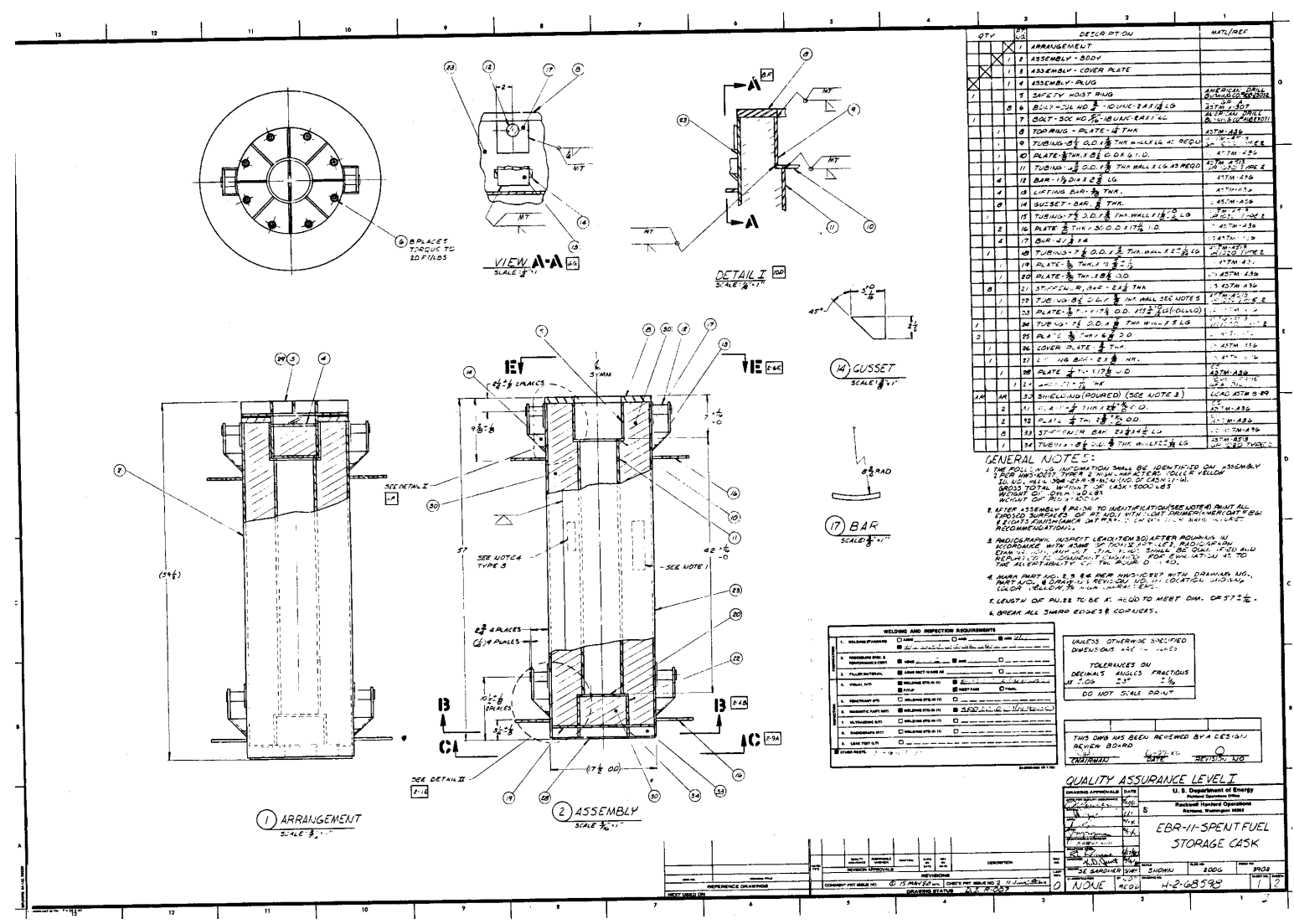

Figure F-9 EBR-II Cask 


\section{GNS-12 Cask}

The GNS-12 cask is designed to transfer Type-B nuclear materials, including highway route-controlled quantity radioactive material on the Hanford Site. The GNS-12 cask consists of an aluminum basket structure housed inside a composite container made of outer and inner stainless steel shells with lead shielding in between. During transport, the cask assembly has two (upper/lower) impact limiters that serve as impact absorbers and thermal insulators. A drawing of the GNS-12 cask is shown in Figure F-10.

The GNS-12 cask does not appear to be very useful as part of a SMF waste disposal package because it is intended for transport of fuel rods and is of an incompatible geometric configuration.

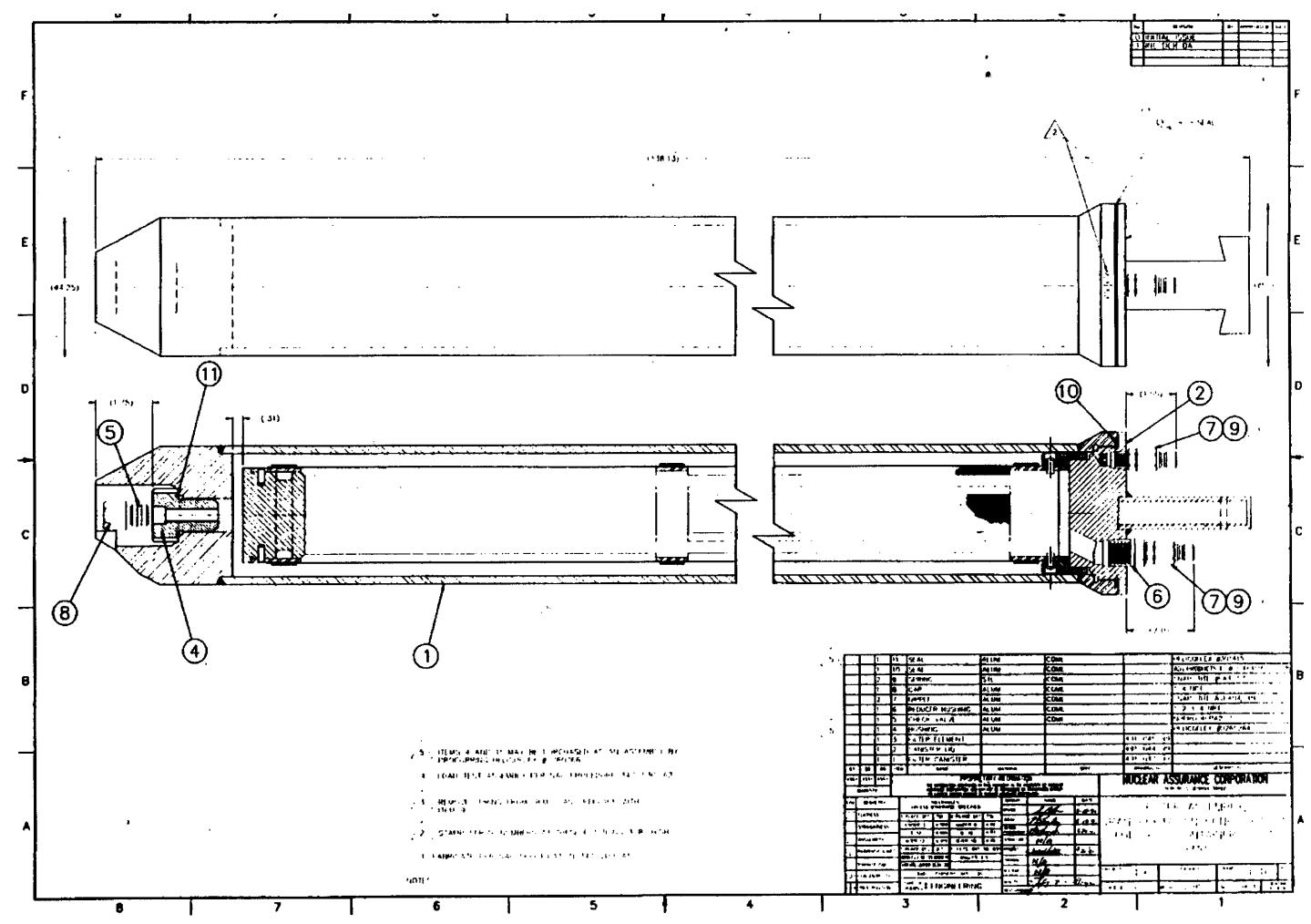

Figure F-10 GNS-12 Cask

\section{Available Type-A Containers for SMF Wastes}

Type-A containers are of two types, namely drums and boxes. Steel drums are available in several sizes, typically $19,38,113,208$-liter $(5,10,30$, and 55-gallon) capacities. Boxes are typically made of steel. Depending on the material of construction, boxes can be very small to very large. Boxes 304.8-cm (120-in.) long, $144.3-\mathrm{cm}(45-\mathrm{in}$.$) wide, and 101.6-\mathrm{cm}(40-\mathrm{in}$.) high with a load capacity of 590-kg (1300lb) are available. 
It is planned to use 55-gallon drums for the majority of the type-A packaging requirements. They are readily available and appropriate for the size and shape of most of the SMF wastes. They are of a size that can be moved into and out of the south cell through the door. For some specific items, it may be more appropriate to use a box to accommodate to the size or shape of the waste item. The larger of the two waste items in the south cell proper, described as boxes, might be one such waste item. 